\title{
INVESTIGATION INTO
}

\section{LONE LANGUAGE LEARNING}

\author{
Erin Bidlake \\ MA Thesis \\ School of Linguistics and Applied Language Studies \\ Carleton University \\ Supervisor: D. Woods
}

August 2005

Copyright $\odot 2005$ by Erin Bidlake 


$\begin{array}{ll}\begin{array}{l}\text { Library and } \\ \text { Archives Canada }\end{array} & \begin{array}{l}\text { Bibliothèque et } \\ \text { Archives Canada }\end{array} \\ \begin{array}{l}\text { Published Heritage } \\ \text { Branch }\end{array} & \begin{array}{l}\text { Direction du } \\ \text { Patrimoine de l'édition }\end{array} \\ \begin{array}{l}\text { 395 Wellington Street } \\ \text { Ottawa ON K1A ON4 }\end{array} & \begin{array}{l}\text { 395, rue Wellington } \\ \text { Ottawa ON K1A ON4 } \\ \text { Canada }\end{array}\end{array}$

Your file Votre référence

ISBN: 0-494-10035-4

Ourfile Notre référence

ISBN: 0-494-10035-4

NOTICE:

The author has granted a nonexclusive license allowing Library and Archives Canada to reproduce, publish, archive, preserve, conserve, communicate to the public by telecommunication or on the Internet, loan, distribute and sell theses worldwide, for commercial or noncommercial purposes, in microform, paper, electronic and/or any other formats.

The author retains copyright ownership and moral rights in this thesis. Neither the thesis nor substantial extracts from it may be printed or otherwise reproduced without the author's permission.
AVIS:

L'auteur a accordé une licence non exclusive permettant à la Bibliothèque et Archives Canada de reproduire, publier, archiver, sauvegarder, conserver, transmettre au public par télécommunication ou par l'Internet, prêter, distribuer et vendre des thèses partout dans le monde, à des fins commerciales ou autres, sur support microforme, papier, électronique et/ou autres formats.

L'auteur conserve la propriété du droit d'auteur et des droits moraux qui protège cette thèse. $\mathrm{Ni}$ la thèse ni des extraits substantiels de celle-ci ne doivent être imprimés ou autrement reproduits sans son autorisation.
In compliance with the Canadian

Privacy Act some supporting forms may have been removed from this thesis.

While these forms may be included in the document page count, their removal does not represent any loss of content from the thesis.
Conformément à la loi canadienne sur la protection de la vie privée, quelques formulaires secondaires ont été enlevés de cette thèse.

Bien que ces formulaires aient inclus dans la pagination, il n'y aura aucun contenu manquant.

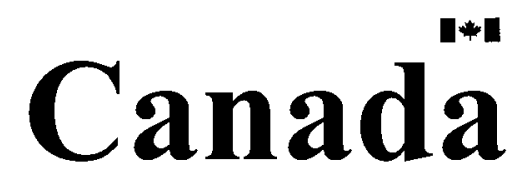




\begin{abstract}
Despite the commercial popularity of "do-it-yourself" language learning packages (programs designed to lead one through self-instructed language learning (SIL)), there has been an obvious neglect by applied linguists and language pedagogues to investigate these programs empirically. To address this neglect, the researcher of this study assumed the role of a lone learner and undertook five months of self-instruction by way of four SILL programs in two languages. Using a diary study to capture the affective factors of her experience, the researcher-diarist illustrates the journey of a lone learner (through insights into such factors as learner preparation and support, sense of progress and pace, sense of failure and laying blame, sense of success through noticing, coping with ambiguity in a teacherless context, and clash of styles) and looks critically at the design of SILL programs. Deliverables of this study include insights into self-instruction, and implications and recommendations for SILL program design.
\end{abstract}


I would like to acknowledge Francis Jones for his ground-breaking work on the topic of self-instruction. His accounts of his personal journey as a lone learner, his study of seventy lone learners, and his examination of SILL programs afforded me seemingly endless ideas and inspirations, and ultimately provided me with a platform from which to launch my own exploration. I am greatly indebted to him and his work.

And my most sincere gratitude to Mish, for being a tireless proof-reader, grammarian, sounding board, and coffee-breaker. Vielen Dank \& dömo arigatō gozaimasu! 
$\begin{array}{ll}\text { Abstract } & \text { ii }\end{array}$

Acknowledgments $\quad$ iii

Table of Contents $\quad$ iv

Chapter 1: Introduction 1

1.1 The phenomenon of self-instructed language learning (SLL): What is it and why do it? $\quad 2$

$\begin{array}{ll}1.2 \text { Questions prompting the study } & 3\end{array}$

1.3 Modes of SILL

1.4 Advantages and disadvantages of SILL programs 5

$\begin{array}{ll}\text { 1.5 Poverty of research on SILL programs } & 7\end{array}$

$\begin{array}{lr}1.6 \text { Research questions } & 8\end{array}$

Chapter 2: Literature review 12

$\begin{array}{ll}2.1 \text { Introduction } & 13\end{array}$

2.2 Part I: Affective factors bearing on my journey of SILL 13

$\begin{array}{ll}2.3 \text { Important concepts in SILL } & 15\end{array}$

$\begin{array}{ll}\text { 2.3.1 Self-instruction and autonomy } & 16\end{array}$

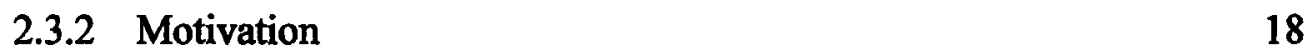

$\begin{array}{lll}\text { 2.3.3 Personal learning styles } & 20\end{array}$

2.3.4 Metacognitive knowledge and learner beliefs 23 
2.4 Learner preparation and support through fostering autonomy

2.4.1 Issues in fostering autonomy 27

2.4.2 Assessing the learner's readiness for autonomy 28

2.4.3 Fostering autonomy through transparency and strategy training 31

2.5 Internalizing metacognitive knowledge for learner empowerment 36

2.5.1 Two constructs of learner beliefs $\quad 37$

$\begin{array}{ll}\text { 2.5.1.a Leamer-context interface } & 38\end{array}$

2.5.1.b Locus of control 39

2.5.2 Learner empowerment: Diary of a lone learner (Jones, 1994, 1995, 1996) 42

2.5.2.a The study 43

2.5.2.b Caveats 45

2.5.2.c Strategic knowledge and learner empowerment 48

2.5.2.d A final note on learner empowerment $\quad 52$

2.6 Self case-studies and diary studies $\quad 52$

2.7 Part II: SILL program design $\quad 57$

$\begin{array}{lll}2.7 .1 & \text { Hayet }(1990 \mathrm{a}, 1990 \mathrm{~b}) & 59\end{array}$

$\begin{array}{lll}\text { 2.7.2 Dickinson (1987) } & 63\end{array}$

$\begin{array}{lll}2.7 .3 & \text { Roberts (1995) } & 66\end{array}$

$\begin{array}{lll}2.7 .4 & \text { Jones }(1993,1996) & 68\end{array}$

$\begin{array}{ll}\text { 2.7.5 Antenos-Conforti (1998) } & 70\end{array}$

$\begin{array}{ll}2.8 \text { Conclusion } & 71\end{array}$ 
3.1 Introduction $\quad 74$

3.2 Methodology: Creating a scaffold for the study 74

3.2.1 My background as a language learner 75

$\begin{array}{lll}\text { 3.2.2 The proposed study } & 80\end{array}$

3.3 Introduction to the materials 84

3.3.1 Rationale for the selected materials 84

3.3.1.a The languages $\quad 85$

3.3.1.b The SILL programs $\quad 86$

$\begin{array}{ll}\text { 3.3.2 Living Language } & 88\end{array}$

$\begin{array}{lll}\text { 3.3.3 Teach Yourself } & 94\end{array}$

$\begin{array}{ll}3.4 \text { Results: The learner diaries } & 98\end{array}$

$\begin{array}{ll}\text { 3.4.1 General comments } & 101\end{array}$

3.4.2 Learner preparation and support 103

$\begin{array}{ll}\text { 3.4.3 Sense of progress and pace } & 107\end{array}$

3.4.4 Sense of failure and laying blame 110

3.4.5 Sense of success through noticing 114

3.4.6 Coping with ambiguity in a teacherless context 116

$\begin{array}{lll}\text { 3.4.7 Clash of styles } & 119\end{array}$

$\begin{array}{ll}\text { 3.4.7.a Activities } & 121\end{array}$

3.4.7.b Audio materials $\quad 124$

$\begin{array}{ll}\text { 3.5 Discussion of major findings } & 125\end{array}$

$\begin{array}{ll}\text { 3.5.1 Affective findings } & 126\end{array}$ 
4.2.1 Communicative Language Teaching (CLT)

4.2.2 Audiolingual Method (ALM)

4.2.2.b Writing to speak: Diary of a lone learner (Jones, 1994, 1995, 1996)

4.3 Evaluative instruments revisited

4.3.1 Learner preparation

4.3.2 Learner support

4.3.3 Leaming activities

4.3.4 Unrealistic claims

4.4 Critique of my four SILL programs

4.4.1 Living Language Complete Basic German and Japanese

4.4.2 Teach Yourself Beginner's German 
5.1 Introduction

5.2 Implications of my findings and recommendations for SILL program design

5.3 Areas in need of future research

SILL program references

References 


\section{Chapter 1: Introduction}




\subsection{The phenomenon of self-instructed language learning (SLL): What is it and why do it?}

Self-instructed language learning (SILL) (a.k.a. "lone learning") is essentially the starting up of (or brushing up on) a foreign language without the aid of a teacher. Of greatest import to this particular study, SILL is often realized through the use of do-it-yourself programs, available for purchase at major bookstores. These programs are sold in packages containing, most frequently, some sort of course book and audio materials. SILL programs are becoming a more and more popular choice among adults wishing to learn and improve on knowledge and skills in their second language (L2). At a time when the world is getting smaller, which is to say that travel and business are occurring on an international scale more than ever before, and when people's busy schedules are getting busier, making it more difficult to work around college timetables and course calendars, self-instruction is the answer to many people's language learning needs. Of course, there are countless different factors that bring adult learners to self-instruction besides scheduling - perhaps the language in question is not offered locally, or perhaps these learners have not found success in formal classroom settings. Whatever the reason, there is a hot market for SILL programs, as is evident from browsing the language aisles of most leading bookstores. 


\subsection{Questions prompting the study}

My fascination with self-instruction, in fact, began with the discovery of the language aisle at Chapters. As a self-identified language magpie who struggles to find time in her own busy schedule for yet more language classes, I was simultaneously dazzled and dubious. How do these programs follow through with the promises displayed so tauntingly on the suspiciously sealed packages? What secrets lie inside the glossy boxes advertising the extraordinary claims "[t]he quickest way to leam a language, guaranteed" (Instant Immersion, box), "[t]he proven way to learn a language" (Teach Yourself, box), and "[s]peak German with confidence in just 6 weeks" (Living Language, box)? As a trained linguist and English-as-a-second-language (ESL) instructor, I was intrigued by these so-called "proven" (yet unknown to me) methods, such as the "highly effective speed-learning method" (Living Language, box), and "[t]he Euro Method" (Instant Immersion, box).

A closer perusal of the packages lining these aisles suggested to me that three types of learners are most attracted to (or at least are most targeted by) SILL programs. These are: the tourist, the business traveler, and the aficionado (those rare language magpies, such as myself, who seem to take up the study of foreign languages for the sheer enjoyment of it). Knowing that each of these three targeted lone learners will approach self-instruction with specific goals and needs, complicated by personal learning styles and preferred strategies, several more questions came to mind: How does the lone learner select the most suitable SILL program for her own needs? How do writers account for the vast continuum of learners who will purchase their programs? How is the 
lone learner supported through her difficult journey of self-instruction? These are only a few of the questions that initially prompted the undertaking of the present study.

Further, I found myself perplexed by an additional issue, one relating to the four skills of language learning in any context, i.e., speaking, listening, reading, and writing. While reading and writing are skills that can arguably be practiced in isolation, speaking and listening do not seem to lend themselves to the SILL context nearly as well. Without a real-life conversation partner, I predicted that speaking in the L2 would be painfully artificial and unrewarding for the lone learner, and learning to comprehend authentic input would be nearly impossible. This issue prompted me to question: Is lone language learning, although a nice idea in theory, actually a contradiction in terms?

Before defining and narrowing the focus of my investigation, I will briefly describe several modes of SILL, along with some advantages and disadvantages of SILL programs. Although these programs have long been pushed to the periphery of second language acquisition (SLA), my aim here is to situate them more centrally within the field because, whether or not applied linguists and language pedagogues wish to take the SILL phenomenon seriously, the vast number of these programs available commercially attests to the fact that members of the unwary general public do take them seriously by investing both their time and money, and consequently need support to critically evaluate the strengths and weaknesses that inevitably lie therein. As Jones (1993) states "it is high time the teach-yourself phenomenon were taken seriously" (p. 453). 


\subsection{Modes of SHL}

There are various ways to go about SILL. Some learners choose to borrow or purchase commercial SILL packages, as I did. As mentioned briefly already, these packages generally (but not always) include a course book, audio materials, and a two-way dictionary. There are also distance education programs and broadcast courses, which are presented on the television or radio, usually with a course book as a resource. Computer assisted language learning (CALL) is also quickly becoming a popular option with the rise of an increasingly computer-savvy public, both for home-study and in self-access language laboratories. Some learners choose not to follow any particular program, opting instead to immerse themselves in the L2 environment and learn in-situ. For the purposes of the present study, I will not be delving further into the possibilities of distance education, CALL, or in-situ learning, and instead will focus exclusively on commercial SLL (audio) packages. I will be addressing my reasons for this particular focus in Chapter 3.

\subsection{Advantages and disadvantages of SILL programs}

While the disadvantages of SILL programs are quite evident, including "lack of teacher feedback, conversation practice and group motivation" (Jones, 1995, p. 96), the advantages that come to light over the course of self-instruction are less straightforward. Proponents (e.g., Antenos-Conforti, 1998; Dickinson, 1987) claim that not only does self- 
instruction provide the convenience sought after by so many adult learners - the learner gets to decide when and where the instruction will take place- but in many ways selfinstruction is an opportunity to embrace one's preferred strategies and adapt the program to one's personal learning style. To borrow a term from Antenos-Conforti (1998), it is an opportunity for learner empowerment. In her study of SILL programs, Antenos-Conforti emphasizes the advantage of the personalized learning pace afforded to the lone learner, and goes on to explain "[t] he individual, with freedom and flexibility (subject only to the helpful hints of the author), takes command of all the elements included within these kits, and becomes an empowered learner" (p. 542). In fact, some researchers (e.g., AntenosConforti, 1998; Dickinson, 1987) even believe self-instruction to be "the ideal learning mode, being most precisely tailored to the learner" (Jones, 1995, p. 96).

The question of whether these programs lend themselves to learner empowerment or not will be addressed further in Chapter 2. For now, it is sufficient to say that, as with every learning context, there are advantages and disadvantages. One important disadvantage in the case of SILL, however, is that there is no opportunity for the learner to be guided by a language teacher over and around the shortcomings of the SILL program (e.g., course book errors, ambiguity, lack of dynamism, and so forth). The lone learner must navigate these for herself, something that potentially makes self-instruction inherently more challenging than classroom-based learning. 


\subsection{Poverty of research on SILL programs}

Curiously, as I began to research empirical support for the extraordinary claims made by SIL programs, my findings were paltry at best. Although these programs have long been available commercially and appear to have become a widely used alternative to traditional language classes, self-instruction has scarcely been studied empirically. As Jones (1993) states “[r]emarkably few empirical studies... have been done into self-study, i.e. learners' use of conscious strategies to teach themselves a foreign language... without classroom or institutional support" (p. 453), and as a result "much of its justification has to come indirectly: from general language acquisition theory or from classroom-based research" (Jones, 1994, p. 441). Even more alarming is the claim by Roberts (1995) that: By contrast with commercially-produced foreign language materials for use in class, those intended for home-study are less exposed to critical scrutiny, the market in them taking place directly between the publishers and potential learners, with no teachers or curriculum planners in between. (p. 513)

How is it, then, that these programs claim their basis on sound and proven methods? As the field of SLA grows and changes, pedagogical methods fall in and out of favour. The popularized Audiolingual Method was once widely used in L2 classrooms, and was easily adopted by SILL programs due to the ease of using pre-recorded materials for "listen and repeat" activities. However, while the Audiolingual Method has been replaced in most $\mathrm{L} 2$ classrooms by currently favoured communicative approaches (Brown, 1994), it seems that the majority of SILL publishers have not followed suit (Jones, 1993, 1996; Roberts, 1995). Despite being largely discredited in the literature, 
and despite the fact that most SLA researchers (e.g., Brown, 1994; Jones, 1993; Matsuda, 2001, 2003; Rivers, 1964; Roberts, 1995; Vann, 1981) now consider the Audiolingual Method to be ineffective and outdated, this method can still be identified as the primary method of many SILL programs for sale today (Jones, 1993, 1996; Roberts, 1995). From this, two further questions strike me. First, if the professional community of applied linguists and language pedagogues have come to regard SILL programs "with an amused disparagement normally reserved for the wackier fringes of classroom methodology" (Jones, 1996, p. 19), from where is the self-instruction research used to design SILL programs coming? Second, should the consumer public be made aware of the methodological gap between accepted classroom-based pedagogy and SILL programs?

\subsection{Research questions}

Loaded with all of these questions and concerns I arrived at the present study. At the outset, I tried to imagine the lone learner wandering the bookstore aisles as I did, selecting a program, bringing it home... and then what? What would be her experience? As Jones (1993) laments "[a]necdote has it that they [lone learners] face a hard, lonely task with a high drop-out rate, especially if they live outside the country where the language is used" (p. 453). How would the lone learner manage on her own? How would she feel? Would she succeed? How would she measure that success? Certain that there is only one way to answer such questions, I undertook the study of four SILL programs, assuming the role of that lone leamer. I did so with a plethora of questions in 
mind, such as: How does the lone learner meet the challenges of SILL? What strategies can she adopt to facilitate self-instruction? What are the strengths and weaknesses of SILL programs? How do the programs compare with each other? How does a particular series adapt its programs to suit different languages? How well do SILL programs account for and meet the needs of lone learners? I chose, as Jones (1994, 1995, 1996 [three separate publications all based on a single study]) did in a similar undertaking, not to make any testable hypotheses based on the conviction that because "I was exploring what was virtually virgin territory in SLA terms, I could expect most of my discoveries to be unexpected" (Jones, 1994, p. 444). Jones (1996) further explains that "[t]o investigate this field by standard hypothesis-testing means... would have presupposed knowledge that does not exist. Self-instruction is still very much a terra incognita" (p. 22). My hope, therefore, is that through the following exploration I can make self-instruction a little less of a terra incognita by contributing to the work only recently begun by researchers like Jones.

Despite my numerous questions, my central aim at the outset was to test the claims made on the SILL packages in order to answer one research question in particular: How does my experience with self-instruction compare with what is promised on the SILL packages? However, this research question put the emphasis on the product of the study (i.e., the end result of the learning) rather than on the process of self-instruction (i.e., the journey itself). As I grew increasingly more interested in the process, two major foci emerged - foci that have become the central framework of the present thesis. The first major focus is on my own personal journey of self-instruction. This journey had both good and bad days, and was mediated always by affective factors (e.g., motivation, 
personal learning styles, metacognitive knowledge, learner beliefs, and so forth) inalienable to me as a learner. Working sometimes with and sometimes against these factors were the SILL programs themselves. As such, the programs emerged as the second major focus of the study. A program's efforts (or lack thereof) to prepare me for self-instruction and to support me along the way oftentimes made the difference between a good and bad day.

In the next four chapters I will present my five-month exploration of four SILL programs in two languages. Throughout these chapters, I will address the two major foci in the following way. Chapter 2, my literature review, is divided into two distinct parts. Part I is concerned with the first major focus, and there I will present a review of the literature concerning the affective factors that had the most bearing on my journey. I will conclude part I with a review of the aforementioned study by Jones $(1994,1995,1996)$ to serve as a precedent for my own study. After describing Jones's study in detail, I will argue for his methodological choice of undertaking a self case-study, as well as a diary study, in order to substantiate my own decision to follow suit. Part II of Chapter 2 is concerned with the second major focus, and there I will present the limited literature on SILL program design.

Chapters 3 and 4 form the analysis of my study, reflecting the first and second major foci respectively. In Chapter 3, I will describe my journey in narrative, beginning with a treatment of my preliminary methodological choices, followed by the analysis of my learner diaries, and ending with an examination of the insights I gained by way of this undertaking. In Chapter 4, I will look critically at the SILL programs I followed, as well as present a discussion of germane language pedagogy. In this chapter, I will further 
discuss the literature on SILL program design introduced in Chapter 2 by emphasizing the design criteria that I found to be most important, based on my experience as a lone learner. Finally, in Chapter 5, I will conclude with a discussion of implications and recommendations for SILL program design, and areas in need of future research.

Before proceeding, I will address a methodological issue that is pertinent to the organization of the discussions. As both the researcher and the diarist of this study, I have found myself struggling to locate my voice within the following chapters. Although this double role has both methodological pros and cons, which are well-established in the literature (as will be illustrated in Chapter 2), I came across no mention of the issue of voice in my methodological readings. Efforts to speak sometimes as the diarist (distinct from the researcher) and sometimes as the researcher (distinct from the diarist) proved impossible. I found myself wrestling with the faint margins existing between my candid learner diaries and guarded academic prose. In the end, I settled on what I hope to be a taut dialogue between the two. Throughout the following chapters, two strident voices can be located. One is analytical, concerned with creating a methodological framework on which sound SLA research can be posited. The other is more intuitive, concerned with the narrative of one lone learner's journey. Because this study is about the journey and not the destination (in other words, it will attend to the process more so than the product), this narrative voice will resound in many of the discussions. 


\section{Chapter 2: Literature review}




\subsection{Introduction}

As described in Chapter 1, Chapter 2's literature review is divided into two distinct parts. Parts I and II reflect the first and second major foci of this study respectively. Part I is concerned with my journey as a lone learner, and there I will present a review of the literature concerning the affective factors that had the most bearing on that journey. To capture the complex interplay of these factors over the course of my study, I chose, as many researchers did before me, to conduct a diary study. For this reason, I will conclude part I with a review of Jones's $(1994,1995,1996)$ study to serve as a precedent for my own study. After describing Jones's study in detail and presenting several other diary studies briefly, I will argue for this methodological choice of undertaking a self case-study, as well as a diary study, in order to substantiate my own decision to follow suit. Part II of Chapter 2 is concerned with the second major focus, and there I will present the limited literature on SILL program design. This review will consist of a critique of SILL package claims along with four evaluative instruments presenting design criteria for SILL programs.

\subsection{Part I: Affective factors bearing on my journey of SUL}

The following sections will establish a framework with which to examine and better understand the affective factors bearing on my journey with SILL. As Jones (1994) states "if we are to find the key to success in self-study, we should perhaps be looking not 
so much at the materials as at the learner" (p. 443). The interplay of affective factors that was captured in my learner diaries and that emerged from the subsequent analysis of those diaries is extremely complex. By necessity, I have narrowed these factors down to the four that emerged most saliently over the course of my journey. These are: motivation, personal learning styles, metacognitive knowledge and learner beliefs. The following sections will present these factors in two ways. First, they will be defined in relative isolation-relative isolation because these factors are interconnected and each one ultimately implicates the others. Second, they will be presented within the context of recent research, which will better illustrate how these four factors interplay with one another.

No literature review can afford to be comprehensive within the ever-limited scope of a single study. Therefore, I will only review the literature required to make clear the assumptions on which I am basing my own study. These assumptions rest on the claim that successful SILL is not only possible, but is "the ideal learning mode, being most precisely tailored to the learner" (Jones, 1995, p. 96; see Antenos-Conforti, 1998; Dickinson, 1987). If, as Antenos-Conforti (1998) claims, successful SILL is a result of learner empowerment, where " $[t]$ he individual, with freedom and flexibility (subject only to the helpful hints of the author), takes command of all the elements included within these kits, and becomes an empowered learner" (p. 542), how does this phenomenon of learner empowerment manifest over the course of SILL? What role do the programs play in this phenomenon?

Current research indicates that programs can facilitate SLL, and thus learner empowerment, by preparing the lone learner for self-instruction and supporting her along 
the way (see Cotterall, 1995; Crabbe, 1993; Dickinson, 1987; White, 1995, 1999).

Preparation can occur by assessing the learner's readiness for autonomy, and by addressing her learner beliefs. Support can occur by providing opportunities for the learner to use her metacognitive knowledge to embrace her personal learning style, as well as by fostering autonomy through transparency and strategy training. Ultimately, however, learner empowerment is not accomplished by the programs, but by the learner, who must take "command of all the elements" (Antenos-Conforti, 1998, p. 542). Below, I will describe the potential site of learner empowerment as being the learner-context interface where the learner and her SILL program meet, and how, at this site, the learner can find empowerment through internalizing the locus of control and taking command of her learning (White, 1995, 1999).

\subsection{Important concepts in SILL}

The following section will introduce self-instruction, autonomy, motivation, personal learning styles, metacognitive knowledge, and learner beliefs. I have already identified the last four concepts as being the affective factors most salient in my journey of lone learning. The first two, self-instruction and autonomy, are included because it is crucial that I define these concepts for my present purposes, as they can be understood in various ways. 


\subsubsection{Self-instruction and autonomy}

A widely accepted and much quoted definition of self-instruction comes from Dickinson (1987), who offers '[t] he label 'self-instruction' is used to refer to situations in which a learner, with others, or alone, is working without the direct control of a teacher" (p. 5). Dickinson makes a distinction between self-instruction and autonomy where: [T] he learner is totally responsible for all the decisions concerned with his learning and the implementation of those decisions. In full autonomy there is no involvement of a 'teacher' or an institution. And the learner is also independent of specially prepared materials. (p. 11)

By these definitions, an example of a self-instructed learner is one who works independently on homework assignments, finds a language study-buddy, or follows the predetermined syllabus of a SILL program or CALL software. An example of a fully autonomous learner is one who structures her own learning activities independently. She might do this through exposing herself to authentic texts such as magazines, newspapers, or movies in the $\mathrm{L} 2$, or traveling to an $\mathrm{L} 2$ destination to learn in-situ.

Jones (1998) further distinguishes between two types of self-instruction. These are: broad and narrow. In the broad sense, he adopts the definition supplied by Dickinson (1987). In the narrow sense, Jones refers to "a deliberate long-term [italics added] learning project instigated, planned, and carried out by the learner alone, without teacher intervention" (p. 378). Although many different tasks arguably fall within the broader scope of self-instruction (e.g., homework, student-led group work, and so forth), it is the narrow scope of self-instruction referred to by Jones as "teach-yourself, i.e. solo 
instruction led by the syllabus of a language-learning package" (p. 378) that is of key interest here.

Please note that I will not be adopting the term teach-yourself from Jones (1998) because it is the proper name of one of the commercial programs under scrutiny in this study and I want to avoid as much referential confusion as possible. To keep these concepts relatively straightforward, I will be making only two distinctions in the present study. To denote what Jones refers to as the narrow view of self-instruction I will continue to use the acronym SILL introduced in Chapter 1, (alternating occasionally with the expression lone learning). To denote the general definition of self-instruction offered by Dickinson (1987) (which corresponds to what Jones calls the broad view of selfinstruction) I will use the term autonomy, as in "[t]his notion of the self in control of a learning situation forms the foundation of autonomous learning" (Derrick \& Carr, 2003, p. 6).

To be completely unambiguous, I will refer to the learning project that I undertook for my study in its entirety as $S I L L$, and the all-purpose notion of any selfmonitored activity as autonomy. The only time this distinction will be of any relevance is when I discuss issues such as fostering autonomy in classroom-based learning. In this context, it is clearly not a question of fostering the use of SILL programs. Rather, it is the question of a teacher's responsibility to encourage her students to become more active agents in their own learning.

According to Wenden (1998) there are three activities particular to autonomous learning. These are: planning, i.e., "clarifying needs, goal setting, prioritizing goals, setting objectives, defining content and progressions" (p. 529); monitoring, i.e., "keeping 
track of how the learning process is going and taking appropriate measures to deal with difficulties that interfere with the process" (Flavell, 1981, as cited in Wenden, 1998, p. 525); and evaluating, i.e., the act of measuring the learning outcome against the criteria the learner has set for herself in order to determine success (see also Cotterall, 1995; Dickinson, 1987). These activities are mediated by the learner's affective factors, such as her learner beliefs and personal learning style. Before my discussion moves on to address those issues, I will quickly negotiate the labyrinth that is motivation.

\subsubsection{Motivation}

Although Ushioda (as cited in Dörnyei, 2001) claims that "[a]utonomous learners are by definition motivated learners" (p. 59), not all autonomous learners are motivated for the same reasons, and every learner's motivation does not manifest itself in the same way. The literature on motivation is highly disjointed and complex "because some of the characteristics of motivation defy categorization, while others seem to fit into two or more categories, while others still, appear inseparable from seemingly unrelated or continually changing aspects of human behaviour" (Barker, 2003, The Challenge section, para. 1). For the purposes of this brief discussion, I will describe only the two constructs of motivation that are necessary to characterize the three target lone learners (i.e., the tourist, the business traveler, and the aficionado) in a general way. These constructs are intrinsic and extrinsic motivation. 
A language learner with intrinsic motivation is one who is motivated to learn because she alone wants to. Perhaps it is the enjoyment of the process itself, or enjoyment of the outcome of the learning, or a bit of both, as Barker (2003) writes:

[T] he point is you and you alone are the source of the impetus to act and, in real terms, you are the one who evaluates the learning that occurs, the level of achievement attained and the relative pleasure of the experience. (Intrinsic Motivation section, para. 1)

On the other hand, a learner with extrinsic motivation is externally regulated, i.e., "motivated to act by the anticipation of some kind of reward or to avoid some kind of punishment" (Barker, 2003, Extrinsic Motivation section, para. 2). For example, with respect to the three target groups of SILL program buyers, the aficionado is, by definition, intrinsically motivated. She undertakes language learning for the sheer enjoyment. The business traveler, in contrast, is likely to be extrinsically motivated. She is liable to be motivated by some external force-perhaps brushing up on her high school Spanish will earn her a raise because she can now negotiate with customers in Latin America, for example. The tourist might fit somewhere in between these two. Perhaps she is intrinsically motivated because a few token phrases in Finnish can add real authenticity to a short vacation, but also extrinsically motivated because a few key phrases of politeness can go a long way in winning over the locals.

Although I claim in my introduction to belong to the aficionado group of lone language learners, my motivation was obviously not exclusively intrinsic. Due to the complicating context of undertaking SILL as part of the research towards my MA thesis, my motivation was extrinsic as well. Intrinsically, my love of foreign language learning 
persisted; extrinsically, my goal to complete this study and to graduate from my degree program was constant.

\subsubsection{Personal learning styles}

The following is a breakdown of the four categories of personal learning styles as described by Antenos-Conforti (1998) (see also O’Malley \& Chamot, 1990). These are: sensory preferences, environmental preferences, cognitive styles, and personality types. Although no single program can possibly account for all combinations of personal learning styles, a program could potentially be more forthcoming in terms of what types of learners would be best suited to its design. For instance, below I will include examples of programs that cater to particular learning styles, where applicable. I will discuss these programs further in Chapters 3 and 4 . For the purposes of this discussion, the examples only serve to reflect the programs available commercially that might appeal more to one particular learning style than another.

Sensory preferences "refer to preferred modes of perception, practice and recollection of information. These are visual, auditory, kinesthetic, and oral/digital mechanical" (Antenos-Conforti, 1998, p. 555). These preferences are what distinguish, for example, visual learners (i.e., learners who learn best by seeing) from auditory learners (i.e., learners who learn best by hearing) from kinesthetic learners (i.e., learners who learn best by doing). Whereas some SILL programs provide opportunities for hearing, seeing, and doing (e.g., Teach Yourself), others only provide opportunities for 
hearing and seeing (e.g., Living Language), and yet others only provide opportunities for hearing and doing (e.g., Instant Immersion).

Environmental preferences “include the learner's most suitable/productive physical surroundings, such as lighting, sounds, body positions, and social environment" (Antenos-Conforti, 1998, p. 555). Some SILL packages advertise their programs as being compatible with other activities, such as driving and gardening (e.g., Instant Immersion). Questions of feasibility aside, there are learners to whom such advertisements would appeal, and learners to whom they would not appeal based on environmental preferences.

Cognitive styles refer to the fact that "[t]he learner's mind has a preferred approach to perceiving, processing, and recalling information. The dichotomies within this preference are: Global/Analytic, Field dependent/independent, and Inductive/Deductive" (Antenos-Conforti, 1998, p. 555). In the SILL context, preferred cognitive styles would manifest most readily in terms of the presentation of lessons and activities. For example, the global/field dependent/inductive lone learner might appreciate programs that advocate more communicative approaches, emphasizing content over form (e.g., Teach Yourself), whereas the analytic/field independent/deductive learner might appreciate programs that use charts and rules to present information, emphasizing form over content (e.g., Living Language).

Personality types refer "to the student's typical manner of relating to society and information. These have been synthesized into polarities: introverted/extroverted; thinking/feeling; judging/perceiving; and sensing/intuiting" (Antenos-Conforti, 1998, p. 555). Most relevant, perhaps, to the SILL context is the introverted/extroverted polarity. 
The introverted lone learner might be more inherently attracted to self-instruction than to classroom-based instruction because she does not have to grapple with such activities as group work, conversation practice, and so forth. However, she might not be as successful as the extroverted lone learner because she might not seek out practice opportunities, such as conversing with native speakers, or finding a study buddy.

It would be wise to acknowledge that, in the case of those preferences that are characterized by the dichotomization of certain learner types (e.g., global/analytic, introverted/extroverted, and so forth), rarely does a learner identify as being on either of the extreme ends of that continuum. Most learners fit somewhere in between, and all of these different kinds of preferences interact in complex ways, which manifest differently in different individuals. I, for example, learn well by seeing or doing, but terribly by hearing. To study efficiently I need a quiet environment with room to spread out and no distractions. Twice I attempted to take advantage of the "transportability" of SILL programs by listening to the audio track outside of my preferred study environmentonce in the bath and once while walking outdoors. Both attempts failed miserably, as I will recount in Chapter 3. As far as cognitive style goes, I belong completely to neither the global nor the analytic camp, as I see the appeal of both and attempt to meld details with the big picture in order to achieve both accuracy and fluency as much as possible when practicing any of my L2s. With respect to personality type, I identify as an introvert, though many who know me would call me an extrovert because I am wellpracticed at compensating for my natural shyness.

I offer these characterizations of myself to demonstrate the vast number of possible combinations that could typify any one learner. It is easy to imagine, therefore, 
that SILL program writers would feel overwhelmed at attempting to account for every learner's personal learning style. However, these programs should be able to provide enough flexibility (wherever possible) for the learner to work within her personal learning style.

\subsubsection{Metacognitive knowledge and learner beliefs}

Wenden (1998) defines metacognitive knowledge as "the relatively stable information human thinkers have about their own cognitive processes and those of others (Flavell and Wellman 1977); it is a specialized portion of their knowledge base (Flavell 1979) acquired formally, informally, deliberately or incidentally" (p. 516). Wenden argues that such knowledge is a crucial factor in self-instruction by "helping learners to become 'active participants in their own performance rather than passive recipients of instruction' (Paris \& Winograd, 1990)" (p. 520). According to Wenden there are three levels of metacognitive knowledge of interest to self-instruction. These are: person knowledge, i.e., "knowledge learners have acquired about human factors that facilitate or inhibit learning ...e.g. age, language aptitude, motivation" (p. 518); task knowledge, i.e., "what learners know about the purpose of a task and how it will serve their language learning needs, e.g. to improve their writing skills; expand their vocabulary; develop fluency in oral communication" (p. 518); and strategic knowledge, i.e., "general knowledge about what strategies are, why they are useful, and specific knowledge about when and how to use them" (p. 519). Although Wenden includes strategic knowledge as 
a sub-type of metacognitive knowledge, some researchers (e.g., Crabbe, 1993; Dickinson, 1987; O'Malley \& Chamot, 1990) seem to view the two kinds of knowledge as more discrete. However, such a distinction does not appear to bear much consequence in most discussions.

O’Malley \& Chamot (1990) further describe learning strategies and strategic knowledge as thoughts, behaviours, and techniques that the learner uses to help her understand, process, retain, and apply new knowledge. Antenos-Conforti (1998) writes that "[i]nnate in these strategies is the learner's individual personality combined with his/her cognitive, sensory, and environmental needs and preferences for perceiving, processing, and assimilating new information" (p. 541). With respect to learning strategies, I should note, the general consensus is "not so much that certain strategies are linked to success, but that successful learners have a wide range of strategies, thus enabling them to choose the most appropriate tools for the task at hand" (Jones, 1995, p. 97) (see also O'Malley \& Chamot, 1990; Oxford, 1989; White, 1995, 1999).

This discussion is closely tied to the notion of the Good Language Learner (GLL). The literature concerning the GLL is oftentimes split between those who believe the strategies used by the GLL can be captured and taught to less successful learners (and thus transform them into GLLs) (see Brown, 1994; Naiman et al., 1978), and those who believe that strategies cannot simply be transferred from one learner to another, because implicit in each individual's strategic knowledge is the metacognitive knowledge of what works best for that particular individual (see Norton \& Toohey, 2001). Essentially, the argument is that what works for one learner will not necessarily work for another. However, despite this controversy, there is no reason why SILL programs should not take 
the opportunity to provide at least some strategic advice to their learners, based on the logic that some is better than none.

Despite the lack of consensus in the literature as to what distinguishes a learner's knowledge from her beliefs, Wenden (1998) asserts that "the choice of one term instead of the other is a tacit recognition that there is a difference" (p. 517). While knowledge is commonly seen as "factual, objective information acquired through formal learning" (Alexander \& Dochy, 1995, as cited in Wenden, 1998, p. 517), Wenden defines learner beliefs as "individual, subjective understandings, idiosyncratic truths, which are often related and characterized by a commitment not present in knowledge" (Alexander \& Dochy, 1995, as cited in Wenden, 1998, p. 517). As I will discuss below, many researchers (e.g., Cotterall, 1995; White, 1995, 1999) view learner beliefs as having an immense influence on the outcome of learning.

\subsection{Leaner preparation and support through fostering autonomy}

There has been much interest of late on the topic of learner preparation and support through fostering autonomy in classroom-based learning (see Brown, 1994; Cotterall, 1995; Crabbe, 1993; Derrick \& Carr, 2003; Dickinson, 1987; Victori \& Lockhart, 1995; Wenden, 1998; White, 1995, 1999). Because “[a]utonomy does not just 'happen'; its implementation needs to be planned and prepared carefully" (Kohonen, 1991, p.108), many researchers (e.g., Brown, 1994; Cotterall, 1995; Crabbe, 1993; Dickinson, 1987; White, 1995) believe it is the teacher's job, not only to give her students the tools they 
need to learn in the classroom, but also to give them the tools they need to continue that learning outside of class.

In the case of SILL it can be argued that the teacher's role has been, not obliterated, but contracted out to both the learner and her learning materials. In the SILL context the learner becomes her own teacher, in that she must take control of the learning in many ways. However, the learning materials also play a key role in replacing the teacher, so it follows that some of the support that would traditionally come from the teacher must come from the materials themselves. Put another way:

The materials must carry out all the functions a teacher or trainer would carry out in the conventional situation-guiding, motivating, intriguing, expounding, explaining, provoking, reminding, asking questions, discussing alternative answers, appraising each learner's progress, giving appropriate remedial or enrichment help... and so on. (Rowntree, 1990, as cited in Benson, 2001, p. 133) Regrettably, the research on fostering autonomy in the SILL context has yet to be done. Therefore, the following discussion must rely on two central assumptions. First, in the context of SLL, the language teacher's role is contracted out, at least in part, to the SILL program. Second, as such, if a classroom-based teacher is responsible for fostering autonomy in her students, these programs are equally responsible for the same. Based on these two assumptions I will be transferring some current thinking about fostering autonomy from the classroom-based context to the SILL context. 


\subsubsection{Issues in fostering autonomy}

Some of the issues pervasive to the notion of fostering autonomy include: developing the learner's metacognitive knowledge (i.e., knowledge of personal learning style and preferred strategies) (see Dickinson, 1987; O’Malley \& Chamot, 1990; Oxford, 1989; Victori \& Lockhart, 1995; Wenden, 1998; White, 1995, 1999), addressing the learner's beliefs about language learning (which influence her readiness to undertake autonomous learning as well as influence the outcome of this kind of learning) (see Cotterall, 1995; Dickinson, 1987; Victori \& Lockhart, 1995), and the role of teachers and materials in fostering autonomy (the provision of learner preparation and learner support) (see Brown, 1994; Cotterall, 1995; Crabbe, 1993; Dickinson, 1987; Victori \& Lockhart, 1995). The following discussion presents an overview of two studies looking at the language teacher's role in fostering autonomy in order to transfer some of this thinking to the SILL context, and thus, identify ways in which the SIL programs can facilitate lone learning through fostering autonomy. These are: assessing the learner's readiness for autonomy and fostering autonomy through transparency and strategy training. A brief discussion of the implications for SILL programs and my present study will follow each section. 


\subsubsection{Assessing the learner's readiness for autonomy}

Despite a teacher's best efforts to foster autonomy in the classroom, not all students are equally ready to undertake autonomous language learning. In her study of learner beliefs, Cotterall (1995) argues that not every learner is necessarily ready for the responsibilities increased autonomy entails. Beginning with the claim that a learner's beliefs about language learning can directly enhance or inhibit success in acquiring an L2 (e.g., the belief that one should avoid making errors at all costs might result in a learner's avoidance of fluency-focused activities), Cotterall uses a questionnaire administered to a group of adult ESL learners $(n=139)$ to investigate their beliefs about language learning. Through this questionnaire she identifies six belief categories that are useful to gauge a language learner's readiness for autonomy. These are: role of the teacher, role of feedback, learner independence, learner confidence in study ability, language learning experience, and approach to studying. She then makes pedagogical suggestions for ways of readying students for autonomy based on these belief categories. The following is a discussion of each category in turn.

Role of the teacher refers to the student's view of the teacher as either an authoritative figure or as a facilitator of learning. Students with the latter view are more likely candidates for autonomous language learning. Students with the former view attribute tasks such as "diagnosing difficulties, allocating time, [and] establishing the purpose of activities" (Cotterall, 1995, p. 197) directly to the teacher. Cotterall (1995) suggests that teachers wishing to foster autonomy discuss their role in the classroom 
openly with students and be explicit about the gradual transfer of these kinds of responsibilities from teacher to student.

Role of feedback refers to how the student depends on and uses teacher feedback. Although Cotterall (1995) does not claim that successful autonomous learners require less feedback, she suggests that these learners "are unlikely to depend solely on the teacher for feedback" (p. 199). Students who are able to obtain feedback from a variety of sources (self-monitoring being an important one of these) are more likely candidates for autonomous language learning. This category is closely associated with the previous one in that students who view feedback as the teacher's exclusive responsibility may not be prepared for the kinds of self-assessment autonomous learning requires. Cotterall suggests that teachers provide their students with opportunities for self-assessment as a way to prepare them for autonomous learning.

Learner independence refers to the extent to which the student is able to define her own learning goals and her willingness to actively work towards these goals. Cotterall (1995) claims that this category is "central to the beliefs underlying autonomy" (p. 199). The more actively students participate in their learning, the more likely they are to be candidates for autonomous language learning. This category is also closely associated with the first one in that students who see the teacher as central to their learning and who see themselves as peripheral are less likely to be successful autonomous language learners. In this case, teachers can prepare students for autonomy by encouraging them to set meaningful learning goals.

Learner confidence in study ability refers to the student's self-identification as either a strong or a weak student. This category reflects the student's attitude towards 
learning in general, and also implies " $a$ belief in the learner's ability to influence the outcome of his/her learning" (Cotterall, 1995, p. 200). The more students self-identify as strong students, the more likely they are to be candidates for autonomous language learning. Because this category is closely tied to the broader notion of self-esteem, Cotterall (1995) suggests it be treated in a similar way—by addressing the student's personal anxieties and emphasizing the self-fulfilling prophesy of such thinking. The teacher's role in this case is to encourage students to explore their personal anxieties and promote self-reflection.

Language learning experience refers to the student's prior experience with language learning, and reflects whether the student has an appreciation of what is involved in such learning. Tied in with this is Approach to studying, which refers to whether or not the student treats language learning as a distinct kind of learning or if she treats it like other kinds of learning. Students who can use their past experiences "of attempting tasks, employing strategies and solving problems to develop their understanding of how language learning works" (Cotterall, 1995, p. 202) are likely candidates for autonomous language learning. For students with limited language learning experience, or for those who have not reflected on their experience sufficiently to gain much of an understanding or an appreciation of language learning, teachers can encourage reflection on how language learning happens, what sorts of skills are needed to learn a language, and what personal attributes will be the most helpful to them in this process.

Language teachers who wish to foster autonomy in their classrooms would benefit from being familiar with these six belief categories, because they can be used to assess 
student beliefs and ultimately to predict readiness for autonomy. Premature attempts to transfer the responsibility of learning from teacher to student could have negative consequences on the student's success in future autonomous learning situations, especially with respect to self-confidence.

This discussion is crucial to the SILL context because there is no screening process for lone learners. Anyone can go to the store, purchase a SILL package, bring it home, and undertake self-instruction. In classroom-based learning, the teacher can assess her students for their readiness for autonomy and adjust her teaching accordingly, but there is very little room for adjustment in the SILL context. However, what SILL programs can do to ready the lone learner for autonomy is attempt to address each of these six belief categories in the program introduction. An introduction or study guide, which openly breaks down the role of the teacher and feedback, the importance of setting goals and self-evaluation, the value of past learning experiences, and so on, can be presented to the learner in an effort to preempt the inevitable frustration and discouragement of the lone learner who is not sufficiently prepared for SILL (see Brown, 1989, 1994).

\subsubsection{Fostering autonomy through transparency and strategy training}

Crabbe (1993) justifies the appeal of autonomy on three grounds. These are: the ideological, the psychological, and the economic. The ideological argument is based on the notion that individual freedom results in a "healthier, happier society" (p. 443). The 
psychological argument is that autonomy enhances learning, because when an individual takes charge of her own learning it becomes more meaningful. The economic argument speaks to the limited resources in society, and the notion that more autonomous learning taking place makes for fewer resources needed to go around. For pedagogical reasons, Crabbe is most interested in the psychological argument, claiming that it is the teacher's responsibility to prepare students for autonomy. In fact, Crabbe goes so far as to suggest that "[a]utonomous learning needs to become a reference point for all classroom procedure” (p. 444).

To implement this suggestion, Crabbe (1993) invites language teachers to look at learning activities as occurring in two domains. These are: the public domain and the private domain. The public domain consists of shared classroom activities, whereas the private domain consists of each individual student's personal learning. Crabbe claims that "[f]or a teacher who aims to foster autonomy, the focus of attention is on both of these domains and the interface between them" (p. 445). Essentially Crabbe advocates the notion that not only do teachers have to create learning activities that will accomplish some learning goal (so that learning can occur in the public domain), but they must also be transparent in how the activity will manage to accomplish that goal (so that learning can occur in the private domain). This kind of transparency will allow students to generalize from task to task. A strategy used in the classroom to facilitate one learning activity can potentially be transferred to another activity in an autonomous setting if students understand how and why that strategy works.

This notion of transparency is closely related to what Wenden (1998) refers to as transfer of learning, which "refers to the application of acquired knowledge and skills 
used in a previous task to the completion of a present task" (p. 526). Wenden lists three essential features of strategy training to foster the transfer of learning. These are: that it be informed, provide conditional knowledge, and promote mindfulness. As she explains: Informed training provides knowledge about the purpose of the strategy - what the expected outcome of using it will be. Training provides conditional knowledge if it tells learners when a strategy can be used so that it is likely that they will use it not only in the training context but in a variety of other appropriate settings. Finally, mindfulness is promoted when learners are taught to determine whether there are similarities between previous learning activities (or tasks) and the present task. The task knowledge yielded by this comparison will, then, be the basis for determining whether the strategy applicable to a former task can be transferred in the present case. (p. 527)

For example, if a teacher wants to teach strategies for dealing with large amounts of text in an L2, she might instruct the students to skim over the text as an initial reading, looking for such things as headings, enumerated points, and key words. However, if her instructions are not transparent, if she introduces the task by simply asking her students to skim the text for these elements without explaining what goal she is hoping to accomplish, her students may not understand the instructions as being generalizable as an approach to managing other texts. It is possible that learning will occur in the public domain as the students follow the instructions for the text in question. However, without transparency, learning may not occur in the private domain because the strategy will not be recognized as being transferable. Transparency fosters autonomy by equipping students with the knowledge that learning strategies in the classroom are generalizable 
and transferable to situations of autonomous learning. To put it in Wenden's (1998) terms, by denying the students this conditional knowledge the teacher will fail to promote mindfulness; thus the strategy will not be identified as transferable and no transfer of learning will occur.

This argument has important pedagogical implications. Crabbe (1993) argues that teachers must take the time in class to explain, not only the "what" of the learning activity, but, most crucially, the "why" of the activity. Without the "why", students are denied an important learning opportunity, which is to gain an understanding and an appreciation of how language learning works. Through such an understanding, students become empowered learners with three important advantages. First, they have access to many different strategies. Second, they have the opportunity to experiment with these strategies to find what works best for them. Third, they have the capacity to evaluate a learning challenge in such a way as to allow them to select the appropriate strategy to meet that challenge.

In a SILL context, transparency is equally, if not more, important. Without the supervision of a teacher, opaque activities may initially appear useless to the learner. As a result, valuable learning activities might be omitted because the learner did not appreciate the importance of the activity. A second danger, more closely related to the one proposed by Crabbe (1993), is that the study skill being presented by the activity may not be recognized as transferable to challenges outside of the SILL program, thus rendering the learner dependant on the program. By prefacing activities with a short explanation of the underlying purpose of any given activity, the learner is trained both to 
recognize the value of an activity and to develop greater autonomy through strategic knowledge.

Admittedly, this discussion takes a very simplified view of strategy training, and begs the question: Is it enough to just tell learners what a strategy is and how it works? If it were that simple, every learner would be a strategic learner. As always, there will be those who will adopt a given strategy and those who will not. To reiterate from Jones (1995), learners who have a wide range of tools in their toolbox seem to enjoy the most achievement; therefore every attempt at filling that toolbox, whether successful or not, is arguably time well spent. The question is, can SILL programs encourage and facilitate this process in any substantial way for the lone learner? Brown (1994) makes several suggestions for modes of strategy training compatible with SILL programs, such as interactive techniques, compensatory techniques, strategy inventories, course book embedded training, and adjunct self-help guides.

My intention here is to establish the primacy and magnitude of fostering autonomy to thereby justify my critique (in Chapter 4) of the SILL programs offering only minimal learner preparation, learner support, and strategy training. Most salient to the above discussion is the consensus that preparing students for autonomy and supporting them in whatever way possible (e.g., by making learning activities transparent, by encouraging self-evaluation and goal setting, and so on) can only lead to better prepared and more successful autonomous learning (see Benson, 2001; Brown, 1994; Cotterall, 1995; Crabbe, 1993; Dickinson, 1987; Victori \& Lockhart, 1995; Wenden, 1998). Increasingly, researchers (e.g., Cotterall, 1995; Crabbe, 1993; Dickinson, 1987; Victori \& Lockhart, 1995; Wenden, 1998; White, 1995, 1999) are 
recognizing the importance of exploring the lone learner's metacognitive knowledge as a means to prepare her for and support her through SILL, by arguing that this is the way to learner empowerment.

\subsection{Internalizing metacognitive knowledge for learner empowerment}

As stated above, in the case of SLL it can be argued that the teacher's role has been, not eliminated, but contracted out to both the learner and her learning materials. Accordingly, in order for successful learning to take place the leamer and her materials must work together within the SILL context. A study by White (1999) shows that a closer examination of the interface where the learner and her materials meet reveals a dynamic relationship between the two. White states that:

[T] he context and the learner are seen as each exerting an influence on the other. According to this view, learners are influenced in new ways by the solo learning context, to extend and develop their learning skills and knowledge about themselves as learners...At the same time, learners exert an influence on the materials, as they approach them, engage with them, transform them in their own way, so they actually become texts and sources for learning for themselves. (p. 449)

Ostensibly, this dynamic relationship creates awareness for the learner and, when exploited fully, gives rise to two important kinds of knowledge. These are: metacognitive knowledge (i.e., knowledge of personal learning style and preferred 
strategies) and strategic knowledge (i.e., knowledge of which learning strategies work best for the learner when faced with which challenges, and how to apply them). The following discussion presents an overview of a study surrounding the emergence and internalization of metacognitive knowledge in the lone learner (White, 1999), which will elucidate the connection between metacognitive knowledge and learner empowerment. Following the discussion of this study will be an example of learner empowerment (Jones, 1994, 1995, 1996). A brief discussion of the implications for SLL programs and my present study will follow each section.

\subsubsection{Two constructs of learner beliefs}

In her study of lone learners, White (1999) investigates two constructs of SILL that emerge through the longitudinal tracking of the expectations and beliefs (and subsequent shifts in expectations and beliefs) of a group of lone language learners. These constructs are: the learner-context interface (briefly introduced above) and the locus of control. Both constructs can be viewed as being externally or internally situated. White shows that as the learner negotiates SILL, these constructs shift from being viewed as external to the learner to being viewed as internal to the learner. 


\subsection{1.a Learner-context interface}

The first construct, the learner-context interface, relates to "a belief in the primacy of the unique dynamic established between the learner and the context in the process of self-instruction" (White, 1999, p. 449). White (1999) shows that although the learner initially conceptualizes self-instruction as flexible in external terms (e.g., convenience), she later revises this belief to include internal flexibility (e.g., by providing opportunities to employ preferred strategies). Inherent in this concept of internal flexibility is the uniqueness of each learner's own experience with SILL. Within the SILL context there is flexibility for the learner to cater to her personal learning style and preferred strategies as she interacts with her resources and vice versa. In SILL, White claims, the learner is free to make use of the strategies she finds particularly useful, provided she is aware enough to identify these (an awareness that generally develops over the period of SILL rather than being present at the outset, especially in inexperienced language learners). According to White, the more aware the learner, the more likely she is to fully exploit that awareness by means of manipulating her materials for strategic learning. White suggests that self-instruction requires "the learner to use his/her cognitive resources to establish an effective working relationship with the target language materials available in that context, in order to transform them into meaningful text" (p. 456). 


\subsection{1.b Locus of control}

The second construct, locus of control, refers to "the orientation of an individual towards what determines their success or failure: a belief in one's ability to shape events is referred to as internal locus of control, while a belief that outside forces control performance is referred to as external locus of control" (White, 1999, p. 452). External factors believed to shape events may include interaction with tutors and quality of course materials. Internal factors may include effort, confidence, motivation, and metacognitive and strategic knowledge of the learner's personal learning style. White (1999) shows that initially her learners viewed metacognitive knowledge of personal learning style as relatively unimportant to the outcome of SILL, ranking it as number 8 out of 9 factors contributing to success on a scale of importance. Learners later revised this belief and metacognitive knowledge rose to number 3 out of 9 on the scale of importance, reflecting the discovery that self-instruction can be enhanced by identifying personal learning styles and preferred strategies, which surface from metacognitive knowledge.

A learner embarking on SILL for the first time will no doubt struggle to identify her personal learning style and preferred strategies. Metacognitive knowledge can be hard won in the initial stages of self-instruction. One informant in White's (1999) study expressed frustration and feelings of confusion, reporting "I have felt adrift so often. I keep wondering-am I doing the right thing? Have I understood this correctly? I thought I was making headway and now I'm confused again" (1999, p. 450). An informant in a related study by White (1995) on autonomy and strategy use described the initial negotiation of how to best manage self-instruction as an extremely lengthy and 
arduous process, reporting "[d]eciding how to tackle things on my own seemed to take me ages and it also took a lot of faith that I would eventually know what I was doing" (p. 209), also reporting "I wasted a lot of time at the beginning working out how I was going to learn from the course and finding out what was effective for me. I wish I'd known that at the start" (p. 209). But after these initial negotiations the learners found that the resulting metacognitive knowledge greatly facilitated and enhanced self-instruction. As one informant explained to White (1999):

Now I see it basically as me and the language - that's it. I'm there, with these materials in a sort of raw form. I somehow have to make them come alive for me...I have to make the first move into those materials, to create a sort of dynamic between me and the materials, so something happens for me... Once you get that dynamic going, you're well on the way, and the whole thing begins. ( $p$. 449)

At the learner-context interface there is a dual influence of the learner on the context and the context on the learner. The result of successful interplay between the lone learner and her context is metacognitive knowledge. The result of this knowledge is the ability to exploit the learning strategies best suited to the learner. Learning contexts that afford the freedom to accommodate such exploitation are arguably unique to SILL and autonomous learning. As described by White (1995):

[Lone] learners have more opportunities than their classroom counterparts to choose what and how they learn. They also have more freedom to determine the 
kinds and combinations of tasks they work on and to ignore activities or sections of the materials which they do not consider to be personally useful for the development of their TL [target language] skills. (p. 208) White (1995) further describes this practice of exploitation, which she says involves:

developing an awareness of the process of language learning and an understanding of the need to master their own performative role in the language. Once such metacognitive knowledge begins to develop, learners have a basis for devising their own means of learning and of managing their learning. (p. 208) Some researchers (e.g., Antenos-Conforti, 1998; Dickinson, 1987) claim that it is through this process of taking control of the learning context and working with awareness with the materials (i.e., managing the learning) that the learner finds empowerment. This experience of empowerment potentially contributes significantly to successful selfinstruction. As one of White's (1999) self-instruction informants put it "you have to do this for yourself" (p. 453).

Applied to the SILL context, the above discussion is important for three reasons. First, internalizing the locus of control is fundamental to learner empowerment and successful lone learning. Until the learner has done this she is merely a passive student under the tutelage of her SILL program. Second, the site of learner empowerment is the learner-context interface. It is at this junction where the learner and her materials meet that the learner can actively influence and take control of her context. Finally, the potential for learner empowerment is the single greatest advantage of the SILL context. 
The next section will continue this discussion by exploring an example of learner empowerment in more detail.

\subsubsection{Learner empowerment: Diary of a lone learner (Jones, 1994, 1995, 1996)}

Most people (with the possible exception of those who market teach-yourself learning materials) know that learning in isolation is a poor way to acquire a language. In most of these attempts, learners flounder around in frustration, making little or no progress. However, some learners, presumably the most motivated and talented ones, do succeed in achieving at least some of their learning goals. (Rosewell \& Libben, 1994, as cited in Benson, 2001, p. 131)

Despite this claim, some researchers (e.g., Antenos-Conforti, 1998; Dickinson, 1987) argue that SILL and autonomous learning are the ideal ways of learning, by empowering the lone learner to control the learning context in ways that best reflect her personal learning style and preferred strategies. Therefore, a treatment of this arguably contentious topic is essential to the present study. Knowing that self-instruction has been characterized as "a hard, lonely task with a high drop-out rate" (Jones, 1993, p. 453), how can the lone learner find empowerment from SILL, and how does that empowerment lead to greater success in language learning? To answer this question I will review the diary study of a researcher (Jones, 1994, 1995, 1996) who has documented a self case-study of lone learning, and who has managed to achieve learner empowerment through metacognitive knowledge. To the best of my knowledge, the following study is the only 
published undertaking of SILL outside of the L2 environment using commercial programs, and thus is an important precedent to my own study. For this reason, I will describe the study in relative detail. Moreover, a second, but no less significant, reason for such an extensive inspection of Jones's $(1994,1995,1996)$ study is that it serves as the first of several examples I will offer to argue in support of diary studies as my own methodological choice. As such, a more thorough argument in favour of diary studies will follow this discussion of learner empowerment.

\subsection{2.a The study}

In this study, Jones $(1994,1995,1996)$ documents through a diary study his eleven-month self-instruction of Hungarian. The study relied exclusively on two SILL programs before moving onto other L2 materials. The following discussion will describe this study in terms of how Jones negotiated the learner-context interface, how he was empowered by this negotiation, and how this empowerment enhanced the SILL experience.

Jones (1994, 1995, 1996), a native speaker of English, undertook the learning of Hungarian for both professional and personal reasons. First, as an applied linguist, he wanted to investigate the phenomenon of SILL. Jones subsequently used this study as the basis of his PhD dissertation (1996). Second, as an avid language learner (he speaks ten languages ranging in fluency from "survival" to near-native speaker), he had an interest in learning Hungarian so as to communicate with close friends living in a 
Hungarian community in Northern Serbia. Both Jones's expertise as an applied linguist and as an experienced language learner are caveats of the study that will be addressed below.

The study was conducted in England, and consequently outside of the L2 environment. Language input consisted of two SILL programs and various authentic materials such as magazines, comic books, and short novels. No recorded materials were available for listening or speaking practice, which Jones (1995) considers "an irremediable defect" (p. 100), and interaction with native speakers was limited to a threeweek holiday in the eighth month of the eleven-month study. It was a fully autonomous undertaking, with no formal classroom instruction at any point. Learning sessions averaged approximately thirty minutes per session, approximately six times per week. These sessions most often took place while traveling to and from work on the commuter train.

To document the study, and to provide himself with an opportunity to practice writing in the L2, Jones $(1994,1995,1996)$ kept introspective diaries written in Hungarian throughout, with entries made every two to three days over the eleven-month period. As he progressed in his ability to write in Hungarian, entries increased in length, with the average entry being about half a handwritten page. The content of the entries was limited by his slowly expanding lexicon and dealt with the usual kinds of topics found in beginner language course books, such as describing his family and his routines, writing letters to friends, and so forth. The content also included reflections and thoughts on his acquisition process (e.g., affective factors, self-evaluations, preferred strategies employed to overcome challenges, and so forth). Until he had the ability to adequately 
express himself in Hungarian, Jones relied on footnotes made in English to ensure that valuable information would not be lost in his effort to write exclusively in the L2. Jones (1996) describes the journaling process in the following terms:

This was a hard, dictionary-and-grammar-bashing task at first, but one which became gradually easier. The sheer effort of writing the diary in the foreign language, however, probably meant that entries were not as frequent as they might otherwise have been. (p. 128)

During the eleven-month period, Jones (1996) claims to have progressed overall from an elementary to an intermediate level, explaining that " $[t]$ his rating was confirmed by my ability, on visiting Hungary the summer after learning had stopped, to handle most tourist situations, and by my inability to join in multi-party conversations not specifically toned down to my level" (p. 127). This relatively modest gain in proficiency can be trusted on the basis of Jones's expertise as both a linguist and an experienced language learner.

\subsection{2.b Caveats}

Before I discuss learner empowerment, I will mention two important caveats to Jones's $(1994,1995,1996)$ study, as these caveats may have a bearing on the generalizability of the findings. As already identified above, Jones has two major advantages over the typical L2 learner. He has extensive expertise both as a linguist and as a language learner, which is not shared by most people. As a result, there is the 
question of whether the following analysis can be generalized to other L2 learners. Jones (1994) addresses this issue by arguing that:

[T]he value of any case-study (a method which, for practical reasons, can only handle a very low number of subjects) is limited by the individual factors affecting the learner(s) in question: cognitive and affective style, aptitude, L2, social and geographical setting, etc. (Skehan, 1989). No matter how insightful that may appear, each study can be no more than one piece in a mosaic.

Nevertheless, as the pieces amass, a larger picture will gradually appear. (p. 444) On that basis, Jones makes no claims that his experience is generalizable. Instead he argues that, although the study may not account for every L2 learner, it could reasonably be a first step towards gathering a body of data that does. Further, he borrows an argument from Abramson (1992, as cited in Jones, 1996) in claiming that:

[C]ase-studies should not be judged in isolation, but relative to other methods of examining the same issue. Thus, in a predictive sense, a case-study can generate hypotheses for a later, more objective study. And in an illustrative sense, a casestudy can add vital real-life structure to the bitty, disparate data provided by multi-subject surveys, experiments or literature reviews. (p. 88)

Thus, this particular case-study, although it does have as its sole participant someone who could be called an example of the extreme language learner, should not be disregarded or underestimated. In a later section I will be making similar arguments for my own self case-study.

As a final note to this caveat, with respect to his impressive repertoire of languages, it should be mentioned that, based on Jones's $(1996,1998)$ study of seventy 
self-instructed L2 learners, Jones (1996) claims that "language-count effects on learning behaviour may fade out after as few as 3 foreign languages" (p. 126). This finding potentially reduces Jones's advantage over other learners considerably.

Further, there is the question of whether the experience of learning Hungarian can be generalized to other languages. Hungarian offers both advantages and disadvantages to the L2 learner. Belonging to the Finno-Ugric family, it is not an Indo-European language and has only one known relative, Finnish. As a result, despite the fact that Jones $(1994,1995,1996)$ began to learn Hungarian already familiar with ten or so other languages (none of which were Finnish, which further reduced the potential advantage Jones enjoys over the typical learner), there was no opportunity to make use of cognates in his effort to build up a satisfactory lexicon. In addition, due to historical efforts to resist German influence on Hungarian in the nineteenth century, there is a tendency for Hungarian speakers to avoid lexical borrowings and opt instead to coin their own words for new concepts. This significantly reduces the number of "internationalisms" offered by most languages. However, this disadvantage is countered by the tendency for new coinages to be in the form of compounds, creating a certain amount of transparency, which can be very helpful to the L2 learner. Nevertheless, Jones (1995) cites the need to build up his lexicon from zero as a "massive obstacle" (p. 99), and most of his learning activities were geared towards overcoming this challenge.

However, Hungarian does offer two advantages to the learner. First, in its written form Hungarian is characterized by an extremely shallow orthography, in that there is a one-to-one representation of alphabetic symbol to sound. As a result, if one can understand a phonetic guide (employing, for example, the International Phonetic 
Alphabet), which adequately relates the sound represented by each symbol, there should be little problem in transferring that knowledge to the written word and being able to predict with extreme accuracy the correct pronunciation. Again, Jones (1994, 1995, 1996) has the advantage in this case of being a linguist and most likely more familiar with phonetic representations than the typical L2 learner. Secondly, the primary stress of every Hungarian word falls on the first syllable. Therefore, compared to English and many other languages characterized by much deeper orthographies and irregular stress patterns, transferring the ability to read in Hungarian to the ability to speak and be understood presents far fewer problems than might be encountered elsewhere.

\subsection{2.c Strategic knowledge and learner empowerment}

Jones (1995) describes lexis as "the single most important component of reading ability; indeed, there is no a priori reason why this should not be true of all skills" (p. 97). As a result, Jones made lexical acquisition a top priority. The following is a description of the learning strategies he employed to engage with his materials and take charge of his self-instruction in ways that best suited his personal leaming style and empowered his learning.

Jones (1995, 1996) distinguishes between two basic categories of learning strategies used in his acquisition of Hungarian lexis. These are: studial and messagebased. Studial strategies refer to activities that take the lexis out of real-text contexts and involve the rote learning of vocabulary. These strategies are more mechanical in nature 
and require conscious processing with an emphasis on metalinguistic tasks. Writing out word lists and marking items for active production or passive recognition, memorization, dictionary work, and using etymology or keyword imagery such as puns to remember new items are all examples of studial strategies. Message-based strategies, on the other hand, involve real-text situations. Here the learner grapples with the language in context, with all the complications (e.g., new item overload) and helpfulness (e.g., contextual clues for meaning) that can entail. Translation, guessing a word's meaning from context, holophrasing (learning a string of words together instead of as individual items), reading authentic texts in the L2, and personalized activities such as writing letters in the L2 are all examples of message-based strategies.

A third category of learning strategies is referred to by Jones $(1995,1996)$ as autonomous strategies. Autonomous strategies comprise the strategies used by Jones that were self-prescribed (not set by his self-instruction course book) and are primarily message-based in nature. These are of most interest to the present discussion because of the claim that the adoption of autonomous techniques ultimately arises from metacognitive knowledge and leads to learner empowerment. An example of one novel autonomous strategy for learning new lexis is a studial-type game invented by Jones. He would open a children's picture dictionary and study all the Hungarian terms on one page. Afterwards, he would close the book and attempt to list all the items that had been in the picture. By recognizing himself as a visual learner, Jones was able to create learning activities that would facilitate his acquisition of Hungarian.

Jones (1995, 1996) describes his acquisition of Hungarian lexis as crossing three thresholds. The first threshold primarily involved studial strategies, i.e., rote 
memorization of vocabulary lists combined with keyword imagery and some dictionary work. Jones felt very dependant on his course book at this stage because real-text presented an unmanageable overload of new lexis resulting in hours of tedious dictionary work. By the second threshold Jones had enough knowledge of core lexemes that meaning could often be guessed from context or from etymology. This threshold evolved from a combination of both studial and message-based strategies to the abandonment of studial strategies. Relying solely on autonomous real-text message-based strategies, the second threshold marked Jones's ability to manage short authentic texts in Hungarian. However, he soon decided that exclusive use of message-based strategies was no more satisfying than exclusive use of studial strategies. He realized that deducing the meaning of a word from context, although allowing him to understand the text, did not necessarily result in him learning the new word because there was no time for conscious processing or internalization. Therefore he reincorporated rote vocabulary study into his lessons to ensure that his lexicon would continue to grow. Thus, in crossing the third threshold, Jones reverted to a combined approach of studial and message-based strategies.

As an experienced language learner Jones's $(1994,1995,1996)$ metacognitive knowledge of his personal learning style, as well as his toolbox of preferred strategies, were already well-developed at the outset of the study. Writing letters to his Hungarian friends, keeping a diary in Hungarian, reading authentic texts of personal interest, oral translation, keeping a vocabulary notebook, and the invented memory game are all examples of the autonomous strategies employed by Jones. These were all selfprescribed activities chosen to compliment his personal learning style, as Jones (1995) 
puts it "the preference was almost certainly influenced by personal learning style" ( $p$. 100).

An additional way Jones $(1994,1995,1996)$ manipulated and interacted with the context and materials of his self-instruction program was to omit the prescribed activities he felt had no use for him. As Jones (1994) reports "skipping most of the formal grammatical exercises because of their dullness, most of my practice activities consisted of free writing" (p. 445). Jones (1994) goes on to say that "[f]ree to choose my own activities (unlike...classroom learners), I avoided grammar drills because message-based work...was simply more enjoyable" (p. 448). Recognizing that the acquisition of lexis is "a laborious and extremely time-consuming task" (Jones, 1995, p. 101), and being familiar with the high drop-out rate of lone learners, Jones attempted to make the process as enjoyable as possible. He was able to do this by using his metacognitive knowledge. Jones $(1994,1995,1996)$ used metacognitive knowledge to apply strategies that he felt would work for his personal learning style, as well as invent new strategies and evaluate prescribed strategies for usefulness. By doing this, he internalized and made use of both the internal and external flexibility inherent to SILL at the learner-context interface. Similarly, by internalizing the locus of control, Jones was able to use his metacognitive knowledge to appropriate his interactions with the materials and the context. The result of these combined efforts was learner empowerment. 


\subsection{2.d Final note on learner empowerment}

I have argued that metacognitive knowledge is the result of negotiating the learner-context interface and discovering the personal learning style and preferred strategies best suited to the lone learner. I have then argued that knowing which strategies are best suited to one's learning results in learner empowerment. While it is impossible to ignore the high drop-out rate of SILL, and hence I must concede to the fact that not every lone learner experiences empowerment and success, I do believe it is possible and that Jones $(1994,1995,1996)$ provides an excellent example of how this is accomplished. To account for the unsuccessful lone learners White (1999) suggests that "some individual differences between learners may mean that they are less predisposed to being able to adjust to language learning in a less conventional context" (p. 456).

\subsection{Self case-studies and diary studies}

Jones $(1994,1995,1996)$ is just one of the many researchers (e.g., Bailey, 1980, 1983; Jones, 1994, 1995, 1996; Schmidt \& Frota, 1986; Schumann, 1980; Schumann \& Schumann, 1977) to conduct a diary study as part of a self case-study for the purpose of SLA research. However, the use of introspective methods such as diary studies and verbal protocols have long been critiqued for reasons of unreliability and subjectivity. Despite their popularity among behavioural psychologists at the turn of the twentieth century, these methods soon fell out of favour and have since been called "untrustworthy 
for scientific purposes" (Watson, 1913, as cited in Brown \& Rodgers, 2002, p. 54). Only in the past two decades has a resurgence of interest marked the adoption of introspection techniques back into serious academic study (Brown \& Rodgers, 2002). Since this resurgence, many researchers (e.g., Bailey, 1980, 1983; Jones, 1994, 1995, 1996; Schmidt \& Frota, 1986; Schumann, 1980; Schumann \& Schumann, 1977) have begun to use introspection in their studies of SLA, and regard it as "well suited for looking at, inter alia, individual learner factors and the status of declarative knowledge" (Jones, 1994, p. 443). As Faerch and Kasper (1987, as cited in Jones, 1996) argue "the best way...of finding out what goes on in the learners' minds is to ask them directly" (p. 88).

A further critique of these methods occurs when they are employed in the case of a self-study. As Jones (1994) writes "we get a triple subjectivity (researcher = observer = introspecting subject), with an increased danger of finding what one sets out to find, rather than what is objectively there" (p. 444). However, Jones goes onto say that:

[L]earner sophistication... appears to increase the research value of diary methods, thus having as learner/diarist someone... who is not only a sophisticated language learner, but also a sophisticated learning methodologist, ought logically to deepen insights rather than mask them. (p. 444).

As already mentioned, Jones $(1994,1995,1996)$ is not the only researcher to make use of reflective journaling in a self-study. Increasingly, researchers (e.g., Bailey, 1980, 1983; Jones, 1994, 1995, 1996; Schmidt \& Frota, 1986; Schumann, 1980; Schumann \& Schumann, 1977) are seeing the benefits of this type of case-study, believing, as Jones (1996) does, that "[s]ubjective depth is the purpose of the case-study" (p. 129). The following is a brief description of several examples of diary studies used in 
SLA research. It is important to note that such studies rarely attempt to test preestablished hypotheses, instead, researchers tend to adopt a heuristic approach in their research.

The Schumanns $(1977,1980)$ conducted diary studies to document their acquisition of Persian in Iran and Arabic in North Africa. Subsequent analysis of the diaries allowed them to examine what they refer to as "personal variables" (Schumann, 1980, p. 51). These variables (which include such things as nesting patterns, transition anxiety, rejection of methodology, maintaining personal agendas, motivation for choice of materials, the strategy of eavesdropping, competition versus cooperation, the hindering role of the expatriate community, and so forth) provide insight into SLA in an extremely personal and reflective manner. The Schumanns feel that such insights may not be as effectively elicited in other contexts.

Bailey $(1980,1983)$ adopted the diary study to document her experience of taking French classes in California. Three major themes emerged from the subsequent analysis of her diaries. These are: response to the learning environment, preference for a democratic teaching style, and the need for success and positive feedback. Despite her initial intention to use the study as a way to record learning strategies, Bailey soon changed focus in her diaries and began to track the affective factors that influenced her learning. She discovered, through this, the negative impact of her competitive personality on her language acquisition.

Schmidt (1986) documented his acquisition of Portuguese in Brazil through a diary study. Consequently, he was able to examine and contrast the effects of formal instruction and informal interactions in order see how they each contributed to his 
language acquisition. He then examined how these learning contexts functioned in different but complementary ways. His analysis of the diaries further allowed him to track linguistic thresholds over the five-month study by monitoring his fluency in terms of his ability to achieve specific goals.

All of these researchers promote the usefulness of diary studies in self casestudies as being an ideal way to gather thoughtful and reflective data on the acquisition process. Moreover, in a comparison of classroom research methods, Brown (1985) reports that " $[t]$ he diary study is one of the best methods for getting at the individual learner variables" (p. 125). Brown cites other advantages of the diary study as being "the most natural of all possible research choices" (p. 133), with minimal "research intrusion" (p. 125), and having the most "immediate use for learners...[by allowing] for selfevaluation, improvement and growth" (p. 133).

One important difference between the diary studies described above (Bailey, 1980, 1983; Schumann, 1980; Schmidt \& Frota, 1986; Schumann \& Schumann, 1977) and the diary study by Jones $(1994,1995,1996)$ is that he wrote his diaries in the L2, whereas the above mentioned researchers wrote theirs in their L1, English. From what I have seen in the literature, Jones's choice was a fairly novel one. As Jones explains, his decision for doing so primarily rested on the need for regular language practice. By living outside of the L2 environment and not attending language classes, Jones was never required to use his Hungarian in any contexts other than self-imposed ones. As his language input was restricted to a very limited number of Hungarian sources, and his language output was limited to the exercises found in his two course books, there was no opportunity aside from journaling to manipulate and interact with what he was learning. 
Journaling was the only dynamic occurrence of language in a static system of texts and uninspiring exercises, although it was rarely painless, as Jones (1996) recounts “[p]ersonalized writing...involved much investment of time and effort" (p. 136). In the case of the other researchers (Bailey, 1980, 1983; Schmidt \& Frota, 1986; Schumann, 1980; Schumann \& Schumann, 1977), writing the diaries in their L1 was offset by the dynamic applications of the L2 occurring in authentic interactions in the L2 environment and in L2 classrooms.

I chose, as the majority of the researchers did, to keep my diaries in my L1, English. This choice was based on several factors. The manageability of keeping a diary in the L2 seemed overwhelming at such a beginner level. Jones's (1994, 1995, 1996) study was significantly more longitudinal than my own (his eleven months devoted to one language compared to my five months devoted to two languages). He was only beginning to feel comfortable keeping his diary in the $\mathrm{L} 2$ after several months of struggling with it. Another reason was that I planned to work only within the curricula of the programs, and so extensive writing practice outside of the programs would work against this goal. Finally, the purpose of my diaries was almost exclusively to record the experience of being a lone learner, not to provide an opportunity for more practice with the L2, as in the case of Jones, and hence it only made sense that keeping the diary in my L1 would yield a more thorough and complete record. 


\subsection{Part II: SLL program design}

This brings my discussion to part II of Chapter 2, where I will attend to the second major focus of my study. I will present a review of the limited literature on SILL program design and a critique of SILL programs. Jones (1993) asserts that:

For the teach-yourself process to be brought in from the lunatic or the comic fringe, two changes need to take place: it needs to be recognized as an object of respectable SLA research; and a reliable canon of materials assessment guidelines needs to be drawn up, so that the type of package that gives the enterprise a bad name...can be a thing of the past. (p. 467)

I have come across five researchers in the literature (Antenos-Conforti, 1998; Dickinson, 1987; Hayet, 1990a, 1990b; Jones, 1993, 1996; Roberts, 1995) who give the design of SILL programs more than a passing glance. Of these five, four (Antenos-Conforti, 1998; Dickinson, 1987; Jones, 1993, 1996; Roberts, 1995) attempted to design an evaluative instrument to be applied to various programs in an effort to measure one program against another and establish general guidelines for SILL program writers. Hayet (1990a, 1990b), the fifth researcher, devotes her critique to debunking the myths of SILL programs (e.g., that the learner has adequate cognitive capacity to both drive her car safely and acquire a second language simultaneously, and so forth) in a less formal manner. I will first draw on several of her insights to set the stage for the general disdain of SILL programs by the larger community of applied linguists and language pedagogues, and will then shift my focus to a description of the evaluative instruments of the other four researchers. 
Dickinson (1987) did not evaluate any actual programs. His suggestions are based on his expertise with both classroom materials and autonomous learning, and they are relevant to the present discussion because they reinforce many of the suggestions of the other researchers. Roberts (1995) and Jones $(1993,1996)$ each looked at a larger sample of programs than I did, while the sample investigated by Antenos-Conforti (1998) is comparable to my own sample of four. Antenos-Conforti looked at five (all for Italian), Roberts looked at twenty-three (for French, Spanish, and German) and Jones looked at forty (for various languages, both European and non-European).

This discussion is important because it demonstrates that there is some work being done in this field. Yet, for some reason, the instruments and the findings from the various evaluations do not seem to be penetrating the world of commercial SHL publishing. One possible (though admittedly cynical) speculation for this is that SILL publishers may not feel motivated to invest in updating the programs. It is much quicker and cheaper to update for content (e.g., changing the currency in thematic units relating to shopping from Deutschmarks to Euros in the German programs) than it is to update for trends in pedagogy (trends that could simply fall out of favour before long, anyway). Yet, if it is simply a case of misinformation or miscommunication, attention must be directed to this matter. The question of how academics in this field can extend their evaluative criteria to be applied to programs for sale today needs to be addressed in order to improve SILL programs and bring them into the realm of "respectable SLA research" (Jones, 1993, p. 467). There is great work to be done in the design of SIL programs.

Although I will not directly apply.the entirety of any of these instruments to the SILL programs in my own investigation, I will base my critiques in Chapter 4 on insights 
gained from considering each of the criterion in turn. As such, not only will I be using my experience with SILL to evaluate the programs themselves, I will also, to a lesser extent, be using my experience to evaluate the following instruments for comprehensiveness and usefulness. In Chapter 4, I will propose my own criteria for evaluation based on a synthesis of what I determine to be the most important elements of these instruments and my experience as a lone learner.

\subsubsection{Hayet (1990a, 1990b)}

Hayet (1990a, 1990b) takes an extreme, yet never hyperbolic, position in her critique of SILL programs. Her efforts to debunk the myths of SILL advertisements are both incisive and comical. Her critique, written in two parts, begins with a look at what she terms "the linguistic mythologies" (Hayet, 1990a, p. 27), and "the secondary mythologies" (Hayet, 1990b, p. 9). I will present a combined synopsis of these mythologies at this time, as well as draw on them periodically throughout Chapters 3 and 4.

The linguistic mythologies (Hayet, 1990a):

1. Promises and pseudo-promises of "results" quickly: This myth speaks to the claim made on many SILL packages that they are privy to secret methods that will allow the learner to acquire the L2 faster than methods available elsewhere (cf., " $[\mathrm{t}]$ he fastest, most intuitive way to learn Japanese" (Instant Immersion, box)) 
2. Added "wealth", a sound investment: The following myths address the package claims that SILL programs will somehow improve the learner's life.

a. Optimum use of our time: This myth speaks to the claim that the learner does not have to devote any special time to SLA, simply plug herself into her Discman while going about other chores, such as driving, walking, and housework. Hayet (1990a) explains that the "at-home foreign-language courses and linguistic hardware firms temporarily set themselves up as time-management consultancy firms, arousing in us all, wretched time-wasters...just as much guilt as necessary" (p. 28). Hayet (1990b) further offers: It may be reassuring to think that domestic tasks are not worthy of the whole of our attention and mental power but the suggestion that learning a foreign language can be achieved "on the side", as a parallel or background process by using whatever mental processing power remains unoccupied, appears to be very misleading. Foreign-language learning as an intellectual process may have its specificities but it is not fundamentally different from other learning processes. However, the respective demands of the tasks involved in learning a foreign language and in walking a dog are tremendously different in nature and in the level of mental commitment which is necessary. (p. 10)

b. Socio-economic and socio-cultural benefits: This myth is aimed first at the business traveler, claiming that improved language proficiency will ultimately result in economic benefits "based on 
greater professional success" (Hayet, 1990a, p. 29), and then at those learners who feel some kind of social inferiority next to multilingual speakers. As Hayet (1990a) explains "these benefits can be construed as a social redemption which makes of past 'language dunces' members of a socio-cultural intelligentsia" ( $p$. 29).

The secondary mythologies (Hayet, 1990b):

3. Learning a foreign language is easy: This myth is related to the optimum use of our time myth in that it appeals to the learner who would like to believe that SLA is possible with a minimum amount of effort (cf., "simply hear the words in Japanese, their English translation, and then repeat" (Instant Immersion, box)).

4. Learning a foreign language is enjoyable: As Hayet (1990b) explains "[i]n such a context, absence of effort soon becomes synonymous with enjoyable and button-pushing does fascinate some" (p. 10).

5. Learning a foreign language is relaxing. As Hayet (1990b) offers "[m]ore than effortless, more than pleasurable, learning a foreign language is also presented as a positively relaxing 'activity'" (p. 10).

6. Learning a foreign language by listening to it: This myth speaks to the premise of many SILL programs that the "listen and repeat" mode of learning is a valid and effective means of SLA. Hayet (1990b) argues that although "[m]aximum exposure to the spoken language is certainly of great importance and such an inductive method may appeal to some who 
already have some formal linguistic knowledge" (p. 11), she warns that it is "a very unrealistic method for a complete beginner" (p. 11).

7. Learning a foreign language is like learning your mother tongue: This myth speaks to a claim that is pervasive to most SILL packages (cf., "[l]earn the same way your learned your native language" (Instant Immersion, box), and "learn naturally, the way you learned English" (Living Language, box)). As Hayet (1990b) quips "[t]he unfortunate thing is that English babies did not learn English by listening and repeating in this adult sense and none of them has yet told us how difficult or enjoyable it was to learn his/her mother tongue" (p. 11).

8. Learning a foreign language thanks to scientifically proven methods: This myth addresses another insidious claim made on many SILL packages. By preying on the typical lone learner's ignorance of SLA pedagogy, these programs use so-called scientific methods to achieve a status of trustworthiness (cf., "[t]he Euro Method... written and developed by university language experts" (Instant Immersion, box), and "[the] highly effective speed-learning method developed by U.S. government experts" (Living Language, box)). The problem is that these methods have not passed through the gauntlet of verifiable academic research and testing to back their claims. Sadly, until the professional community of applied linguists and language pedagogues takes time to evaluate and critique these methods, the unwary lone learner's naivety will continue to be exploited. 
9. All you need is provided: This final myth addresses the claim that SILL packages are comprehensive in their contents, and that nothing is lacking in their package to turn a tyro of any given language into a confident speaker.

Hayet's (1990b) final critique of SILL programs addresses the isolation of lone learners:

Leaving aside some foolish, albeit amusing, claims, the fact remains that the learners are isolated both from the direct sources of the foreign language and from any interaction with fellow learners or tutors...So much for the communicative approach to language-learning, to most learners' hopes and needs, let alone the little more than empty promises made...No direct help is available, no renewed incentive is given, individual or special needs are ignored, no facilities exist to cater for them. (p. 12)

These myths, and Hayet's (1990a, 1990b) critiques of them, will be interwoven throughout my study.

\subsubsection{Dickinson (1987)}

In his methodological handbook on self-instruction and language learning, Dickinson (1987) suggests the following twelve criteria to keep in mind when designing SILL programs: 
1. A clear statement of objectives: This criterion is so that the learner can assess whether this program is suitable to her needs and objectives.

2. Meaningful language input: This criterion entails comprehensiveness and also "the degree of support supplied to the learners to help them to discover meanings" (p. 81).

3. Exercise materials and activities: For this criterion, Dickinson (1987) puts an emphasis on sufficiency, variety, capacity to maintain interest, and feasibility in the self-instruction context.

4. Flexibility of materials: This criterion aims to strike a balance between catering to different learning styles and accomplishing the learning task.

5. Learning instructions: For this criterion, Dickinson (1987) puts an emphasis on intelligibility, adequacy, appropriateness, and the provision of examples.

6. Language learning advice: Examples of this criterion include study tips, autonomy training, strategy training, identifying personal learning style, and so on.

7. Feedback and tests: Although feedback often occurs in the form of answer keys, Dickinson (1987) argues that "learners need more than simply the correct answer. They need to know why they are wrong, where they went wrong, and sometimes they need to know how they got the correct answer" (p. 83). Tests on the other hand should be evaluated for validity, comprehensiveness, and level appropriateness. 
8. Advice about record keeping. This criterion is so that the learner can monitor her progress and be self-evaluative by tracking her learning experience.

9. Reference materials: Dickinson (1987) asserts that:

The information presented should be limited to that which is relevant to the stated objectives and written in a way which is intelligible to learners. It should make references to the occurrences of the items in the text, so contextualizing them. It should also make cross-references to other units in which the items are dealt with. (p. 85)

10. Indexing: This criterion is for quick referencing.

11. Motivational factors: Dickinson (1987) lists such things as "attractiveness of the book, the layout, type face, color work, illustrations and so on" (p. 86). Other factors include the accessibility of the content, the size of the units, and whether the materials not only state, but explain the learning objectives of any given activity.

12. Advice about progression: Dickinson (1987) suggests beginning SILL programs with a needs analysis and learner contract, and ending with a "Where do I go from here?" discussion, which could advise the learner to seek out authentic materials, language classes, study buddies, and native speakers.

What Dickinson (1987) stresses most is his concern that the lone learner receive ample support from her materials, and that these materials have the features of any 
excellent language teaching resources, i.e., "interest, variety, clarity, and so on" (p. 80). Remarkably, this list was first published seven years prior to any of the related literature I was able to unearth in my searches.

As noted above, Dickinson (1987) does not apply these criteria to any programs within the context of his handbook. As he reports:

There are many ways to set about writing a book such as this, and one of the ways I have not adopted is to base the book on the results of research showing the effectiveness of self-instruction in language learning: the results do not exist because the research has not been done...I have tried to make it clear that the procedures and techniques recommended here are suggestions and speculations. (p. 1)

Yet, his criteria are remarkably similar to that of the following researchers, who have carefully designed their evaluative instruments to be as comprehensive as possible, based on findings resulting from the examination of many SILL programs. For this reason, and for the apparent thoroughness of his design criteria, a treatment of Dickinson's evaluative instrument is pertinent to this discussion.

\subsubsection{Roberts (1995)}

In his evaluation of twenty-three SILL programs for French, German, and Spanish (eight series in three languages each, except for one missing the Spanish program), Roberts (1995) uses an evaluative instrument comprised of five sections: 
1. Composition and technical quality of materials: This section is interested in the superficial features of the packages (i.e., what materials are included, and the quality of the materials in terms of length, durability, and so forth).

2. Linguistic analysis: This section is interested in whether the programs cover basic categories of phonology, lexis, and syntax appropriately and adequately, especially in terms of the program's alleged objectives.

3. Communicative analysis: This section is interested in opportunities offered by the program for authentic communication. Roberts rationalizes that " $[t]$ his section was included because a course could offer a great deal of grammar or parroting of sentences, yet not model any communication" (p. 514).

4. Pedagogical analysis: This section is interested in the program's methodological choices, whether the program makes realistic claims, and the provision of learner support, feedback, and sociocultural information. This section also considers whether an element of fun is present in the activities.

5. Summation: This section consists of a general evaluation of the course (i.e., whether the evaluator would recommend it to learners with corresponding learning objectives).

Roberts (1995) found that “among the series of home-study language courses examined, not a single one may escape reproach, though some more than others" (p. 
525). Among the most important conclusions of this investigation, Robert highlights the following three: First, gauged by the many programs available for purchase, the demand for SILL programs must be a real one. However, these programs are outdated on the whole, and Roberts asserts they would never be incorporated into current classroombased L2 instruction. Second, Roberts claims that "[n]o doubt it is a capital-intensive enterprise for publishers to re-jig their courses, which is why they attempt to go on selling them long after ideas about language teaching have changed" (p. 526). Third, Roberts expresses little surprise in reporting that "[n]one of the extravagant claims for the courses discussed bear close scrutiny, as suspected at the outset. A hard-line view would be that such claims should not be allowed, but of course, they rest on ambiguities, as does much advertising" (pp. 526-7).

2.7.4 Jones (1993, 1996)

Jones's $(1993,1996)$ checklist, designed to evaluate SILL program design, uses an instrument with six investigative categories. Jones (1993) claims that "the checklist questions are non-judgmental: in terms of this design philosophy, a 'good' package would be not so much one that has ticks in certain areas, but one that has a large number of ticks overall" (p. 457). The six categories are:

1. Language-contrastive factors: This section looks at the $\mathrm{L} 2$ in terms of inter-language contrastivity for such features as phonology, script, lexis, and grammar. 
2. Learning objectives: This section tries to identify the program's target learner, along with the target learning objectives (e.g., speaking, listening, reading, writing, and so forth), as well as comparing the advertised objectives with the apparent objectives.

3. Syllabus: This section teases out details of the syllabus such as approach, presentation, sequencing, and so forth.

4. Role of materials: This section is interested in the materials contained in the package, including the size of units, the authenticity of text/audio, the accessibility, and the occurrence of various features (e.g., repetition, translation, games, personalization, and so forth).

5. Relationship with the learner: This section looks at learner preparation and support through strategy training.

6. General/subjective comments: This section is an opportunity for evaluators to make personal comments.

Among Jones's $(1993,1996)$ findings, he highlights four as being particularly important. First, Jones (1993) finds that the "methodology [of the program] tends to follow the prevailing fashion at the time of first publication" (p. 465) and that "there is a depressing survival of audio-lingual-type courses" (p. 465). Second, “[p]ersonalized tasks are extremely rare” (p. 465). Third, "[1]earner autonomy and strategy development rarely occurs" (p. 465). Finally, there is "no evidence of an increase in learner support features with recency of first publication" (p. 465). 
In Antenos-Conforti's (1998) evaluation of five Italian SILL programs, she used an instrument originally developed by Colussi Arthur (1995, as cited in AntenosConforti, 1998). This instrument is based on five tables:

1. Overall organization: This table is interested in such things as number of pages, appendices, glossaries, and indices.

2. Table of contents: This table is interested in such things as number of lessons, and in which lessons certain parts of speech are addressed (e.g., verbs, nouns, adjectives, and so forth).

3. Organization of each lesson: This table is interested in such things as the manner of presenting new information, cultural notes, exercises, and review notes.

4. Exercise types: This table is interested in whether the programs provides exercises for a variety of different skills (e.g., pronunciation, comprehension, grammar, and so forth).

5. Ancillary materials: This table is interested in what kinds of additional materials (if any) are included with the programs (e.g., two-way dictionary, verb quick reference guide, and so forth).

In contrast to the above researchers, Antenos-Conforti (1998) claims that "the composition of Italian do-it-yourself kits are based on 'sound pedagogical materials, with carefully conceived design'(Nuessel, ‘Second Year Programs' 548) and they are 
enhanced by those unique properties inherent in self-teaching programs (i.e., the audiocassette component, and the answer keys)" (p. 554). This positive summation is very contradictory to the rather disappointing findings of Roberts (1995) and Jones, $(1993,1996)$. This disparity could arguably have several sources. It could be the result of a small sampling of only one language. More probable, however, is that it is on account of the fact that Antenos-Conforti never personally attempted to learn by any of these programs. She is a fluent speaker of Italian and her positive summation of these programs could be a result of the disconnection between looking at something as an insider (already familiar with the complexities of Italian), and looking at it as an outsider (still overwhelmed by the intricacies yet to be acquired).

\subsection{Conclusion}

With respect to the first major focus of my study (part I), I have looked at several important issues involving the interplay of affective factors (i.e., motivation, personal learning styles, metacognitive knowledge and learner beliefs) encountered in SILL, as well as issues in learner preparation and support, fostering autonomy, strategy training, and learner empowerment. In Chapter 3, I will use these discussions as a framework to reflect upon my own experiences as a lone learner working with the SILL programs. Furthermore, in Chapter 2, I have argued for the use of self case-studies and diary studies, reviewing the literature for precedents to my methodological choice to conduct a diary study. Finally, reflecting the second major focus of my study (part II), I have described 
the evaluative instruments used by other researchers to assess SIL program design. In Chapter 4, these instruments will be revisited as I select what I determine to be the most essential design criteria (based on my experience as a lone learner) and apply those to the programs in question for evaluation.

From here I will move on to my own study to see whether or not I was "able to adjust to language learning in a less conventional context" (White, 1999, p. 456), and to see whether or not I found learner empowerment through SILL. 
Chapter 3: The diary study 


\subsection{Introduction}

Reflecting the first and second major foci respectively, Chapters 3 and 4 together form the analysis of my study. In Chapter 3, I will look at the learner diaries I kept while undertaking SILL for the interplay of my affective factors, as presented in Chapter 2. In

Chapter 4, I will look critically at the SILL programs under investigation using the design criteria first described in Chapter 2.

Before I relate my experience as a lone learner, it is necessary to explain and justify the methodological decisions I made at the outset of this journey. In this chapter, I will first describe in narrative those choices I made that shaped and directed my study throughout, as well as introduce the four SILL programs in question. I will then present my experience as a lone learner in detail as it emerged through the analysis of my learner diaries. This discussion will be presented in two ways. First, I will outline the six significant trends relating to the interplay of affective factors that surfaced from the diaries. Second, I will present a summary of major findings, which will highlight the connections between the trends.

\subsection{Methodology: Creating a scaffold for the study}

In my earliest planning stages, I came across one researcher in particular whose work was extremely formative to the present study. Jones $(1994,1995,1996)$, as already described in detail in Chapter 2, attempted something similar to what I envisioned for my study and 
I used his example to guide my own. Jones borrows an argument from Mitchell (1989, as cited in Jones, 1994) in claiming that "[s]mall-scale studies usually have to make a choice between objective rigor (hypothesis-driven, controlled-variable, single-issue experiments) and subjective richness (open-ended, holistic explorations); only larger studies can afford the luxury of both" (p. 443). And so I embarked on a self case-study in search of subjective richness through a diary study.

Just as my journey began browsing the language shelves at Chapters, so will my narrative. The following sections will outline some of the preliminary choices I made and why I made them. However, before I explain my decisions, it is important to first present my background as a language learner, thus providing a grounding to better understand the ways in which I have approached language learning in general, and this project in particular.

\subsubsection{My background as a language learner}

As I mentioned in Chapter 1, my interest in SILL programs began the afternoon I first discovered the language aisle at Chapters. As I also mentioned, the discovery of this aisle produced in me a strong feeling of ambivalence-a simultaneous reaction of repulsion and attraction. I was torn between not giving the packages a second glance and picking up half a dozen. I was charmed by the vast selection of languages, by the promises of fluency, and particularly by the allusion of convenience. Having relocated to 
Ottawa to begin work on my MA in Applied Language Studies, I found I had very little time left over to spend on my favorite hobby.

Although I did not appreciate foreign language learning when my parents enrolled me in early French immersion at the age of six, by the time I had graduated from high school I considered myself to be quite the language magpie. I went on to live and work in France for a year, thus crowning my twelve years of French immersion in the public school context with a year of French immersion in the most authentic of contexts. This year marked my first experience with SILL in-situ. After France I moved to Mexico, where I lived and worked for several months, thus marking my second experience with SILL in-situ. I had taken only one year of Spanish in my last year of high school, but it did not take long before I was speaking Spanish with as much fluency as French (although, admittedly, with a great deal less accuracy due to my lack of grammar study). Returning to Canada to begin my BA in theoretical linguistics, I spent all my elective credits on foreign language classes, resulting in two and a half years of French, two years of Spanish, and a year of Russian. Off and on during these years I was also enrolled in non-credit courses to learn American Sign Language (ASL) to complement the ASL I had picked up working as a lifeguard one summer at a camp for Deaf children (an additional experience of SILL in-situ). And these were only the languages I studied formally! Among the languages I have looked at briefly for reasons of travel or just plain curiosity are Portuguese, Modern Greek, Hungarian, Thai, and even a little Esperanto and Ancient Greek.

Ultimately, however, I consider myself only trilingual in English, French, and Spanish, with some barebones knowledge in Russian and ASL. With each language I 
approach, whether my goal is to achieve fluency or simply to order Pad Thai, I have found nothing that equals the excitement of those first few weeks of study, where sounds transform from exotic to familiar, where seemingly random assortments of letters on the page begin to form words and take on meanings. Simply put, I love foreign language study. Yet, as an experienced language learner, I appreciate how difficult it can be. I have suffered through the painful days in France, when certain people would laugh at my accent, and that embarrassing day in Mexico, when I was lost and could not understand even the most basic directions. I have survived the relentless dictées (spelling quizzes) of French class, and the poor grades on my Spanish composition papers because I devoted more time to developing ideas than I did to checking my conjugations. And there were days when the Russian case system nearly broke my spirit! Yet I persisted and I still persist—because, yes, I seem to have a talent for it, but mostly because I love it.

As I have indicated, I had experienced at least one form of SILL previous to this study (although I did not recognize it at the time!)-in-situ self-instruction. In the cases of French and Spanish, the in-situ periods occurred after prior classroom-based learning. In the case of ASL, the in-situ period consisted of my first contact with the L2. Although I had had extensive experience with autonomous learning (as defined in Chapter 2 to include such activities as homework, student-led group work, and working with study buddies), until this study, my only experience with SILL was limited to in-situ learning. Notably, I have always preferred in-situ learning to classroom-based learning, taking great pleasure in contact with native speakers and finding the ensuing motivation to expand my knowledge in order to better communicate to be invaluable. However, I acknowledge that without the hours I spent conjugating verbs and memorizing the 
grammatical gender of nouns in the classroom-based context, my knowledge of French and Spanish would be immeasurably less precise. (As a side note, it seems, from my experience, that in-situ learning and SILL programs are possibly even more incongruous than SILL programs and classroom-based learning. If so, it is remarkable, then, that they (in-situ learning and SILL programs) are both considered to be related under the broader heading of SILL.)

So, with in-situ learning being my only point of reference for SILL, my discovery of the SLL industry had a profound effect on me. Of course, I knew these programs existed-I had seen them used in movies such as Love Actually (Bevan et al., 2003), the British film in which the character played by Colin Firth attends a self-access center so he can propose to a non-English speaking Portuguese woman. Also, the US film Spanglish (Ansell et al., 2004) in which the character played by Paz Vega decides, several years after emigrating to the U.S. from Mexico, that she needs to learn English and uses a SILL video program to accomplish this (with rather incredible results!). Yet, until I came face to face with the packages themselves, they never seemed applicable to me. After my experiences in France and Mexico, I was more adamant than ever that optimal language learning occurs in the $\mathrm{L} 2$ environment, with foreign language classes as a fallback when such luxuries as trips to Moscow are impossible. Yet, even so, part of me was drawn to the potential of SILL programs. Although I have carped on SILL programs from the beginning for their inflated promises and claims, I must admit that despite all cynicism, in my weaker moments I was charmed. I found myself wondering: Is SILL the ideal setup? With no time to attend language classes and no interest besides in paying hefty tuitions for credits I would never use, SILL programs seemed like the perfect answer. 
Browsing through dozens of languages from Arabic to Urdu, I knew I would have to experience SILL for myself. Better yet, if I could somehow turn this exploration into an MA thesis...Which brings me to my proposed study, as described in the following section.

However, one final issue to address is the question of whether my experience falls within the margin of what can be considered the "typical lone learner's experience". If what I am about to relate is nothing more than an interesting anecdote applicable only to me, what is the point? My intention, as I have previously stated, was to assume the role of the typical lone learner, but who is she? Some clues to her identity are offered by Jones $(1996,1998)$ in his interview study of seventy self-instructed learners in the UK. These learners were contacted by way of a British university's self-access center database. Although this sampling was biased toward members of the university community (two-thirds were either students or staff members) such a bias was unavoidable, as Jones (1998) recounts "truly independent learners are hard to contact" ( $p$. 382). A second, and more important, bias is that only native English-speakers were contacted; thus issues such as how "exotic" an L2 is perceived to be are extremely compromised. However, since I cannot pretend to be a typical lone learner who is not a native English-speaker, such a bias does not drastically impinge on this present discussion.

From this sampling, the typical lone learner is found to have studied between two and four languages. Of the languages she has studied, she has generally done so in both solo and mixed (solo and classroom-based) contexts, with a likelihood that she has spent at least some time in the L2 language environment (usually on holidays). Of the 
languages she has studied, it is most likely that they include at least one of French, Spanish, or German. The tendency is that, if she has studied only one or two foreign languages, these languages fall within the Romance and Germanic families. The more languages she has studied, the more likely she has studied an exotic language (i.e., neither Romance nor Germanic). Therefore, from this, albeit brief, profile, it seems that the typical lone learner and I are not so disparate. With renewed confidence that my experience is more than simply anecdotal, I will proceed to describe my proposed study in the following section.

\subsubsection{The proposed study}

As previously stated in Chapter 1 , my intention at the outset was quite simple. I wanted to test the effectiveness of several SILL programs against the claims made on their packages. If, after sitting through a year of university credit courses in Russian, (requiring five hours a week of in-class and language laboratory study, not to mention countless hours memorizing word lists and completing homework assignments on my own time), I had not achieved what I considered conversational fluency, what magic method could be behind the promise "[s]peak German with confidence in just 6 weeks" (Living Language, box)?

To test these claims, I decided to choose two languages unrelated to each other and not closely related to any language I had already studied. After some thought, I settled on German and Japanese. I then selected two SILL series with programs 
published in both languages, and which appeared to be among the most popular series carried by Chapters: Living Language and Teach Yourself (further discussion with respect to my selection of languages and series will follow in the next section). With two series in two languages each (a total of four programs), I knew I would have my work cut out for me, but my aim was to have a sample that I could compare and contrast in several ways (e.g., by series, by language, and so forth). I decided that this relative breadth would give me the best possible grounding to fully understand what the typical lone learner is up against.

To guide my study, I proposed to follow the program's instructions exactly as they were laid out by the writers, and to work only within the curricula of the programs themselves (which is to say I would complete the prescribed activities, but avoid consciously employing any of the language learning strategies I had collected over my years of language study unless the writer explicitly invited me to do so). In following the program's directions, I proposed to devote only the recommended amount of time to my diurnal learning sessions. For example, Living Language recommends spending half an hour a day on the lessons, claiming that this arrangement will result in speaking the language in question "with confidence in just six weeks" (Living Language, box). Finally, to document my experience as a lone learner, I proposed to keep a diary where I would reflect on my feelings of success and frustration and give my impressions of the day's experience immediately after every learning session. Upon completion of the study, I proposed to use this record to gain insight into the lone learner's journey with SILL programs and, ultimately, to corroborate or contradict the extraordinary claims made on the packages. 
These were the considerations I made at the outset, with later negotiations made over the course of the study as issues arose. For example, I later questioned: How should I account for the problems associated with sequencing? I had decided to first look at both of the German programs, and then look at both of the Japanese programs, working in the order of Living Language first and then Teach Yourself. How would one program influence later programs? What were the consequences of following one program with another in the same language? There was no way to prevent my experience with one program from influencing my experience with the next. I decided it would simply be something I would have to be conscious of and attempt to compensate for as much as possible. I also questioned how many weeks I should devote to each program. In the end, I decided to allow time itself to determine that issue. With half an hour or so devoted to SILL everyday, how long would it take me to complete each program? Would I advance more quickly with one language than with the other?

These were my original intentions and the proposed guidelines by which I meant to conduct the study. Of course, not everything went as planned. As mentioned in Chapter 1 , over the course of the study my aim to test the claims made on the SILL packages gave way to more interesting questions with more puzzling, less straightforward answers. Was I speaking "German with confidence in just six weeks" (Living Language, box)? Sadly, no. In fact, despite my most sincere efforts, I speak barely more German now than I did before I began. What was missing? What were the consequences of these missing elements? How did I, as a learner, attempt to adapt to and compensate for program shortcomings? How did the programs attempt to anticipate and to account for my individual needs? 
Another major change to the study that occurred only in the writing stages of this thesis was the abandonment of an entire series. The Instant Immersion Series, alluded to several times in the previous two chapters, will not play a central role in this thesis, despite my initial intention to include it as such. The reasons for this decision are twofold. First, as an all-audio series (no course book is included in the package), it is much less comparable to the Living Language Series and the Teach Yourself Series than those two are to each other, and, consequently, my efforts to compare and contrast the three felt contrived. Second, and most crucially, my diary entries during the periods I worked on Instant Immersion are largely incomplete. After having already followed the Living Language and Teach Yourself programs, my study of Instant Immersion felt redundant and seemed like a poor use of my time. As a result, I rushed through the programs, listening only for salient features that may have been of use to my investigation, but not approaching it in the role of a typical lone learner. Since this study is based so heavily on qualitative introspection, a lack of diary data is a great problem indeed. Consequently, Instant Immersion will serve only to enrich the study in a peripheral sense, and I will focus the remainder of the paper on the Living Language and Teach Yourself programs. In the following discussion I will attend to some of the many questions that have arisen so far by providing insight into the lone learner's journey and the design of commercial SILL programs. In doing so, this study will provide a much needed window into the world of SILL, not only for potential lone learners, but also for the writers and publishers of SILL programs. First, however, I will introduce the SILL programs I used for this study. 


\subsection{Introduction to the materials}

This section will first provide a rationale for my selection of SILL programs and languages. I will then introduce the two series I investigated in this study: Living Language and Teach Yourself. For both series I will briefly describe the publisher, the various programs offered by the series (i.e., the series within the series), the package, the claims made on the package, the contents of the package, the general set-up of the curriculum, and some of my expectations for the series at the outset of the study. Although I will comment on one or two program features critically in this preparatory discussion, drawing on the critique by Hayet (1990a, 1990b) introduced in Chapter 2, the formal discussion of my analysis and evaluation will follow in Chapter 4, where I will critique the four SILL programs in greater depth.

\subsubsection{Rationale for the selected materials}

The following two sections will provide a more detailed rationale for my selections of languages and SILL programs. 


\subsection{1.a The languages}

As already mentioned, for this study I chose two languages: German and Japanese. This choice was largely motivated by a personal interest in the two languages. My interest in Japanese originally stemmed from my perception of it as an exotic language, unlike any I had studied previously. German, on the other hand, was already familiar to me due to its close relationship to English, yet I had never studied a Germanic language as an L2. I chose German for two reasons. First, I had always wanted to study German, and second, I thought it would be interesting to contrast it with my experience studying Japanese, a completely unrelated language. Additionally, I wanted to see how I would cope with the challenges of two very diverse languages in the SILL context, and how the design of the SILL programs would attempt (or would not attempt) to accommodate these different languages.

To quickly introduce the languages, German, an Indo-European language of the Germanic family, shares a multitude of cognates with English, has roughly five phonemes with no English equivalents, has a fixed stress pattern, and is a combined synthetic language with a flexible SVO word order. Japanese, considered to be a language isolate, shares some lexis with English through borrowings and internationalisms, has roughly ten phonemes with no English equivalents, uses pitch accent with no fixed stress pattern, and is an analytic language with an SOV word order. Therefore, although English is more like German in terms of phonology, lexis, stress, and word order, it does share its analytic construction with Japanese, in contrast to the German combined synthetic construction. 
I predicted at the outset that I would have a considerably easier time making sense of German in the SILL context than I would of Japanese. Its close relationship to English is an advantage that cannot be downplayed. Additionally, I have enjoyed much more exposure to German than to Japanese, as a result of living and traveling in Europe. Consequently, to ease myself into my exploration of SILL, I decided to begin with German, and then move on to Japanese. This was a decision that I later congratulated myself on, as I will describe in the analysis of my diaries. More than once during my study of Japanese I recorded thinking grimly:

If I hadn't already had a decent experience with German, I might have been completely scared off of this project today. (Diary, April 8, LLJ [Living Language Japanese])

\subsection{1.b The SILL programs}

As described in Chapter 1, there are various ways to go about SILL, such as commercial programs, distance education programs, broadcast courses, CALL, learning in-situ, and so forth. My rationale for focusing singularly on commercial SILL programs is two-fold. First, these programs have been around a relatively long time compared with other SILL options, such as distance education, broadcast courses, and CALL, yet, as I have remarked, there is very little empirical evidence to explain their longevity. Second, the scope of my study created limitations, which unavoidably lent themselves to a fairly narrow focus, thus ruling out a broader look at other SILL possibilities. 
As already mentioned, I selected two series for this study: Living Language and Teach Yourself. For both of these, I chose to look at both their German and Japanese programs (so four programs in all). My choice of these two series was quite deliberate. As my intention was to assume the role of the typical lone learner, I chose to examine the programs I determined she would be most likely to purchase. Consequently, I selected the two series that appeared to be most carried by Chapters. After visiting several stores in several cities, these two stood out as the most popular, based both on their prevalence on the shelf and from talking to various sales clerks who attested to their popularity.

Otherwise, I began this study rather blindly, as I assumed the typical lone learner would. From looking over the packages, it is evident that the learner targeted by these series is not a trained linguist. She is a tourist, a business traveler, or an aficionado looking for some fun, with a limited amount of linguistic savvy to inform her decision. Aside from soliciting sales clerks and browsing websites (more on websites below), as I did, how would she choose between the colourful boxes, all boasting their own magic methods? Looking at the tightly sealed packages of the two series, there are very few distinguishing features that indicate the vast differences that lie within. The following section will begin to tease out those hidden differences.

In terms of sequencing, I chose to go in the order of Living Language first and then Teach Yourself. This order was largely indiscriminate and I followed it for both languages. After deliberating the issue at length before setting out, I could not think of any justification for any particular order, or for adopting a different order for each language. I reasoned, if sequencing did have a great effect on my experiences with the different programs, I wanted the effect to be consistent between languages. 
The following section will provide an overview of the two series. I will begin with a discussion of Living Language and then move on to Teach Yourself.

\subsubsection{Living Language}

The first series I plucked from the shelf was the Complete Basic Series by Living Language. Its blue and red box seemed to occupy the most shelf space, and the Chapters sales clerk enthusiastically called it one of their most popular. However, before making the purchase, I did a bit more digging and learned the following from the Living Language website:

Living Language, a Random House Company, has been designing SILL programs since 1946. Originally the programs were designed by the U.S. government for the use of military personnel and diplomats. (This early use of SILL programs is historically significant because it marked the beginning of the Audiolingual Method, which will be discussed further in Chapter 4.) The programs cover 23 languages in total, with different program set-ups geared toward different target learners. The two basic programs (by which I mean the two offering a more or less complete or standardized curriculum of basic grammar and vocabulary) are the Ultimate Series and the Complete Basic Series.

The Ultimate Series is described as taking a more academic approach to language instruction (i.e., lots of grammar explanations) and is geared toward "serious language learners" (Living Language, 2005). This particular series is available at the beginner, intermediate, and advanced levels. Completion of all three levels is said to be 
"[e]quivalent to two years of college-level study" (Living Language, 2005). The Complete Basic Series puts less emphasis on formal grammar study and more emphasis on a traditional "listen and repeat" approach to SLA. This approach is based on the Audiolingual Method, which will be discussed further in Chapter 4. According to the website, the Ultimate Series relies on a "comprehensive approach" (Living Language, 2005), whereas the Complete Basic Series relies on a "'building block' approach, beginning with simple words and phrases and progressing to more complex expressions" (Living Language, 2005). However, nowhere is this difference elaborated on further. A secondary difference, according to the website, is that the Ultimate Series emphasizes reading, writing, grammar, and culture, whereas the Complete Basic Series emphasizes conversational competency. Again, unfortunately, nowhere is this difference ever explained. Additionally, in contradiction to this last claim, the first sentence of the Complete Basic German introduction asserts that "Living Language German makes it easy to learn to speak, read, and write German" (Kleinmann, 1993, p. xv). (However, as this series offers no opportunity to practice writing German at all, and no opportunity to read anything in German other than short, isolated sentences, I was left extremely puzzled by this bold assertion long after my completion of the program. This issue will be addressed further in Chapter 4.)

Other peripheral programs offered by Living Language include the All-Audio Series, the Advanced Series, the Skill Builders Series, the Business Companion Series, a culture guide called the In the Know Series, the Fodor's/Living Language for Travelers Series, a series called In-Flight—advertised as "[a] 60-minute survival guide that lets you learn before you land" (Living Language, 2005)-and two programs geared for children 
called the Learn Together Series and the Baby's First Steps Series. Depending on the popularity of the language in question, it may be offered in all eleven of the series (e.g., French), only in one of the series (e.g., Yiddish), or somewhere in between (e.g., German and Japanese). Despite the large number of programs offered by Living Language, only three seem to be carried routinely by Chapters. These are: the Complete Basic Series, the Ultimate Series, and the Skill Builders Series. However, after contacting Random House for reasons described further below, an editor at Living Language was kind enough to send me a few samples of two series I had not encountered at Chapters. She sent two packages from the In-flight Series and one package from a newly designed series not yet promoted by their website called the Without the Fuss Series. This was largely in response to my polite, although unapologetic, critique of the outdated, albeit traditional, methods used in the Complete Basic Series. In reply, the editor I contacted urged me to browse through their other programs to see that the Complete Basic Series is not representative of everything Living Language has to offer.

However, according to the website, the package, and the people at Chapters who stock this series by the dozens, the Complete Basic Series is the most popular of all the Living Language Series, which is why I chose to investigate it (as such, please note that whenever I refer to "the Living Language programs", as I will often do throughout the next few chapters, I am referring exclusively to the Living Language Complete Basic Series, unless otherwise specified). The website advertises that it is "[a] best-selling course, with everything you need to learn basic, conversational German. Over two million sold" (Living Language, 2005). Purportedly, then, everything you need to learn is a course book, a two-way dictionary, and three audio CDs. As described in Chapter 2, 
Hayet (1990b) considers the claim "[a]ll you need is provided" (p. 12) to be one of the secondary SILL mythologies, arguing that " $[\mathrm{b}] \mathrm{y}$ limiting the possible language-learning material and tools exclusively to whatever products they are selling, thus implicitly denying the existence of other legitimate material or tools, the at-home foreign-language courses firms [sic] introduce our final mythology" (p. 12).

Back at Chapters, I found myself struggling to imagine the contents of the red and blue boxes. The packages are sealed tightly, so without being able to flip through the contents of the box, the potential buyer has only the claims made on the glossy cover to inform her decision. These claims include "[f]or beginners or those who want a thorough review", “[s]peak Japanese with confidence in just 6 weeks", "Living Language...uses a highly effective speed-learning method developed by U.S. government experts”, “[j] ust listen and repeat after the native speakers on the recordings to learn naturally, the way you learned English", "[t]he best-selling language course that really works" (all from Living Language, box), and, of course, there is also the price tag asking $\$ 38.00$ Canadian.

Only at home, with the contents of the package spread out before her, can the learner begin to sift through the materials critically (and hopefully she is happy with her purchase because, since the package contains $\mathrm{CDs}$, it is no longer returnable according to the Chapters return policy). Accordingly resigned to my purchase, I ascertained the following:

The course book begins with an introduction that promises "[i]f you can study about thirty minutes a day, you can master this course and learn to speak German in a few weeks" (Kleinmann, 1993, p. xv). The course is divided into 40 lessons, with each lesson presenting several lists of new vocabulary items roughly grouped into themes 
(e.g., there is a lesson that presents food-related vocabulary and a lesson that presents deictic words). Vocabulary is introduced either singularly, or in short isolated sentences. Grammar is presented in the form of a table (e.g., there are tables showing the paradigms for case, grammatical gender, and verb conjugations). After each lesson is an activity, either in the form of matching a column of German items with their English translations, or in the form of multiple choice. The final quiz at the end of Lesson 40 consists of 25 multiple choice questions testing isolated vocabulary items taken from the preceding $\mathbf{4 0}$ lessons. In this final quiz, a short sentence in German is presented with a missing item (the English translation of which is provided in brackets) and the learner must choose one of three listed answers. At the end of the quiz is the claim "[w] quiz you can consider that you have mastered this course" (Kleinmann, 1993, p. 278).

Please note that, in the case of Living Language, every example I offer for one language finds its parallel in the other languages offered by the Complete Basic Series. Each program is identical in packaging and approach. Inside the course books the majority of the vocabulary lists are largely identical between languages (the only real exception being lists comprised of cognates). Whenever possible, even the grammar is presented in a parallel fashion. I was disappointed to find the two jokes offered by the German program repeated in the Japanese program, somewhat deadening the punch-line for me.

As mentioned above, I contacted the people at Living Language to get a bit of insight into the design of the Complete Basic Series. In particular, I was curious about the so-called "speed-learning method" (Living Language, box), which, according to the inside cover of the course book, was devised by someone named Ralph Weiman. My 
contact at Living Language was unable to speak to me on the record, due to restrictions set by the legal department of Random House. No one there was able to give me any specifics on Weiman or his "speed-learning method" (Living Language, box). My searches outside of Living Language for Weiman lead me in only one direction-back to the Living Language Complete Basic Series. From what I can tell, Weiman devised the method behind the Complete Basic Series previous to 1956, when the first edition of the German program was written by Genevieve A. Martin and Theodor Bertram. Later editions appeared in 1985 and 1993, revised and updated for content by Walter Kleinmann. The first edition of the Japanese program was written by Ichiro Shirato in 1962. Later editions appeared in 1985 and 1993, revised and updated for content by Hiroko Storm. Whatever the "speed-learning method" (Living Language, box) might be, both programs rely on an outdated "listen and repeat" set-up (more on this in Chapter 4), despite the claim made by the website that "[1]anguage study should not be all drills and rote memorization: languages should live" (Living Language, 2005).

The alleged popularity of this series was (and continues to be) puzzling to me for several reasons. The methods are clearly outdated and there appears to be no empirical evidence that anyone has successfully learned to "speak, read, and write" (Kleinmann, 1993, p. Xv; Storm, 1993, p. xv) in a foreign language by way of this series. Although the appeal of the claims made on the box may be enough to entice the learner to purchase it, I had to wonder, are the materials inside the box enough to motivate her to keep at it? How many of these packages are purchased, flipped through once or twice, and then abandoned to the bookshelf? Could the success of this series be supported by a throng of wishful thinkers? If so, I certainly counted myself among them at the outset of this study. 
Irrespective of my nagging doubts, and with sincere optimism and the hope of discovering a convenient and empowering means of SLA, I set out, 30 minutes a day for six weeks, to test the box's confident claims.

\subsubsection{Teach Yourself}

The second series I plucked from the shelf was one called Teach Yourself. The packages published by Teach Yourself are characterized by large translucent, albeit tightly sealed, encasements. As a result, what most attracted my eye, as I perused the shelves, were the visible course books inside, their covers decorated with what could be snapshots selected from a world traveler's photo album. In two words, the Teach Yourself packages appeared fresh and trendy. Taking up nearly as much space on the shelf as their Living Language counterparts, and equally praised by the sales clerks, these packages commanded my attention. Through further inquiries into the series, I learned the following:

The first publications from the Teach Yourself label appeared in 1938 and were geared towards assisting the British populace through the Second World War. As such, the first titles that appeared involved topics such as Teach Yourself Pig-Keeping, PoultryKeeping, and Air Navigation. Over the years, the series has designed self-instruction books ranging in topics from Teach Yourself Golf and Teach Yourself Dream Interpretation, to Teach Yourself Ethics, Teach Yourself Digital Photography, and Teach Yourself Tantric Sex, along with over 50 foreign languages. Within the language 
programs the two basic series are the Beginner's Series and the Complete Series. Other peripheral programs include the Beginner's Script Series, the Complete Grammar Series, the Instant Series, the One-Day Series, the Quick-Fix Series, the Starter Series, and the Vocabulary and Verb Series.

From what I gathered, the Complete Series is comparable in its aims to the Living Language Ultimate Series, in that it takes a more comprehensive approach to teaching grammar, reading, writing, listening, and speaking. Explanations are detailed and quite technical, with the aim of teaching language through a grounding in theory. The Beginner's Series, on the other hand, is more comparable to the Living Language Complete Basic Series, in that it takes a rather light-handed and conversational approach. It is geared towards those learners who "are daunted by the prospect of complicated grammar, classes, and course books" (Teach Yourself, 2003). Because of this comparability, I chose to investigate the Beginner's Series for the present study (and as such, please note that whenever I refer to "the Teach Yourself programs", as I will often do throughout the next few chapters, I am referring exclusively to the Teach Yourself Beginner's Series, unless otherwise specified). As with their Living Language counterparts, the many colorful packages lining the shelves at Chapters attest to their popularity, and as with their counterparts, the tightly sealed packages prevent potential buyers from seeing far beyond the promises of the glossy covers. The transparent packaging reveals two audio CDs and a course book, but, predictably, there is no way to flip through the course book to get sense of what may be in store for the potential learner. The claims touted on the packages include "[t]he proven way to learn a language", "[i]ntroductory programs that get you speaking quickly", and "[achieve] everyday 
communication, cover all the basics, go at a steady pace, build your confidence to speak" (all from Teach Yourself, box). The cost of the Teach Yourself package is $\$ 31.95$ Canadian.

At home once again, I combed through the materials of the now non-returnable package. At this point, the similarities between the Living Language and Teach Yourself Series dissolved, leaving behind two vastly different approaches to SILL. Finally able to thumb through the package contents, I uncovered the following:

The course book is divided into twenty lessons and evidently relies on communicative approaches to instruction (which will be described further in Chapter 4). The lessons are largely thematic (e.g., three lessons from the German course are entitled At the restaurant, In the hotel, and Shopping), and many different kinds of activities are involved in each lesson (e.g., vocabulary lists, fill in the blank, matching, multiple choice, translation, completing dialogues, drawing maps, telling time, crossword puzzles, and so forth). Grammar is rarely the focus of an activity and the learner is often encouraged "not [to] try to learn everything at once" (McNab, 2003, p. 103), and "not [to] worry about understanding every word" (Gilhooly, 2003, p. 22). Unlike Living Language where the activities can all be fitted with a straightforward answer key, the Teach Yourself activities are often open-ended. The consequences of this are two-fold. First, the learner has to face the ambiguity of not being able to check her answers against an exact answer key. Second, the activities tend to appear less evaluation-driven (i.e., right or wrong, pass or fail) and more practice-driven (i.e., they encourage creativity, experimentation, and risk-taking). 
Another difference I noticed immediately between the Living Language and Teach Yourself programs is the variation between programs within the series. Although both the German and Japanese programs follow the same general design, as described above, there are interesting differences between the programs, which reflect the individual preferences and styles of the writers. The Japanese program, written by Helen Gilhooly (2003), takes a narrative approach to the lessons by using the story of a British student who moves in with a Japanese family to link together the various themes. As the British student, Anne, negotiates the challenges of communicating in Japanese, so does the learner. Other characters are reoccurring within the story, as well, such as Anne's host family, the Yamaguchi family, and Anne's classmates. There is no narrative thread in the German program, written by Rosi McNab (2003). Another choice made by Gilhooly is to make the final lessons independent of each other, and thus optional. Once the learner has completed the first thirteen lessons (which must be done in the order they are laid out because each lesson builds on knowledge learned in previous lessons), she can approach the last seven lessons to suit her own needs and goals. In the German course the only lesson that is independent of the others is one that presents technical explanations of German verbs. The learner can decide for herself if she would like a better understanding of the workings of German verbs and then choose to skip or not skip this lesson accordingly.

Compared to the very pragmatic directives asking for thirty minutes a day for six weeks by the Living Language Complete Basic Series, the program instructions recommended by the writers of the Teach Yourself Beginner's Series focus more on encouraging the learner to figure out what works best according to her personal learning 
style, by providing lots of study tips and learning strategies in the form of suggestions. The writers both counsel the importance of frequency of learning sessions over length. As Gilhooly (2003) offers "[a] little, often, is far more effective than a long session every now and then. So try to put in about 20-30 minutes' study each day, if possible, or two to three times per week" (p. xii). Gilhooly identifies the need for the learner to establish her own pace, by further suggesting "[f]ind a balance between moving through the book and revising what you have already learnt" (p. xii). Pace is something that is never addressed by Living Language.

And so I set out, twenty to thirty minutes a day, nearly everyday. The appeal of Teach Yourself was on more than one level. The aesthetic appeal of the package itself was immediate (the course book pages contain drawings and lively fonts), and also the change from the Audiolingual Method to a more communicative approach promised relief from the tedium of "listen and repeat". Finally, the content delivered through contextual dialogues and activities was definitely something to look forward to...I wondered, could this be the program that would work for me?

\subsection{Results: The learner diaries}

I will now describe the recurrent, and thus significant, trends that emerged from the analysis of my learner diaries. For the purposes of this analysis, I followed the examples of other researcher-diarists (e.g., Bailey, 1980, 1983; Jones, 1994, 1995, 1996; Schmidt \& 
Frota, 1986; Schumann, 1980; Schumann \& Schumann, 1977) in the examination and coding of my diaries. Bailey (1983) breaks diary analysis into three steps. These are:

1. "The journal entries are revised for public perusal" (p. 72). In many cases this step involves concealing the identities of people referred to in the diaries. In my case, no such references were made. I did, however, remove instances of potentially offensive language.

2. "The researcher studies the journal entries as data, looking for 'significant' trends" (p. 73). After reading through the diaries several times, during which time I coded sections thematically, I was able to discern six significant trends, as listed below.

3. "The factors identified as important to the language learning experience are discussed" (p. 73). My discussion of the six trends will be presented below.

To simplify my diary citations, I will use the following notational system. Living Language will be abbreviated as LL and Teach Yourself as TY. German will be indicated with a $\mathrm{G}$ and Japanese with a J. Accordingly, a citation noted as "Diary, January 18, LLG" can be interpreted as a diary entry made on January $18^{\text {th }}, 2005$, while following the Living Language Complete Basic German program. A citation noted as "Diary, April 30, TYJ" can be interpreted as a diary entry made on April 30", 2005 , while following the Teach Yourself Beginner's Japanese program. Furthermore, for maximum clarity, I will block format all diary excerpts.

In my discussion, I will most often make generalizations that account for both languages of the series (e.g., where I refer to the Living Language programs, I will be 
referring to both the Japanese and the German packages published by the series). Where I do not generalize in this way, I will be more specific.

To organize this potentially unwieldy discussion in the most succinct manner possible, I have grouped the recurrent, and thus significant, trends extracted from my diaries under six headings. These are: Learner preparation and support, Sense of progress and pace, Sense of failure and laying blame, Sense of success through noticing, Coping with ambiguity in a teacherless context, and Clash of styles. The Learner preparation and support section will describe my reflections on issues such as assessing individual needs and goals, strategy training through learning tips and transparency, and negotiating the learner-context interface. The Sense of progress and pace section will describe my struggle to establish a pace that would satisfy my need for a sense of progress without sacrificing my comprehension of the content. The Sense of failure and laying blame section will describe the identity crisis I experienced as a result of feelings of failure, along with my efforts to cope with that crisis. The Sense of success through noticing section will describe occasions of positive learning sessions. The Coping with ambiguity in a teacherless context section will describe how I dealt with course book opacity and input overload without teacher mediation. Finally, the Clash of styles section will describe how I negotiated my personal learning style in and around the SILL programs, with a specific look at learning activities and audio materials.

As much as possible I will treat the recurrent trends in isolation, but, as with my discussion of the affective factors in Chapter 2, many of these trends are inextricably entangled and implicated by association. After discussing each of the six trends, I will present a summary of the major findings to illustrate the connections between them. The 
summary of major findings will reflect the two major foci of the study by first presenting the major findings pertaining to the affective factors (the first major focus), and then presenting the major findings pertaining to the SILL programs (the second major focus).

\subsubsection{General comments}

I will first make a few general comments about my experience as a lone learner, which may not surface otherwise through the relatively limited (although suitably representative) excerpts taken from my diaries. I spent roughly five months on my study of the four SILL programs. I began on January $2^{\text {nd }}, 2005$ with the Living Language Complete Basic German program and finished on May $27^{\text {th }}, 2005$ with the Teach Yourself Beginner's Japanese program. I spent about six weeks each on the Living Language programs and about four weeks each on of the Teach Yourself programs. The shorter time allotted to the Teach Yourself programs was due, in part, to the fact that much of the content in the early lessons was largely review for me, as I had just completed the Living Language program for the same language.

I worked in the mornings, five or six days a week. I tried to maintain consistency in my daily learning sessions, always setting aside at least an hour for myself to both work with the SILL program in question and to reflect in my learner diary. I worked almost exclusively at home, at my desk, which I knew to be my preferred study environment. As mentioned in Chapter 2, twice I attempted to use my SILL audio 
materials away from my desk (once on a walk and once in the bath). My diary entries for those days reflect how badly this experiment went. As I recorded:

I've just returned home from walking down to the village and back, plugged into my headphones and my Japanese audio track. What a disaster! I absolutely do not have enough brain space leftover (after devoting what I need to such things as not getting hit by a car, keeping the wind from blowing those annoying strands of hair in my eyes, and generally just walking) to learn a foreign language! $\mathrm{Oh}, \mathrm{I}$ have such a headache. (Diary, May 14, TYJ)

In general, I looked forward to each day's session. Although I did not achieve the results I had optimistically hoped for, I was still engaged in what I continue to regard as my favourite hobby_foreign language learning. My efforts to acquire German were slightly more successful than my efforts to acquire Japanese. There is no doubt in my mind that this is due to the relationship German shares with English, the vast number of cognates between German and my other L2s, and the greater familiarity I have with German over Japanese. Yet, my overall acquisition of German was still inadequate and disappointing, as was my overall acquisition of Japanese.

Caveats affecting the generalizability of this study are similar to those described for Jones $(1994,1995,1996)$. First, I am an experienced language learner, yet Jones $(1996,1998)$ found that language count effects are negligible after three languages. Second, I have formal training in both theoretical and applied linguistics. If anything, this advantage manifested only in a greater acquaintance with certain morpho-syntactic processes than what might be had by most learners (e.g., case assignment, nullification of subjects/objects, and so forth). However, since my overall impression of most 
grammatical explanations was one of complete bewilderment, this advantage did not seem to benefit me very much.

I will now present the six significant trends identified in my learner diaries, followed by a summary of major findings.

\subsubsection{Learner preparation and support}

As argued in Chapter 2, successful SILL is possible, but requires careful preparation of the learner and diligent support by the learning materials. Preparation can occur in the form of addressing the learner's beliefs about language learning and assessing her readiness for autonomy. Support can occur in the form of fostering autonomy and strategy training. This section will present diary excerpts in which I reflect on the learner preparation and support afforded to me by my SILL programs. Because I regard preparation and support to be two of the most crucial features of SILL programs (to be discussed further in Chapter 4), this section is conceivably the most vital of the six sections, in terms of facilitating my experience as a lone learner.

One of the earliest measures taken by the Teach Yourself programs to ready me for autonomy was to prompt me to consider my individual needs and goals. By building options into the lessons, the programs gave me flexibility to tailor the learning context to suit my needs and make the most of my learning sessions. As I noted:

Some of the grammar sections are optional. For example, if I just want to learn conversational German, I can skip right over them, but if I want a better 
understanding, I can study them as much or as little as I want. I really appreciate these kinds of options. (Diary, February 23, TYG)

As in this last excerpt, I found that sometimes entire sections were optional. In other instances, choosing what to spend time on was less straightforward, as in the case of building vocabulary from word lists. As I commented:

The program makes it clear that there are some words I will want to know actively and some that I will just want to know passively, depending on my needs. In fact, the program invites me to think about these sorts of things throughout my learning sessions in order to make them as efficient as possible. (Diary, February 25, TYG)

As well as prompting me to consider my individual needs and goals, this last excerpt serves as an example of strategy training, by providing me with a strategy for coping with an overload of new lexis (i.e., marking lexis for active production versus passive recognition). Although I found several instances of strategy training in the Teach Yourself programs, such training was extremely scant in the Living Language programs. As I remarked:

Today I came across the first example of learner support by a Living Language program. The book, to my great surprise, actually counselled me that the following lesson on particles was going to be very complex and that I shouldn't feel obliged to memorize every point, but just try to become familiar with the different particles so I will recognize them later. It was so unprecedented that I barely recognized it as strategy training. (Diary, March 23, LLJ) 
In this case, the program's attempt to teach me a strategy for dealing with overwhelming complexity was the only attempt at learner support by a Living Language program recorded in my diary. In contrast, I found many attempts at strategy training in the Teach Yourself programs. As I recorded:

This book makes several learning strategies really explicit, which is so helpful. For example, the learner is encouraged to use words already known in German to decode larger compounds. (Diary, February 18, TYG)

This last excerpt reflects on a suggestion for a specific strategy, whereas the following excerpt reflects on an instance of strategy training by way of making activity instructions transparent. As I noted:

I was surprised to see references made to what particular activities are supposed to achieve. It's definitely helpful to recognize the point behind a learning activity. Makes it a lot harder to skip over when you know why it's there. (Diary, April 30, TYJ)

Over the course of my study I developed a different relationship with each of the programs. These relationships played a significant role in my negotiation of the learnercontext interface (i.e., "the unique dynamic established between the learner and the context" (White, 1999, p. 449)). In the case of the Living Language programs, my relationships were characterized by mistrust and resentfulness, fuelled by my frustration to make the learning context accommodate my needs and personal learning style (this frustration will be addressed below). In the case of the Teach Yourself programs, my relationships were mostly characterized by cooperation and acceptance. This was due, at 
least in part, to the supportive tone of the program instructions, inviting me to approach the learner-context interface without fear. As I mentioned:

I feel encouraged by the friendly and non-confrontational tone of the program instructions-always telling me not to worry, to take my time, not to get caught up in what doesn't make sense immediately, always telling me just to try my best. So helpful. I don't feel like it's me against the materials, the way I sometimes did with the Living Language programs. I feel like we're in this together. (Diary, April 31, TYJ

This positive relationship manifested in both general and specific ways. Generally, I felt encouraged to try my best and not dwell on my failures, while, specifically, I was emboldened in the face of particular challenges. As I remarked:

There was a really complicated lesson today, but I felt ready for it. The instructions emphasized that I needn't try to memorize everything at once-that it's not necessary for me to learn everything perfectly right away because German speakers will most likely get a sense of what I'm trying to say and understand me well enough. That was really reassuring. I was able to approach the lesson with more confidence. (Diary, February 24, TYG)

Without question, I felt immensely more supported by the Teach Yourself programs than I did by the Living Language programs. The issue of lone learning is something that was never even addressed by the Living Language programs. There was no mention of either the specialized context or of the challenges particular to lone learning (e.g., establishing a pace, coping with ambiguity, and so forth), as in the Teach Yourself programs. As I observed: 
Wow, this Teach Yourself program actually addresses the reality of lone learning in the introduction, acknowledging different personal learning styles, preferred strategies, and the need for the learner to find her own pace. The Living Language program didn't even allude to these things. (Diary, February 14, TYG) It only took a few sentences for the Teach Yourself programs to acknowledge the reality of lone learning, but those few sentences served to prompt me to reflect on my learner beliefs about language learning, to consider my readiness for autonomy, and to think about my own personal learning style and preferred strategies. Instigating these kinds of reflections and considerations are vital to fostering autonomy, providing learner preparation and support, and, thus, to successful lone learning.

\subsubsection{Sense of progress and pace}

Perhaps what I struggled with most throughout the study was finding my own pace. I experienced a great deal of tension between needing to advance through the programs (for reasons of motivation) and needing to spend a bit more time on a given lesson (for reasons of mastering the material before moving on). Progress was often measured in terms of advancing through the course books, not in terms of acquiring the

L2s. As I observed:

Today was a good day. I felt on top of the lessons, which was a much needed feeling. I actually advanced in the book. I guess I measure my progress in the 
number of pages I can cover and feel good about. It's important to feel a sense of progress. (Diary, January 18, LLG)

Unfortunately, sometimes I chose to move on prematurely in order to achieve that sense of progress. As I noted:

I know I'm not ready to move on-I don't have command over what I've already covered - but I just need to advance. I need to feel some sense of progress.

(Diary, January 20, LLG)

This was especially true in the case of the Living Language programs. It took almost no effort at all to glide through the "listen and repeat" lessons. I certainly did not need to know a word's meaning to repeat it, nor did I need to know its grammatical gender (in the case of a noun), how to conjugate it (in the case of a verb), or where to place it in a sentence (in the case of a preposition or a particle). Similarly, it did not take much knowledge to successfully complete most of the activities presented in the Living Language programs, particularly in the case of German. With so many cognates shared between German, English, French, and Spanish, and with my many years of deductive practice (these kinds of activities turn up in every language class!), I found I could complete most of the activities with barely any active knowledge of German. As a result, moving forward in the programs was easy-until I would pause a moment to selfevaluated and reflect on what I had learned. Upon realizing that nothing was sinking in, that the knowledge I was acquiring was nothing more than passive recognition of isolated words and phrasal chunks, I often felt frustrated and overwhelmed. As I observed:

The lessons are so dense and the pace is so quick. They shove too much at me, too quickly, without time to digest or practice. I can't absorb everything. But I 
don't want to repeat the same lessons everyday, over and over. I need to advance to feel motivated, but the trade off is feeling lost half of the time. (Diary, January 27, LLG)

Consequently, when I got to the Teach Yourself programs, I was confronted with how little I had actually learned from the Living Language programs. Suddenly asked to construct full sentences, to comprehend dialogues and even participate in them, I grew frustrated and upset at my ineptitude. As I commented:

Didn't I just complete six weeks of Japanese study? Why do I feel like I'm starting at square one? (Diary, April 27, TYJ)

Working with the Teach Yourself programs, I struggled anew to establish my pace, but for a different reason. The Teach Yourself lessons were much longer than the Living Language lessons (an average of 10-12 pages compared to an average of 4-6 pages), with much more work required per lesson (e.g., many more activities). Although I wanted to cover a whole lesson within the time-frame of each learning session, this was not always possible, and, as a result, I often left a session feeling scattered and uncertain. As I recorded:

I feel like I want to do an entire lesson in one sitting, but it's too much. Maybe if the lessons were a bit shorter, they would be a bit more manageable. I wish there was a review lesson, every four or five lessons, with no new information, just a chance to practice what I've learned in different ways. That way, I could advance in the course book without confronting new content. As it stands, I just end up rushing and feeling flustered. (Diary, May 12, TYJ) 
While Living Language never addresses the issue of pace, Teach Yourself does in the introductions to the course books (cf., "[f]ind a balance between moving through the book and revising what you have already learnt" (Gilhooly, 2003, p. xii)). Although this made perfect sense to me, I found it difficult to follow the good advice. As I remarked:

Sometimes I feel overwhelmed because of what they expect me to know, like vocabulary I've only been introduced to once might pop up in a translation exercise. Of course, the instructions tell me not to go ahead to the next lesson until I've mastered the current one, something I have been pushing quite a bit. It's the tension between feeling a sense of progress through advancing in the book, and feeling a sense of progress through knowing the material well. (Diary, February 24, TYG)

Finding my own pace was an issue throughout the entire five months, and something I never quite resolved. I suppose it is one aspect of language learning that I had never confronted before. The pace of in-situ learning is the pace of life-less tangible and more discrete than other modes of learning, and, of course, the pace of classroom-based learning is more or less set by the teacher-like it or not.

\subsubsection{Sense of failure and laying blame}

One extremely persistent trend I found in my diaries was the struggle with my identity as a self-perceived good language learner. True, I had begun this study with a healthy amount of confidence, some might say arrogance, based on my history as a pretty 
successful language learner. Combined with my training in applied and theoretical linguistics, as well as my experience as an ESL instructor, I felt that I had an advantage over most lone learners. In terms of my learner beliefs, I had some fairly deep-rooted beliefs in myself as an independent learner, and a great amount of confidence in my study ability, both of which served to indicate my readiness for self-instruction, according to Cotterall (1995). Thus, if anyone could find success in the SILL context, I figured I probably could.

So imagine my dismay when I realized, several weeks into the study, that I was still unable to accomplish the most menial of transactions in the L2s. I began to question my own abilities, my very identity as a language learner. My beliefs were thoroughly shaken. As I noted:

I really feel like I'm failing at this. I'm not picking up any of the non-cognate vocabulary. These word lists are exhausting and just not helpful. (Diary, January 15, LLG)

Somedays this sense of failure was particularly intense, causing me to experience panic and defeat. As I recorded:

I don't even want to talk about it. So painful. I'm a complete failure. I know nothing. I have no clue how to speak German, all I can do is repeat the audio. Without the audio I only know a handful of phrases. This is a disaster. What should I do? (Diary, January 30, LLG)

Faced with this identity crisis, I grew more and more indignant. I began to search for reasons why I was not succeeding, looking for the source of my incompetence. 
Unable to tolerate the idea that I was to blame entirely, I chose to blame the SILL programs for my perceived failure. As I commented:

I'm just not learning Japanese. This program is bogus. I refuse to take full responsibility for this. I am not a bad language learner. I am not in this alone. (Diary, March 16, LLJ)

The more blame I assigned to the programs, the more I distanced myself from them, until the learner-context interface was divided. As I mentioned previously, my relationship with the Living Language programs was one characterized by mistrust and resentfulness. This was largely due to my growing impression that I was working against, rather than with, the materials. Suddenly I began referring to the programs in terms of "them against me". As I remarked:

I'm frustrated and disappointed in this program. Is it my fault? I feel completely shut out by the materials, like they don't care who I am, like their job is just to list all the information and it's my fault if I can't learn from them. (Diary, March 22, LLJ)

Most profoundly, the result of this growing division was the externalization of the locus of control. Rather than experiencing the learner empowerment I had hoped for, I suddenly felt disempowered and at the mercy of the context. Tragically, this feeling was amplified by my suspicion that I had been set-up to fail by the package promises. As I commented:

I am not going to apologize for not being able to learn Japanese using this program. I am showing up, every morning, going through the lessons and trying. I am pulling my weight. The program isn't meeting me halfway, isn't considering 
my needs. If I came into this with unrealistic expectations, those expectations were based on promises made by the programs in the first place. (Diary, March 19, LLJ

I must clarify that this feeling of disempowerment was especially true in the case of the Living Language programs. I did enjoy a better relationship with the Teach Yourself programs, but I wonder if this was not a product of a "good cop/bad cop" dynamic. For example, I felt much more comfortable with the Teach Yourself materials, by comparison they were very nurturing and supportive, yet the fact that I still failed to learn much of anything while following the programs cannot be ignored. In this case, I hesitate to give Teach Yourself too much credit, because my favourable impressions of the programs could be a result of my choice of sequencing. Had I followed the Teach Yourself programs first, I am not positive that I would have been as quick to praise them. This struggle at the learner-context interface to defend my learner beliefs and my identity as a good language learner was emotional and extremely trying. In the end, I recognize that the distance I created at the interface was self-protective and reactionary. Fortunately enough time passed between the experience of these emotions and the subsequent analysis of my diaries to achieve some amount of detachment from the disturbing events.

Although this discussion is fully representative of many diary entries, it is not representative of all entries. The next section will address some of the happier days. 


\subsubsection{Sense of success through noticing}

It is true that my journey had some very dark hours, but those times served to make the good days even better. The diary entries reflecting positive learning sessions all have one thing in common. They all refer to some instance of my ability to make connections and notice patterns in the L2s without the direction or help of the SILL programs. In other words, they all reflect events that reinforced my learner beliefs regarding my self-perception as a good language learner. They further reflect events that served to bolster my intrinsic motivation to invest myself in the learning context, as a result of finding pleasure in the process. As I observed:

I'm feeling so good today! I can already pick out some things without being told. Like I'm pretty sure the name for Wednesday, Mittwoch, can be broken down as "mid + week". And Schreibpapier, which means "paper", can be broken into "scribe + paper". (Diary, January 10, LLG)

I especially took great satisfaction from putting to use my knowledge of other languages. By pooling my familiarity with the lexis of several languages, I simultaneously found excitement in making connections independent from the materials and took great pleasure in exploiting my repertoire of L2s. As I recorded:

I'm really proud of myself. I figured out a few new things today without being told. For example, the word for "pen" is Feder, and although I couldn't place it immediately, I knew it made sense on some level. Then I made the connection between Feder and "feather", probably cognates, I reasoned. Then I remembered 
that the word for "pen" in French is plume, which translates literally in English as "feather". This is fun! (Diary, January 18, LLG)

Although noticing often involved using knowledge obtained outside of the SILL programs (as in the examples above), sometimes I was able to make connections by using information obtained within the SILL programs. As I noted:

Okay, I think I'm onto something. So, the months of the year all end with -gatsu, and I'm guessing that means "month". I already figured out that each month is constructed by saying "number + ending". So if I'm right that -gatsu means "month", then saying "January" is like saying "one-month", or something like "first month". If I'm right, this is an easy way to remember the names of the months. Why didn't the book point this out? I feel like a superstar. (Diary, March 21, LLJ)

Taking time to make these kinds of connections is an example of a strategy I used to cope with the ambiguity of learning in a teacherless context. In a classroom-based context, I would have had no qualms about putting up my hand and asking the teacher to explicitly account for such patterns. However, having neither a teacher nor a native speaker around to answer questions and clear up ambiguities proved to be a huge adjustment. As I reflected:

Being able to notice things and make connections is important to lone learning because there isn't any one else around to make those connections for you, and the book certainly doesn't always do it. (Diary, January 15, LLG).

In the following section I will discuss other issues pertaining to coping with ambiguity. 


\subsubsection{Coping with ambiguity in a teacherless context}

As a lone learner I confronted ambiguity on a daily basis. This ambiguity manifested in many ways (e.g., course book errors, baffling explanations, opaque instructions, truncated answer keys, contradictions between (and even within!) programs, and so forth). Unaccustomed to lone learning, I found so much ambiguity to be a veritable obstacle, especially at first. As I recorded:

I'm just trying to do what the book tells me to do, but sometimes there are sections of the lessons that aren't accompanied by audio, and there are no instructions for what to do with these sections. It makes me anxious, like I'm missing out on something. (Diary, January 26, LLG)

As in this last excerpt, the frequent opacity of many of the course book instructions was a real issue. Although Crabbe (1993) and Wenden (1998) primarily argue for transparency in terms of strategy training (i.e., the need to explain the "why" of the activity in order to encourage the transfer of knowledge), I often found myself yearning for more transparency simply in terms of the "what" of the activity. As I remarked:

Some sections begin by saying 'Study these sentences' and some don't. What's the difference? Am I supposed to turn off the audio and spend extra time just on those particular sentences? It's not clear. (Diary, January 24, LLG)

Although opacity was a problem I often encountered in terms of instructions, I also encountered it in terms of explanations. As I noted: 
Japanese has at least three different ways to count from 1 to 10 . But there aren't any explanations for when to use what. Does this program think I have a Japanese roommate to fill in all the blanks? (Diary, March 14, LLJ)

Of course, some days I fared better with this than others. I developed a few strategies to get me through the worst of the ambiguities, such as exploiting knowledge of my other L2s and looking for patterns in the input (as described in the previous section). Another strategy was simply to guess. As I observed:

Guessing has played a huge role in this process. Without a teacher to ask the quick little questions, I either have to figure it out on my own or just forge ahead with a guess. (Diary, February 8, LLG)

One of the biggest challenges was in terms of working with activity answer keys. As I noted:

Worse than getting an answer wrong is not having anyone around tell you why the right answer is right. (Diary, March 22, LLJ)

Due to the nature of the activities, the answer keys for the Living Language programs were less of a problem to negotiate than those for the more open-ended Teach Yourself activities. As I remarked:

While I appreciate the open-ended activities, I never know if I'm doing them right because there usually isn't an answer key. And when there is a bit of a key, sometimes I think there must be more than one possible answer, because even if my answers don't really match up, I still feel like they could be okay. So I still don't know if I'm doing it right. (Diary, February 27, TYG) 
Another major issue, with respect to learning in a teacherless context, was coping with information overload - a different kind of ambiguity. With no teacher to mediate the more complex concepts, I frequently became overwhelmed by the density of certain lessons. As I remarked:

German has 28 different forms for the article! Three grammatical genders, four cases, a singular/plural distinction, and a definite/indefinite distinction. And it was all presented to me in a single lesson, in a single chart. And then, in the same lesson, I'm told that there are no rules for how to form plurals. The book actually comes right out and says that I need to memorize each word's plural form individually. When I read that I was filled with instant anxiety. (Diary, January 13, LLG)

I found that the Living Language programs, in particular, presented grammatical concepts in overwhelming concentrations of information. As I noted:

The entire German case system was just given to me in a single lesson. What a lot of information to pack into one sitting. I would have liked to have seen each case presented in its own lesson, with time to practice before moving on. I'm never going to learn like this. I just don't understand! (Diary, January 13, LLG) Despite my experience as a language learner, my coping strategies, and my multiple motivations and desires to acquire these $\mathrm{L} 2 \mathrm{~s}$, it was often these situations of unmediated overload that prompted me to skip over important lessons, resulting in my sense of failure and, ultimately, my total despair of success.

I can't believe how much information I just read and reread and then listened to and then reread and I feel like none of it sunk in. Today's lesson was absolutely, 
overwhelmingly, impossibly technical. I don't get it. I don't see how anyone can get it, presented in this way. Maybe I'll just skip it, learn it on the fly. Ha!

Famous last words. (Diary, March 26, LLJ)

Often the choice to design lessons in one way or another is based on underlying assumptions about language teaching and learning, which manifest in adopting one particular method of instruction over another (Brown, 1994). As previously alluded to, there are two approaches to language pedagogy of relevance to this study. These are: the Audiolingual Method and Communicative Language Teaching. I will describe these in more detail in Chapter 4. For now it is sufficient to say that my personal learning style did not always cohere well with the approaches taken by the SILL programs, as in the case of the choice by the Living Language programs to present large amounts of grammar in the form of charts and tables without contextual grounding. In the next section I will discuss other ways in which my personal learning style clashed with the SILL programs.

\subsubsection{Clash of styles}

Approaching the SILL context as an experienced language learner meant that I had already had lots of opportunity to experiment with and determine my personal learning style and preferred strategies. My metacognitive knowledge informed me that I learn best, for example, through visual and kinesthetic means, and that I remember new content better when it is contextually grounded. Many diary entries reflect my attempts to negotiate my learning style in and around the SILL context. As I remarked: 
Finally lexis is being introduced in short phrases instead of interminable lists. I hate studying words in isolation -I need some kind of context. I'm really pleased to be moving onto this, it feels like I've crossed some kind of threshold. (Diary, January 11, LLG)

As I described in an earlier section, it did not take a lot of work to glide through a learning session while using the Living Language programs. Although I admit to taking advantage of the effortless (though ineffective) "listen and repeat" set-up on some days, I was not afraid to really challenge myself when the programs made the challenge interesting. I found the Teach Yourself programs to be much more demanding, but simultaneously more engaging, as they worked better with my personal learning style. As I mentioned:

I can already tell the Teach Yourself programs are going to take a lot more work, but I think that's a good thing. There's lots of opportunity for active participation and interaction with the materials, which I know I can learn from. (Diary, February 10, TYG)

As well as needing new information to be contextually grounded, with lots of opportunity to interact with content in context, I have a preference for authentic-feeling activities. This preference most likely comes from the success I have enjoyed with insitu learning-or, in parallel, it is possible that I have been successful with in in-situ learning because I appreciate authentic activities. As I observed:

One thing that is really challenging is that not all the dialogues are translated anymore. Most of the lexis is introduced at some point previous to the dialogue, but it's tough to put it all together. Sometimes I can't make sense of it. But that's 
good. It feels a bit authentic. It's as close to real life as I'm getting right now. (Diary, February 18, TYG)

Overall, however, neither the Living Language nor the Teach Yourself programs were able to completely accommodate my personal learning style, by virtue of being SILL programs. By and by, I had to come to terms with the fact that my pseudoextroverted nature is not well-suited to lone learning. As I recorded:

The lack of authentic practice is really getting to me, and there's just no getting away from that in the SILL context. Does that mean these programs have nothing to offer me? I bet if I was living abroad I could use them quite happily to complement my in-situ learning, by building up my lexicon and clarifying grammatical points during down-times. (Diary, April 17, TYJ)

Aside from these general issues, two specific style clashes were salient in my diaries. These involved the SILL learning activities and the SILL audio materials.

\subsection{7.a Activities}

Part of trying to adjust my personal learning style to the SILL context meant negotiating learning activities that were not well-suited to me. This was especially true in the case of the Living Language programs. As I remarked:

I don't feel like the book is giving me any rein to work with the materials in ways that might better cater to my personal learning style. The matching and multiple choice activities are completely useless - way too easy for me, and too easy to 
cheat! How am I supposed to learn how to conjugate verbs if I'm never given the opportunity to practice? Multiple choice only teaches me to recognize the right answer, but passive recognition isn't going to help me in real life. (Diary, January 12, LLG)

Lack of appreciation for the Living Language activities made it very tempting to skip over them. As I mentioned:

The activities are boring and I don't believe they're worthwhile. I want to skip them, but I feel like I have to go through the motions. I just don't take them seriously. How can I learn Japanese by playing matching games? (Diary, March 16, LLJ)

In particular, I found the static presentation of content through the use of word lists and the ineffectual matching and multiple choice activities to be an irremediable problem with the Living Language programs. As I noted:

I feel like the omission of any and all writing activities in Living Language is a huge gap for me. I remember things better when I have to write them down and work with them, answering questions and doing activities that force me to create sentences, conjugate verbs, assign case, and so forth, instead of rote repeating and matching out of context - that's just not my style. Shouldn't I be writing paragraphs about my family at this point? Describing my daily routine? Recounting what I eat for breakfast and when I brush my teeth? (Diary, January $31, \mathrm{LLG})$

The place of writing in L2 learning is an issue much larger than this brief mention. Suffice it to say, of the four major skills of language learning (speaking, listening, 
reading and writing), writing is an oft-neglected and greatly under-rated fourth (see Harklau, 2002; Lam, 2000; Matsuda, 2001, 2003; Vann, 1981; Weissberg, 2000). Markedly, this neglect is not accidental. The emphasis of speech over writing is a fundamental characteristic of the Audiolingual Method (Brown, 1994), and one of the major criticisms against the now outdated method (Matsuda, 2001, 2003; Rivers, 1964). As this topic deserves much more attention than can be spared here, I will continue this discussion in Chapter 4, where I will argue for the importance of writing in L2 learning, and against the SILL programs (such as Living Language) that privilege speech over writing.

Another reason why I took issue with the Living Language activities was because they left very little opportunity to learn from mistakes. Once a matching activity was held against the answer key and the score was tallied, there was not a lot of incentive to go back and re-match the items paired incorrectly. As a result, activities felt more like tests, like evaluations that served to determine my worthiness in terms of whether I would advance or be held back. Conversely, I found the Teach Yourself activities to be a welcome break from those of Living Language. As I commented:

Teach Yourself activities are so much nicer than the ones in Living Language. They feel less evaluative, less right or wrong. In Living Language if I do well on an activity it's like I passed, if I do poorly, it's like I failed. If I pass I feel good, if I fail I feel discouraged and even embarrassed. In contrast, the Teach Yourself activities never make me feel like a failure. If I do poorly on one it's not a huge deal, just an opportunity to learn from my mistakes. I can go back and change my 
answer around, make it stronger. And there are so many different kinds of activities that I always do well on at least a couple. (Diary, April 5, TYJ) A second major clash of styles occurred with respect to the audio materials. The following section will present this issue.

\subsection{7.b Audio materials}

Very early on I realized, with some amount of tragic irony, that I am not an auditory learner. Sadly, I found that the use of audio materials did not cohere well with my sensory preferences. As I remarked:

I'm beginning to think I'm just not an auditory learner. I would much prefer to just read through the course book and complete activities. I mean, Japanese phonology isn't so tough. I could pick that up later, for now, I just want to be able to string a sentence together. (Diary, March 9, LLJ) As a result, I found that, although my instinct was to rely heavily on the course book, I felt obliged to spend time on the audio materials, believing that they would prove more useful in the long run, despite my difficulty to appreciate them. As I mentioned:

When reviewing, I'm not sure if I should listen to the audio, use the book, or try to do both. I know my visual recognition is way better than my auditory recognition, so maybe I should work harder on the listening component. I mean, isn't that what these programs are all about? But, while reading word lists is boring, listening to word lists being read is even worse! (Diary, January 11, LLG) 
In fact, I had a lot of trouble making the audio materials work for me. Part of the problem was that sometimes I felt rushed by the "listen and repeat" format, whereas sometimes I found it so monotonous that it could not hold my attention. As I reflected: This "listen and repeat" stuff is totally inadequate. There isn't time to listen to the speaker, read the German words, repeat the utterance, and check the translation with any kind of precision. So I have to either learn the course book lesson ahead of time, or keep pausing the audio track. It's frustrating. I want to be able to follow the audio and the book simultaneously. (Diary, February 8, LLG) Trying to find some successful compromise between my preference for visual learning and my commitment to fully exploring the audio component of the SILL programs proved to be too much for me. In the end, I persisted in my efforts to use the course books and the audio materials simultaneously, but, of course, it was largely unsuccessful, and likely to my own detriment.

\subsection{Discussion of major findings}

In this section I will sum up and discuss the major findings of the six significant trends identified in my learner diaries. I will organize these findings into two parts. The first part will focus on the findings pertaining to the affective factors and the second part will focus on the findings pertaining to the SILL programs. These two distinct parts are important because they reflect the two major parts of my literature review, as well as the major foci of Chapters 3 and 4 , respectively. 


\subsubsection{Affective findings}

Throughout the previous sections, in which I have described the six significant trends identified in my diaries, the most implicated affective factors were motivation, personal learning styles, metacognitive knowledge (including strategic knowledge), and learner beliefs.

Embarking on this study, I believed myself to be ready for self-instruction. This sense of readiness was on account of my self-identification as a good language learner. I believed myself to be both well-practiced in autonomous learning generally and in language learning specifically, as well having profited from many years of successful classroom-based and in-situ experience, which served to reinforce my confidence in my language study abilities. As a self-described independent learner, I felt capable of both determining my own learning goals and needs, as well as capable of self-monitoring and self-evaluation. Further, I saw myself as extremely motivated, which I predicted would greatly increase my chances for success. This motivation was both intrinsically seated, based on my love of foreign language study, and extrinsically seated, based on my intention to use the experience of lone learning as a major component of my MA thesis.

Unfortunately, it did not take long before my self-confidence was shaken. My need to progress through the programs at a steady pace, coupled with both overwhelmingly complex grammatical explanations and uninspiring activities (both of which I was frequently persuaded to gloss over without much care), resulted in painful and disappointing self-evaluations. Upon realizing that I was not developing the language skills and fluency I had hoped for, I experienced a mild identity crisis. Initially 
viewing the failure as my own, I quickly moved on to blame the materials for my inability to acquire the L2s, so as to defend my learner beliefs and my view of myself as a good language learner. Assigning blame to the materials initiated a divide at the learnercontext interface, at which point I began to refer to the programs in terms of 'them against me". At the same time, this attribution of fault resulted in the externalization of the locus of control. Instead of experiencing learner empowerment, which results from an internalized locus of control, I experienced feelings of extreme disempowerment.

These feelings of disempowerment only lifted at moments when I found myself capable of noticing and making connections independent of the materials. At these moments, I experienced relief, because these occasions served to reinforce my learner beliefs and self-identity. Further, I felt increased motivation to continue on with the journey, as I was reminded of the pleasure I take in language learning. These instances of noticing often occurred through the application of my preferred strategies. Strategically using the knowledge I had acquired during the study of other languages and the study of theoretical and applied linguistics, I was often able to make connections, identify patterns, and more or less cope with the frequent ambiguity, opacity, and complexity of the course book instructions and explanations.

However, one obstacle that I found difficult to navigate around was the clash I experienced between program instructional approaches and my personal learning style. I encountered problems adjusting my visual and kinaesthetic learning style to the auditory style of the materials. I further struggled to work my way through the learning activities that were not well-suited to my needs and goals. The lack of contextually grounded input and the absence of authentic input further worked again my metacognitive knowledge, 
which informed me that I need both context and authenticity to find success in foreign language learning.

\subsubsection{Findings pertaining to SILL programs}

In terms of the SILL programs, the two most significant findings pertain to learner preparation and support. Although I initially considered myself as already adequately prepared for lone learning before the outset of the study, I did remark with appreciation on attempts by the Teach Yourself programs to prepare me further by addressing the reality of lone learning, and by prompting me to reflect on the specialized context and challenges unique to SILL programs. I further appreciated the attempts to foster autonomy by inviting me to reflect on my personal learning style, as well as my specific needs and goals. To accommodate these needs and goals, I was grateful to see options built into the Teach Yourself programs, thus providing me with some amount of flexibility to tailor the context to my specifications. I was disappointed to find nothing of this nature in the Living Language programs.

In terms of learner support, the Teach Yourself programs were exemplary in their suggestions of study tips and learning strategies. Although I still encountered issues with respect to opaque instructions and explanations, there were obvious efforts made to be more transparent throughout the course book. The Living Language programs, on the other hand, were not nearly as conscientious in this respect. I recorded only one 
suggestion of a learning strategy, and overwhelming opacity in nearly all instructions and explanations.

Finally, my transactions with the materials at the learner-context interface were found to be markedly opposite. With the Teach Yourself programs, I felt supported and encouraged, while, with the Living Language programs, I felt abandoned and antagonized. As I argued in Chapter 2, the site of learner empowerment is the learnercontext interface. For this reason, it is the divide I experienced with the Living Language materials at this interface that removed any hope of finding learner empowerment while following those programs. In the case of the Teach Yourself programs, had I taken more time with the materials and not been so discouraged by my previous experiences with the Living Language programs, I may have found learner empowerment there. Yet, I doubt it. Because I do not believe I would have ever been able to realize the claims and promises made on the packages, I feel that I would have always felt some sense of failure. For me, my expectations to "[s]peak Japanese with confidence in just 6 weeks" (Living Language, box) and “[achieve] everyday communication" (Teach Yourself, box) would have always eluded me, leaving me with a feeling of disempowerment.

\subsection{Conclusion}

In Chapter 3, I have presented a narrative of my journey as a lone learner from start to finish. As I have already admitted with some amount of sheepishness, I did not learn to speak German or Japanese via these SILL programs. As a linguist and a researcher, that 
outcome is interesting and something to be investigated, as I have done here. As an enthusiastic language learner, that outcome is disappointing and regrettable. I earnestly wanted these programs to live up to their claims. For me, the idea of simultaneously acquiring two foreign languages and an MA degree was nothing less than intoxicating.

In the end, alas, I can only claim to have acquired a very basic morpho-syntactic understanding of how the two languages work, along with a handful of words and phrasal chunks. Pressed to do so, I could probably introduce myself to a stranger, order a coffee, and, on a very good day, describe the members of my family in both languages with minimal errors and a mostly comprehensible accent—certainly not the conversational fluency I was aiming for, based on the promises made to me by the SILL packages. What upsets me most is the decision by the SILL publishers to sacrifice realistic learning expectations for outlandish promotional guarantees. The trade-off of selling lots of programs by way of these inflated promises is setting learners up to fail (in terms of what the packages claim is possible). As an ESL instructor, the very idea of making myself look good at the expense of my students' sense of success is unfathomable. I was shocked to receive, as a reply to an email I wrote inquiring about the high drop-out incidence of learners using SILL programs, the response "I think they [learners] have unrealistic expectations. Many (most!) just buy the book/package and don't even open it. Of those that do open it, most don't get beyond the first unit" (Catmur, G., Project Editor for Teach Yourself, personal communication, 7 March, 2005). Is a learner to be blamed for unrealistic expectations upon purchasing a package that declares " $[t]$ he proven way to learn a language" (Teach Yourself, box) when her most sincere efforts are unsuccessful? 
Perhaps it is some amount of conceit that allows me to assume that because I could not learn via these programs, no one can. I will be the first to admit that I am not well-suited to this mode of SILL. My most successful language learning experiences have all come from situations of in-situ learning, where I have had no choice but to put all my communicative strategies to use - or else not eat! However, Jones (1995) raises a similar question (concerning his difficulty to autonomously develop learning activities to compensate for inadequate learning materials), when he asks "if an experienced language learner finds designing autonomous activities overburdensome, what hope is there for the inexperienced?" (p. 109). My intention is not to sound condescending, rather, to show concern for what other lone learners face upon embarking on a SILL program. If publishers only show concern for their sales indices, and applied linguists and language pedagogues disregard the programs altogether, what is to become of lone learners without the discipline-specific knowledge to disassociate their failure to live up to package promises from their abilities as language learners? If neither the SILL industry nor the professional community will look at these programs critically, how can the typical lone learner be expected to?

With those questions in mind I will turn to the second major focus of the study and present a critical discussion of SILL programs in Chapter 4. There, I will synthesize the findings of my diary study with the design criteria for SILL programs, as introduced in Chapter 2, in order to critique the programs I followed and, ultimately, to formulate some practical recommendations for SILL program designers, which will be presented in Chapter 5 . 
Chapter 4: Critique of the SILL programs 


\subsection{Introduction}

In this chapter, I will first address such issues as pedagogical methods and approaches to language instruction, as well as the neglect of writing in L2 learning (and, most crucial to this discussion, in the SILL context). I will go on to revisit the evaluative instruments that propose assessment criteria for SILL program design (as presented in Chapter 2). Based on the insights I gained from my personal experience as a lone learner, I will synthesize and highlight some of the design criteria that is most pertinent to the SILL context and, ultimately, of most practical value to lone learners and SILL program writers. Using these design criteria, I will conclude the chapter with a more thorough critique of the four SILL programs.

\subsection{Introduction to pedagogical methods: A note on why methods matter}

As I mentioned in my diary analysis, a writer's choice to design SILL programs in one way or another is based on underlying assumptions about language teaching and learning, which manifest in adopting one particular method of instruction over another (Brown, 1994). As previously alluded to, there are two approaches to language pedagogy of relevance to this study. These are: the Audiolingual Method (ALM) and Communicative Language Teaching (CLT). The former is an established pedagogical method characterized by a body of tenets, which direct all pedagogical activity. In contrast, the latter is more of an approach characterized by a common goal, which is to focus all 
pedagogical activities on meaningful communicative tasks. As an approach, there is no single way to go about CLT, rather, pedagogical activities are all the means to a meaningful and communicative end.

As Brown (1994) explains, for the writer to adopt one method or approach over another is to make a very strong statement about her view of language teaching and learning, if not a strong statement about her view of language itself. For example, the adoption of ALM indicates a view of language as a hierarchical system of rule-governed structures. The adoption of CLT indicates a view of language as a system existing for the purpose of exchanging meanings. Further, whereas proponents of ALM have a behaviorist view of language learning (where learners are trained through modeling to produce the desired response), proponents of CLT have an interactionist view of language learning (where learners develop their abilities to communicate through meaningful interactions). It is difficult to imagine two more diametrically opposed views of language teaching and learning. For this reason, when such views direct a writer to adopt one approach over another, the effects on the materials are profound. The choice to teach language through a "listen and repeat" (i.e., behaviorist) set-up versus the choice to teach through meaningful communicative activities radically affects the learning context.

Many of the SILL series boast their own methods (e.g., Living Language advertises "the speed-learning method" (box), and Instant Immersion advertises "[t]he Euro Method" (box)) as being developed by experts (cf., "[c]ontent written and developed by university professors and linguistic experts" (Instant Immersion, box), and “developed by U.S. government experts" (Living Language, box)). Hayet (1990b) critiques the tendency for SILL programs to promote their homegrown "science": 
It does not really seem to matter if all the "revolutionary" foreign-language learning methods have to advocate is to listen to tapes half an hour a day or recommend you should do it "the natural way". The methods have received a scientific seal of approval; they have actually been designed scientifically or by scientists. Alleged scientific backing softens abusive claims and eventually confers a certain amount of respectability. (p. 11)

Nevertheless, the methodologies of most SILL programs can be identifiably traced back to adaptations of more established methods and approaches to language pedagogy. The "speed-learning method" (box) advertised by Living Language is an obvious adaptation of ALM to suit the SILL context. Conversely, the method adopted by Teach Yourself, advertised as being "[t]he proven way to learn a language" (box), is an example of a communicative approach to language teaching. I will elaborate on this argument below. Another issue I first addressed during the analysis of my diaries was the neglect of writing activities in the Living Language programs, a neglect that, unfortunately, is pervasive to other areas of L2 learning also (see Harklau, 2002; Lam, 2000; Matsuda, 2001, 2003; Vann, 1981; Weissberg, 2000). Because one of the tenets on which ALM is based is the belief that speech should precede writing in L2 learning (Brown, 1994), SILL programs that adopt ALM as their pedagogical method will tend to de-emphasize writing. Following my introduction to ALM and CLT, I will discuss the role of writing in L2 learning, as well as a short example of how writing can be a successful means to improved speech. I will use this example to support my critique of SILL programs that do not include writing activities as part of their curricula, as in the case of the Living Language programs. 
CLT is the currently favoured approach to language pedagogy (at least this is true for most parts of North America, where I have conducted my research). As such, I will begin with a discussion of CLT before moving on to a discussion of ALM, which, in the past twenty years or so, has fallen out of favour in most SLA contexts. Remarkably, it is still flourishing in the context of SILL programs.

\subsubsection{Communicative Language Teaching (CLT)}

As described by Brown (1994), CLT is a pedagogical movement of the latetwentieth century that aims for a communicative approach to language teaching. Proponents of this approach believe that:

1. "Language is a system for the expression of meaning" (p. 70).

2. The learner's role is as an "interactor giving as well as taking" (p. 71).

3. The teacher's role is as a "facilitator of the communication process, participants' tasks, and texts" (p. 71).

4. Activities should "[e]ngage learners in communication, involve processes such as information sharing, negotiation of meaning and interaction" (p. 71); therefore, emphasis is on activities "involving real communication, carrying out meaningful tasks and using language which is meaningful to the learner" (p. 70). 
5. Materials have their "[p]rimary role in promoting communicative language use" (p. 71). As such, they should be "task-based... [and] authentic" (p. 71).

The Teach Yourself Beginner's Series seems to make use of an instructional approach with an underlying relationship to CLT. The Teach Yourself programs base their lessons around a variety of interactive and meaningful task-based activities, with a minimum amount of drills and repetition. These programs take responsibility for providing opportunities to practice the skills of communication and expression, and for facilitating those opportunities in any way possible. The learner is responsible for selecting appropriate activities for her needs, completing learning activities, identifying and employing learning strategies, self-evaluation, and interacting with the materials in ways that she finds helpful.

\subsubsection{Audiolingual Method (ALM)}

As described by Brown (1994), ALM is a pedagogical movement of the midtwentieth century that sets its tenets on a behaviorist approach to language teaching. Proponents of this method believe that:

1. "Language is a system of rule-governed structures hierarchically arranged" (p. 70).

2. "[S]kills are learned more efficiently if oral precedes written" (p. 70). 
3. Learners are "[o]rganisms that can be directed by skill training techniques to produce correct responses" (p. 71).

4. The teacher is "[c]entral and active... provides [the] model, controls direction and pace" (p. 71).

5. Activities are "[d]ialogues and drills, repetition and memorization, [and] pattern practice" (p. 71).

6. Learning takes place through "analogy not analysis" (p. 70).

The Living Language Complete Basic Series seems to make use of an instructional approach with an underlying relationship to ALM. These programs base their lessons around drills, repetition, and memorization, with an emphasis on speaking practice over writing practice, and the expectation that finer grammatical points will be learned inductively. The programs are responsible for controlling the activities and providing the models, while the learner is responsible for following the directives of the programs and being trained in the process to produce the desired effect.

\subsection{2.a The role of writing}

One of the defining features of ALM is its emphasis on the oral, as opposed to the written, mode (see ALM criteria number 2). This is an extremely relevant issue in the SILL context, where many programs primarily make use of learning activities that can be easily fitted with an answer key (e.g., matching, cloze passages, and multiple choice) and 
consequently do not give opportunities for writing practice. Although the use of these kinds of answer keys can facilitate the process of self-evaluation in a teacherless context, it can also result in limited and static opportunities for the learner to interact with the L2. By not asking her to manually manipulate the new lexis through writing in messagebased tasks (using processes such as conjugation, pluralization, case-marking, and so forth), the programs deny her the opportunity to work with language creatively in the written form. Consequently, the programs ignore an entire group of learners whose personal learning style may be kinaesthetic. The idea that it is possible for a learner to acquire a language by passively listening to it and repeating what she hears goes against current thinking.

The two output modes of language learning are speaking and writing. Without a real-life conversation partner, speaking the $\mathrm{L} 2$ can be fairly unrewarding. Writing, on the other hand, is a viable output mode in the SILL context, which affords valuable output practice to the leaner. So why do many SILL programs skirt around it, even while promising that following their programs will "make it easy to learn to speak, read, and write" (Kleinmann, 1993, p. xv; Storm, 1993, p. xv), as in the case of the Living Language programs?

In fact, many researchers (e.g., Harklau, 2002; Matsuda, 2001, 2003) argue that the area of writing in all L2 learning contexts has been largely neglected. Matsuda (2001, 2003) cites the popular belief that this neglect is due to the rise of ALM in the late 1950's. As introduced above, ALM is based on assumptions of SLA pedagogy that privilege speech over writing. However, Matsuda argues that this emphasis cannot be 
blamed on ALM entirely, as it first took root in the ideology of scientific linguistics in the late nineteenth century.

However, the place of writing in L2 learning has been tenuous at best throughout all pedagogical shifts (Brown, 1994). To illustrate this, one must look only briefly at the place of writing in the four major pedagogical movements of the last century, as described by Brown (1994). First was the grammar translation method, wherein writing was central to all curricular activities. Next was the Direct Method, wherein writing became peripheral, based on the notion that in first language (L1) learning writing is the last of the four major skills (i.e., listening, speaking, reading, and writing) to develop and consequently this order should be mimicked in L2 learning. Next was ALM, wherein writing continued to be peripheral as curricular activities were centered around drills of "listen and repeat". Finally, there is the current adoption of CLT, wherein writing is incorporated into curricular activities through meaningful tasks.

As writing has moved from being an exclusive focus, to being systematically purged from the curriculum, to being reinstated for general communicative purposes, advocates of the importance of writing in L2 learning (e.g., Harklau, 2002; Hudelson, 1993; Kreeft Peyton \& Staton, 1993; Kroll \& Vann, 1981; Staton et al., 1988; Weissberg, 2000) have cause for concern. Many of these researchers (e.g., Harklau, 2002; Vann, 1981; Weissberg, 2000) question the pedagogical emphasis on what Vann (1981) calls the "carefully sequenced chain of learning: listening, speaking, reading and writing" (p. $155)$, in which writing is seen as an afterthought to speech.

Carroll (1999, as cited in Harklau, 2002) explains that "[e]very theory of second language acquisition hypothesizes that learners come to know the grammatical properties 
of some language by being exposed to instances of it in meaningful conversation [italics added]" (p. 332). From this statement one can deduce that the neglect of writing is not necessarily because teachers regard writing as unimportant, but that they simply regard speech as more important. Therefore, if research can show that writing actually enhances speech, instead of simply robbing time from speech in the curriculum, it is possible that writing could move from the periphery of SLA to claim a more central place in the L2 curriculum. In the following section, I will provide an example of a lone learner for whom writing did enhance speech.

A current classroom-based CLT trend that explores writing in the L2 curriculum is the use of learner diaries written in the L2 (introduced in Chapter 2). Journaling has gained more and more popularity among researchers and teachers (e.g., Hudelson, 1993; Kreeft Peyton \& Staton, 1993; Staton et al., 1988)-yet primarily as a means to bridge the gap between speech and composition, and less so to develop L2 fluency in general, in such a way as to encourage and facilitate oral proficiency. This unidirectional view of the speaking-writing phenomenon (that improved speech lends itself to improved writing, but not vice versa) is an area in need of further investigation. Neglecting the possibility that diaries might develop oral proficiency, advocates of journaling (e.g., Hudelson, 1993; Kreeft Peyton \& Staton, 1993; Staton et al., 1988) promote the potential of this practice primarily to develop writing skills. Arguing that "journals could contribute to the development of fluency in written language" (Hudelson, 1993, p. xi), these researchers see "journals as a context for writing development" (Kreeft Peyton \& Staton, 1993, p. 3), advising students to begin by writing 'like you speak', wherein '[t]he 
underlying assumptions are that writing is highly dependent upon speaking and that speaking is primary" (Kroll \& Vann, 1981, p. vii).

Despite the marginalization of writing within L2 learning research, Harklau (2002) claims that writing is "key to understanding SLA in...classrooms where literacy plays a central role in communication" (p. 329). She goes on to argue that "[w]hile toddlers do not say and write their first word on the same day, classroom-based second language learners may do exactly that" (p. 334). Harklau, among others (e.g., Weissberg, 2000), claims that within the limited, albeit expanding, research in the field of $L 2$ writing, there has been a secondary imbalance in emphasis. This field, she argues, privileges the study of how students learn to write in their L2, without considering how students learn their L2 through writing. As Harklau stresses "I believe we need to understand and articulate why...applied linguists seem much more likely to ask how students learn to write in a second language than to ask how students learn a second language through writing" (p. 332).

In her observation of an ESL classroom, in which she hoped to collect data on the types of face-to-face communicative interactions occurring between teacher and student, Harklau (2002) made a disturbing discovery. She found that the majority of students had fewer than two dialogic interactions with the teacher over the course of a day, and that these interactions were for the most part limited to monosyllabic exchanges. Yet, when she asked herself if these students were learning English, "the answer was clearly yes" (p. 331). If yes, she next asked herself, how? She observed that, given the choice between following along in the course book and listèning to the teacher's simultaneous lecture, the students generally devoted their attention to the textual support over the oral delivery. 
One very telling incident involved a student spelling from memory a new vocabulary term that he wanted to make use of but could not pronounce. On this day, the teacher held up a picture of a silhouette and asked the class what she was holding. The student raised his hand and said "“Oh! Is it a s-i-1-h-o-u-e-t-t-e?" (p. 331). Clearly these adult students, already literate in their L1, are using literacy in their L2 to assist their acquisition of English.

Further, a study by Weissberg (2000) tracking the progress of five ESL students over three and a half months found that grammatical accuracy and the occurrence of new morpho-syntactic forms appeared first in the students' writing, and only after in speech. In fact, overall gains in writing accuracy were more than double the gains made in speech during the period of observation. This notion of writing preferred over speech as the primary medium for the appearance of increased linguistic proficiency seems to support the idea that L2 learning can and does occur through writing. In his argument, Weissberg goes so far as to claim "[i]t seems clear that the L2 composition classroom is not just a place to learn about writing; for some students it may be the best place to learn the new language" (p. 52).

A third example comes from Lam's (2000) study of the Internet used to assist L2 literacy and linguistic development. This study documents how electronic chatting transformed a frustrated and struggling ESL student into a fluent and passionate English speaker. Over the period of one year, this student, through the use of online interactions with native and non-native speakers of English, created a virtual world in which he felt comfortable to express himself, to test out linguistic hypotheses, and to participate in authentic discourse. Through these written interactions he found new motivation to 
increase his fluency and new confidence in his communicative abilities, both of which later transferred from his virtual world interactions to his real world interactions.

A final example comes from a student at Carleton University. In a discussion of the uses of literacy in the L2 classroom, he confided "[w]hen I'm speaking, it's like I'm reading. It's impossible to use a word before I've read it" (Admed, S., personal communication, 18 March, 2005). This student and, it would not be improbable to say, many others like him link their oral proficiency to their L2 literacy. Yet almost no acknowledgement of this phenomenon is mentioned in the literature. Clearly the above examples indicate that there has been a neglect in the research to identify the effect of writing on the oral proficiency of $\mathrm{L} 2$ learners.

The emphasis on speech over writing found in many of the SILL programs for sale today, a possible result of the adoption of ALM as the underlying method of instruction, is potentially a harmful one. In the SILL context, where opportunities to interact with the $\mathrm{L} 2$ are already drastically limited by definition, to deny the lone learner the opportunity to work creatively with the L2 through writing only restricts her learning further. As a lone learner with a preference for kinaesthetic learning, I often felt that by not providing me with opportunities to work with the $\mathrm{L} 2$ creatively, and by not encouraging me to manually manipulate the new lexis in message-based tasks (through processes such as conjugation, pluralization, case-marking, and so forth), that I would never be able to accomplish these feats in speech. As a highly literate L2 learner, it only makes sense for me to use every tool I have on hand to manage the onerous undertaking that is SLA. As I remarked in my learner diary: 
These matching activities are too easy. With so many cognates, finding the match to a sentence containing words like "taxi" and "coffee" are a cinch. Actual translation (although tedious) would be a better option, because in order to do that I would have to look up all the grammatical stuff like case and gender, as well as the vocabulary. That way it would still be easy to mark the answer for right or wrong, but I would actually have to pencil in the German translation, instead of just guessing the correct match from a list. I think just the simple act of writing would help a lot. (Diary, January 19, LLG)

In the following section I will return to Jones's $(1994,1995,1996)$ study (first described in Chapter 2) to briefly provide an example of a lone learner who successfully used writing as a way to enhance his L2 oral proficiency.

\subsection{2. b Writing to speak: Diary of a lone learner (Jones, 1994, 1995, 1996)}

In his study, Jones (1996) asks:

Logically, learners should acquire most automaticity in those skills (e.g., fullspeed listening, formal writing) which they practice most...But can automaticity acquired in one such skill be transferred to another (a crucial question in selfinstruction, where realistic practice in speaking is difficult to obtain)? (p. 37) It is to this precise question that I will now direct my attention. Jones (1994, $1995,1996)$ had no contact with native speakers of Hungarian until the eighth month of his eleven-month study. Before this time his only source of language input was in the 
form of reading-both course books and authentic Hungarian sources. He had no opportunity to listen to spoken Hungarian by way of recorded materials or authentic discourse. Further, he had no opportunity to speak Hungarian, except to himself, on which Jones (1994) reports "though I found myself doing this whilst alone, it appeared to have no consciously observable effects on my performance with a real interlocutorperhaps because real interlocutors allow you much less message formulation time" (p. 450). His primary means of interaction with the target language was through the introspective diaries, which he wrote exclusively in Hungarian. He credits this process of journaling in the $\mathrm{L} 2$ as being central to his overall acquisition, asserting that, although this practice "involved much investment of time and effort...it presumably aided acquisition not only through the 'deep' semantic processing needed for handling real messages...but also through repeated working-memory overload" (p. 448).

Crucial to this present discussion, in the eighth month, Jones $(1994,1995,1996)$ spent three weeks visiting friends living in a Hungarian community in Northern Serbia. This holiday marked the first occasion on which Jones could put his acquisition of Hungarian to the test. Remarkably, Jones (1994) found that:

[W] hat was surprising - especially when compared with the prevalent (if recent) methodological belief that without extensive communication practice activities, you condemn learners to tongue-tied dysfluency once they have to deal with reallife language situations-was how quickly the knowledge from months of language study became available for speaking. (p. 450)

Further describing his first spoken interactions, Jones reports that: 
In the course of conversations with a native-speaker in the $8^{\text {th }}$ month, it took about 5-6 hours to build up a reasonable fluency ([marked by] chunked phrases rather than word-by-word production; risk taking; willingness to focus on message and let the form take care of itself). (p. 450)

Significantly, Jones (1994) goes on to question "[s]ometimes automaticity seemed to be already in place (was there perhaps some carry-over from writing fluency here?)" (p. 450). Or, Jones (1996) suggests "perhaps because, as Meara (1993) implies, underlying lexico-grammatical access was reasonably fast as a result of free writing" ( $p$. 141). In my view, the answer to this riddle is obvious enough. Having relied almost exclusively on writing in the L2 for language production practice, and having had no occasion to practice speaking Hungarian, when Jones finally had his opportunity, the necessary speaking fluency was available to him. Clearly this shows that, in Jones's case at least, transfer from writing proficiency to oral proficiency is possible. To explain this unexpected fluency, Jones (1996) offers:

Though oral output practice is vital for spoken fluency, it seems that it need not happen in the same time-frame as input. If this experience - one at odds with a core assumption of recent classroom methodology-is generalizable to at least some other learners, it removes one of the key theoretical objections to selfinstruction: that its lack of interactive practice is an insurmountable barrier to oral fluency. (p. 141)

With respect to the problem of how writing prepares the L2 learner for speaking, Jones (1994) claims that "[n]ot all message focus need be interactive—in writing, for example, an imaginary reader may well be almost as good as the real thing" (p. 443). 
Therefore, through reflective journaling with no intended audience aside from himself, Jones managed to establish the linguistic fluency in writing that he would later carry over to enhance his oral proficiency.

Another possible explanation for this transfer is the use of formulaic language. Formulaic (or holophrastic) language is the phenomenon of learning strings of words as unanalyzed chunks. For example, initially many $L 2$ learners might memorize and produce the phrase "how do you do?" without being able to segment it into morphemes (e.g., preposition, verb, pronoun and so forth) until later on in their acquisition. Jones (1996) seems to have relied on formulaic language a great deal, reporting that "[f]or grammar memorization, holophrastic examples of use (especially if selected by myself) appeared more readily useable for production and reception than noun and verb tables" (p. 136). One notable diary entry states "[i]t seems that it is easier to learn sentences or expressions instead of lone words [ $3 \frac{1}{2} / 2$ months]" (p. 138). This is one possible explanation for Jones's relatively easy transfer of his writing ability to his speaking ability. The formulaic language practice over months of journaling could have played a large part in his unexpected oral proficiency.

Jones (1996) further offers, "[a]s for practice, research indicates that formal manipulation is less effective than message-based work for the automatization of grammar" (p. 136). This claim predicts that, had Jones chosen to follow only the SILL course books with their tiresome and static grammar tasks, and had he not devoted so much time to his real message-based diaries, his first experience speaking Hungarian may not have been quite as successful. 
From this discussion, there is evidence to support an affirmative answer to the question: Can oral proficiency be enhanced through writing? In the case of Jones (1994, $1995,1996)$, the absence of native-speaker contact and recorded materials forced him to restrict his study of Hungarian to reading and writing, yet when given the opportunity to speak, the language fluency was there.

\subsection{Evaluative instruments revisited}

In terms of what I found to be most important to SILL program design, I have made a few essential features quite clear. These features include: learner preparation, learner support, learning activities that provide a variety of ways to work with the L2 creatively (particularly through writing), and the absence of claims that would lead to unrealistic expectations on the part of the learner. I will discuss each of these criteria in turn, highlighting where they might be located within the evaluative instruments proposed by Hayet (1990a, 1990b), Dickinson (1987), Roberts (1995), Jones (1993, 1996), and Antenos-Conforti (1998). Although none of the researchers account for all four of these features in their evaluating instruments, Dickinson, Roberts, and Jones each account for three of the four. 


\subsubsection{Learner preparation}

Learner preparation, as I have described it, involves such things as addressing the learner's beliefs about language learning and readying her for autonomy. In Chapter 2, I presented both of these topics and discussed their vital role in successful lone learning. However, of the five researchers, only Dickinson (1987) and Jones $(1993,1996)$ devote any criteria to learner preparation in their instruments.

In terms of readying a learner for autonomy, both Dickinson (1987) and Jones $(1993,1996)$ recommend a clear declaration of objectives on the part of the SILL program. This falls under the Clear statement of objectives criterion in the case of Dickinson, and the Learning objectives criterion in the case of Jones. Such a declaration requires the learner to identify her learning needs and goals in order to judge whether or not the SILL program is suitable for her. In his Flexibility of materials criterion, Dickinson also stresses the need for materials to have some degree of built-in flexibility, in order to cater to different learning styles and preferences. This capacity to identify needs, goals, and preferences is an important aspect of learner independence, as described by Cotterall (1995). Another aspect of independence is the ability to self-evaluate. In his Advice about record keeping criterion Dickinson further recommends that the SILL program supply suggestions for keeping a learning record so that the learner can monitor and evaluate her progress throughout. 


\subsubsection{Learner support}

Equally as essential to successful lone learning is the provision of learner support by the SILL program. The two facets of learner support I have most emphasized are fostering autonomy and strategy training. Criteria for these are found in Dickinson (1987), Roberts (1995), and Jones (1993, 1996).

In terms of fostering autonomy, an important suggestion by Dickinson (1987) is the inclusion of some form of support with respect to progression, which falls under the Advice about progression criterion. By beginning the SILL program with a needs analysis and a learner contract, the learner who loses motivation and has difficulty monitoring her progress can return to these documents for support and direction.

While Roberts (1995) only makes a brief mention of learner support under the Pedagogical analysis criterion, both Dickinson (1987) and Jones (1993, 1996) devote entire discussions to this topic. In Dickinson's Language learning advice criterion and Jones's Relationship with the learner criterion, fostering autonomy through strategy training plays a central role. Both criteria recommend that programs provide study tips, autonomy training, learning strategies, and advice about accommodating personal learning styles. In further relation to strategy training, Dickinson places a heavy emphasis on the need for transparency in explanations and instructions, as is evident in both the Learning instructions criterion and the Motivational factors criterion. 


\subsubsection{Learning activities}

With respect to learning activities that provide a variety of ways to work with the L2 creatively, along with opportunities to do so through the written mode as well as other modes, the consensus is fairly unanimous, as Dickinson (1987), Roberts (1995), Jones (1993, 1996), and Antenos-Conforti (1998) all make some kind of mention in favour of this.

In his Exercise materials and activities criterion, Dickinson (1987) emphasizes the need for learning activities to take a variety of different forms and to sufficiently cover the content in question. In his Communicative analysis criterion, Roberts (1995) stresses the need for activities to incorporate diverse opportunities for authentic communication. Jones $(1993,1996)$ stresses, in his Role of materials criterion, the importance of a mixture of different kinds of activities. Finally, in her Exercise types criterion, Antenos-Conforti (1998) emphasizes the need for activities to provide opportunities to practice a range of different skills. All of these authors further highlight the need for activities to be level appropriate, to be feasible in the SILL context, to be accompanied by easy-to-understand instructions, and to have the capacity to maintain the learner's interest. 


\subsubsection{Unrealistic claims}

In the analysis of my learner diaries I conveyed the kind of damage that can result from the use of unrealistic promises and claims by SILL publishers to promote and sell their packages. Although the peril of such claims is chiefly Hayet's (1990a, 1990b) territory, this issue is also broached by Roberts (1995) in his evaluative instrument under the Pedagogical analysis criterion, where he addresses "whether claims made for the course by its publishers were consistent with what was in fact offered, [and] whether any timescale for learning specified by the publishers was realistic" (p. 515).

Hayet (1990a, 1990b) argues against a plethora of advertised claims made by SILL packages, which she terms "the linguistic mythologies" (Hayet, 1990b, p. 9). These range from unrealistic expectations in terms of how long it will take to learn the L2, a learner's freedom to learn the L2 while going about other chores, the supposed ease and fun of learning the L2, how learning an L2 is like learning an L1, how learning an L2 has never been easier thanks to scientific methods, and so forth. Hayet argues that all of these claims are more or less damaging and result in unrealistic expectations on the part of the learner-expectations, as I illustrated through the analysis of my learner diaries, that can be quite devastating. 


\subsection{Critique of my four SILL programs}

In the following section I will critique the four SILL programs I followed using the evaluative criteria presented above. Because both of the Living Language programs are identical to the point where they seem to have been written around a fairly rigid template, I will be discussing them together. However, the two Teach Yourself programs are dissimilar enough that I have chosen to discuss them separately.

\subsubsection{Living Language Complete Basic German and Japanese}

In my opinion, the Living Language Complete Basic Series (German and Japanese) (Kleinmann, 1993; Storm, 1993) is lacking in all four criteria.

In terms of learner preparation, the program objectives are extremely unclear. The declaration "Living Language German [or Japanese] makes it easy to learn how to speak, read and write German [or Japanese]" (Kleinmann, 1993, p. xv; Storm, 1993, p. $x v)$ is outrageous. The idea that these programs make it easy for the learner to accomplish any of these skills through the limited, uninspiring, and pithy lessons is difficult to believe, yet, without any opportunity built into the programs to practice writing in the $\mathrm{L} 2$, this claim that the programs teach writing is the most contemptible. Similarly lacking in the programs is any amount of built-in flexibility. The lessons proceed in a linear fashion, each building on the next. Therefore the learner, lest she should miss some vital information which would return to haunt her later, must work 
through every one of the lessons, whether she wants to learn the vocabulary for apartment hunting or not. As such, these programs never address the learner's needs, goals, or personal learning styles.

I further find these programs remarkable for the lack of learner support offered throughout. The most that is given in terms of learning strategies and study tips is almost exclusively confined to two sections at the beginning of the course book. The introduction counsels "[h]ear it, say it, absorb it through use and repetition" (Kleinmann, 1993, p. xv; Storm, 1993, p. xv). The instructions section further advises "[r]ead Lesson 1 all the way through...Start the recording, listen carefully, and say the words aloud in the pauses provided...keep repeating the lesson until you are comfortable with it" (Kleinmann, 1993, p. xix; Storm, 1993, p. xix). The Japanese course book makes a later attempt to assist the learner through a particularly complex lesson, by offering “[d]on't try to memorize anything; just read each section until you understand every point. Then, as you continue with the course, try to observe examples of the points mentioned" (Storm, 1993, p. 33); however, other such attempts are few and far between.

The learning activities offered by the Living Language Complete Basic Series are extremely disappointing. Only two types of activities are presented. These are: multiple choice and matching. These learning activities offer no variety in terms of the activities being presented or in terms of the skills being practiced - and absolutely no opportunity to work with the L2 creatively through writing (or even through speaking, for that matter!).

Finally, with respect to unrealistic claims, the promise "[s]peak German [or Japanese] with confidence in just 6 weeks" (Living Language, box) is an exaggeration at 
best, as shown by my study. After six weeks following this program, I did not even come close to such results, despite my most sincere efforts.

\subsubsection{Teach Yourself Beginner's German}

I found the Teach Yourself Beginner's German (McNab, 2003) program to be quite good, with regards to the four criteria.

In terms of learner preparation, the program objectives are easy to locate and quite clear. The package states that "[b]eginner's German is written for the complete beginner who wants to move at a steady pace and have lots of opportunity to practice" (Teach Yourself, box). Because one of the aspects of lone learning with which I struggled most was finding a pace, it is presumptuous of the program to advertise that all learners will move at a steady pace. The opportunity to do so is there, but there is nothing built into the program that would assist the learner in finding her steady pace, especially if she struggles, as I did, to complete the entirety of one of the lengthy lessons in each of her learning sessions. What is built-in, however, is some amount of flexibility. In particular, Lesson 11 is a completely optional lesson that focuses on the grammatical rules of verb conjugation. The learner who is only interested in conversational German is advised to skip this lesson, whereas the learner who is more interested in the mechanical aspects of German is invited to look over the lesson. As such, the learner is encouraged to explore her independence by considering her own needs, goals, and preferences. 
With respect to learner support, $\mathrm{McNab}$ (2003) attempts to develop a relationship with her lone learners by directly addressing the reality of self-instruction, in saying: The guidelines given in this introduction are intended to provide some useful advice on studying alone and on how to make the most of the course...People learn in different ways: some like to learn rules, a very few find it easy to learn by heart, some like to learn by writing things down and others prefer to learn by association. Try different methods until you find which works best for you. (p. vii)

She further provides many forms of study tips and language learning advice, such as "[r]emember that studying 20 minutes regularly is more effective than spending two hours at one session every so often" (p. 2). Some of the many learning strategies and tips she offers throughout the book include marking word lists for active production versus passive recognition, suggesting that the learner record her own voice into a tape recorder to check her accent against the recorded materials, and not getting discouraged by overwhelming complexities, because "even if you don't get them right, Germans will still be able to understand what you are asking for" (p. 81).

The learning activities in the Teach Yourself Beginner's German are extremely diverse and interactive. True to the communicative approach, all activities are designed to practice skills and knowledge in meaningful ways. These activities include, but are not exhausted by, fill in the blank, matching, multiple choice, translation, completing dialogues, drawing maps, telling time, crossword puzzles, asking and answering questions, writing descriptions, and so forth-a variety of activities that draw on a variety of skills, including writing. As such, the answer keys are not comprehensive of all the 
activities. For some of the activities (e.g., fill in the blank, matching, multiple choice, crossword puzzles, and so forth) there are complete answer keys for the learner's reference. For others (e.g., translation, completing dialogues, and so forth) there are partial answer keys, with the provision of possible answers and the acknowledgement that other possible answers exist. For yet other activities (e.g., asking and answering questions, descriptions, and so forth) there are no answer keys.

In terms of unrealistic claims, the Teach Yourself Beginner's Series is quite conservative. Although I take exception to the claim "[t]he proven way to learn a language" (Teach Yourself, box), it is not because communicative approaches to language teaching are unproven or unsuccessful. Rather, it is because such a claim on the cover of a sealed package with no evidence to substantiate it does nothing to help inform the potential buyer.

\subsubsection{Teach Yourself Beginner's Japanese}

Of the four programs, the Teach Yourself Beginner's Japanese (Gilhooly, 2003) provides the best example of successful learner preparation and support. In terms of program objectives, learning activities and unrealistic claims, my evaluations for this program are identical to those discussed in the Teach Yourself Beginner's German section, so I will not repeat myself here.

One of the most obvious attempts at learner preparation included in the Teach Yourself Beginner's Japanese (Gilhooly, 2003) course book is the huge amount of built- 
in flexibility, which affords the learner enormous control over the learning process and the freedom to adapt the materials to better suit her needs, goals, and preferences. Of the twenty lessons, the first twelve must be followed sequentially, as each lesson builds on knowledge gained in previous lessons. Once these twelve lessons are completed, however, the thirteenth lesson is completely optional, as it is devoted to learning about Japanese script, and, while the final seven lessons return to more communicative curricula, they can be completed in any sequence so desired by the learner, or simply omitted. As none of the lessons assume any knowledge on the part of the learner other than what was presented in the first twelve lessons, the final seven lessons are completely independent of one another.

With respect to learner support, I consider the Teach Yourself Beginner's Japanese (Gilhooly, 2003) to be exemplary. Gilhooly (2003) provides significantly more study tips, learning advice, transparency, and strategy training throughout her course book than even does McNab (2003) in the German course book, perhaps based on the belief that the English L1 learner of Japanese needs more support than does the English L1 learner of German. The program makes use of an icon throughout the book that denotes a Learning Tip. The tips are presented as advice in the form of suggestions, not directives, as revealed by the explanation of the Learning Tips icon, stating: Sections marked ' $i$ ' give you two sorts of advice: (1) hints on developing techniques to improve your learning skills; hints on mastering a particular structure or grammar point; hints on remembering vocabulary; hints for developing your confidence, and so on; and (2) about Japan...(p. x). 
An example of a learning tip that provides the inexperienced learner with some study advice on how to proceed might be:

Learning Tip: Before you begin this section, go back to the Conversation and listen to it or read it again. This should help to clarify all the new language you have learnt. If there is something you are still not sure about, look it up in the Explanations section before proceeding to the Practice section. Make this a habit for all the units-it will increase your confidence and improve your performance in the activities. (p. 8)

Another excellent example, dealing with the issue of information overload, might be:

Many of the listening exercises contain extra vocabulary which you haven't learnt. Do not worry about understanding every word: the aim of the exercises is to help you develop the important skill of scanning information and selecting the parts that you need. (p. 22).

Learning Tips like these are found throughout all of the twenty lessons of the course book. It seems clear that this program is making an effort to anticipate the kinds of challenges the lone learner will encounter in SILL, and to offer guidance and suggestions for ways to deal with these challenges. Gilhooly (2003) tends to avoid explicit directions and instead offers suggestions, inviting the learner to either make use of or disregard these suggestions depending on whether the learner perceives them to be useful or not. The book later states in the context of a Learning Tip that "[d]ifferent people learn in different ways" (p. 34). This tells the lone learner that the Learning Tips are suggestions for ways to enhance learning, but that the learner is ultimately in charge 
of the learning process. Clearly this Teach Yourself program is trying to foster autonomy through transparency, strategy training, and learner support.

With further relevance to learner support are the many "pep talks" given in the Japanese course book, which help to develop a relationship with the learner. Gilhooly (2003) attempts to preempt the learner's apprehension about the exotic nature of Japanese by saying:

Japanese is still regarded as an 'exotic' language by many people and believed to be 'too difficult to learn'. Nothing could be further from the truth-Japanese is a very accessible language and can be a great deal of fun. (p. vii)

Of the four SILL programs, I found this one in particular to be the most supportive of me throughout my journey as a lone learner. Yet, I still only acquired a minimum amount of Japanese during my study of the program. What accounts for that? Perhaps I still have not uncovered the missing element that will guarantee success for the lone learner, if indeed there is one. Or perhaps the program is not to blame-perhaps, despite all of this support and preparation, I am simply unsuited to the SILL context and such an undertaking was doomed from the start. Or perhaps this program was unsuccessful because it was the last of the four SILL programs I followed and I was tired. Or perhaps it was a mixture of all of the above. There is no way to know for sure. It is only through the documentation of similar journeys by other people that this field of study can hope to amass enough pieces of the puzzle to finally see the big picture, in order to finally understand SILL programs and the reality of lone learning. 


\subsection{Conclusion}

This concludes the analysis section of my study. In Chapter 3, addressing the first major focus of my study, I presented my journey as a lone learner in narrative, beginning with the methodological decisions that ultimately shaped and directed my study, and finishing with a discussion of the analysis of my learner diaries. In this discussion, I presented the six significant trends concerning the interplay of affective factors that emerged from the analysis. In Chapter 4, addressing the second major focus of my study, I illustrated two relevant pedagogical approaches to language instruction, as well as the effect of choosing to adopt one approach over another. Synthesizing the evaluative instruments presented in Chapter 2 with the design criteria that I found to be most crucial to my experience with SILL, I critiqued the four SILL programs I followed during my journey. In Chapter 5, I will conclude my study by presenting the implications of my findings, some recommendations for SILL program design, and the areas in need of future research. 


\section{Chapter 5: Conclusion}




\subsection{Introduction}

In the preceding four chapters I have described my five-month journey as a lone learner. I have illustrated, through my narrative, the analysis of my learner diaries, and my critique of the four SILL programs, as many facets of this journey as possible. I will now conclude by presenting the implications of the study and the recommendations for SILL program design that have surfaced as a result of my journey, as well as some of the areas in need of future research.

Throughout my journey, a great deal of questions have arisen-some of which I have articulated within these discussions, some of which I have not. Although I began with a particular research question in mind (i.e., How does my experience with selfinstruction compare with what is promised on the SILL packages?), I did not confine myself to this question because, as I have already stated, this study is about the journey and not the final destination. My excess of questions and dearth of answers came as no surprise. Questions must precede answers, and, since this area has been so greatly neglected, it only stands to reason that the initial queries into SILL programs and lone learning will let loose a great torrent of questions. I have faith that the answers will follow.

I can, however, suggest the implication of my findings, and offer a number of recommendations for SILL program design. 


\subsection{Implications of my findings and recommendations for SILL program design}

Perhaps the greatest implication of my findings is that there is something wrong with the SILL programs I undertook, and this something is likely generalizable to other SILL programs as well. If a highly motivated and experienced language learner (who is also a trained linguist and an ESL instructor) cannot find success with any of the four SILL programs she undertook despite her most sincere efforts, what hope is there for the inexperienced? Unfortunately, identifying that something is wrong is considerably easier than determining exactly what the problem is. For insight into this larger issue I have looked to the six significant trends identified in my learner diaries (which illustrated the interplay of affective factors that greatly influenced my experience as a lone learner). From these trends, it is possible to see how I negotiated the SILL context, working both with and against my SILL programs.

Ultimately, these six significant trends translated into recommendations for SILL programs. The four major recommendations that I will make for SILL program design align with the four design criteria I presented in Chapter 4. SILL program writers need to address learner preparation (by making program objectives clear and providing flexibility within the materials to account for different personal learning styles), learner support (by fostering autonomy and strategy training), the neglect of writing activities in their curricula, and the unrealistic claims made by the SILL packages that lead to unrealistic learning expectations. I do not claim that addressing these four criteria will guarantee successful lone learning. I have, however, shown by way of my learner diaries that it would be a good place to begin to resolve some of the issues pervasive to SILL programs. 


\subsection{Areas in need of future research}

As stated in Chapter 1, I followed Jones $(1994,1995,1996)$ in maintaining an openended approach to my study, because "the project was dictated by its exploratory nature. When exploring and mapping out a virtually unknown field, we need a maximally openended approach, for we do not know in advance which details are relevant and which are not" (Jones, 1996, p. 367). As Jones (1996) suggests "[t]he next step would be to focus down on certain key area, but also to take a more tightly-controlled, hypothesis-testing, rather than hypothesis-generating approach" (p. 367). Key areas of potential future research are:

- To get a better picture of how different learner factors (e.g., affective factors such as motivation, personal learning styles, metacognitive knowledge and learner beliefs, as well as personal factors such as age, proficiency, and so forth) affect the learner-context interface, different programs could be tested on different learners to show the potential for learner empowerment, and the outcome of the learning.

- Larger-scale studies (e.g., comparing a control group of learners using one particular SILL program in isolation with a test group of learners using a SILL program along with supplementary materials providing additional learner preparation and support) could provide more generalizable findings than single case-studies.

- A study could be done to compare and contrast different pedagogical methods and instructional approaches of SILL programs. For example, in the case of Living 
Language versus Teach Yourself, are learners willing to trade open-ended learning activities (which provide opportunities for writing but are accompanied by ambiguous answer keys) for static learning activities (which provide no opportunities for writing but are accompanied by more "user-friendly" answer keys)?

- During the writing stages of SLL program design, individual program features (e.g., particular activities, lessons, study tips, and so forth) could be tested on learners to compare and contrast different possible set-ups.

- Longitudinal studies that track a learner for a period of time after completing the SILL programs could compare the staying-power of the linguistic proficiency gained in the SILL context to the proficiency gained in classroom-based contexts.

- Similarly, an interview study in the L2 could compare the resulting proficiency of lone learners with classroom-based learners.

Because SILL programs and lone learning have been neglected for so long by the professional community of applied linguists and language pedagogues, there are countless possible studies that could be done to shed some empirical light on the matter. Such studies would be, not only useful to the writers who design SILL programs and the learners who attempt to use them, but useful to SLA researchers in general to gain a better understanding of language teaching and learning in a less-conventional context. To reiterate from Jones (1993) "it is high time the teach-yourself phenomenon were taken seriously" (p. 453). 


\section{SILL program references:}

\section{Living Language}

Kleinmann, W. (1993). Living Language: Complete Basic German. Toronto: Random House.

Living Language. (2005). Living Language website. Retrieved June 2, 2005 from http://www.randomhouse.com/livinglanguage/

Storm, H. (1993). Living Language: Complete Basic Japanese. Toronto: Random House.

\section{Teach Yourself}

Gilhooly, H. (2003). Teach Yourself Beginner's Japanese. Chicago: McGraw Hill Companies.

McNab, R. (2003). Teach Yourself Beginner's German. Chicago: McGraw Hill Companies.

Teach Yourself. (2003). Teach Yourself website. Retrieved June 2, 2005 from http://www.teachyourself.co.uk/

\section{Instant Immersion}

Barstow, M., Niwa, M., \& Koezuka, M. (2002). Instant Immersion Japanese. Renten, WA: TOPICS Entertainment, Inc.

Wideburg, L. (2002). Instant Immersion German. Renten, WA: TOPICS Entertainment, Inc. 


\section{References:}

Ansell, J., Brooks, J. L., \& Sakai, R. (Producers), \& Brooks, J. L. (Director). (2004). Spanglish [Motion picture]. USA: Columbia Pictures Corporation.

Antenos-Conforti, E. (1998). Self-instructional programs for Italian in the 1990's. Italica, 75, 541-563.

Bailey, K. (1980). An introspective analysis of an individual's language learning experience. In R. Scarcella \& S. Krashen (Eds.), Research in second language acquisition (pp. 58-65). Rowley, MA: Newbury House Publishers, Inc.

Bailey, K. (1983). Competitiveness and anxiety in adult second language learning: Looking at and through diary studies. In H. Seliger \& M. Long (Eds.), Classroom oriented research in second language acquisition (pp. 67-102). Rowley, MA: Newbury House Publishers, Inc.

Barker, M. (2003). Understanding motivation: A review of relevant literature.

Retrieved June 10, 2005, from http://http-server.carleton.ca/ barker/motivation/

Benson, P. (2001). Teaching and researching autonomy in language learning. London: Longman.

Brown, C. (1985). Two windows on the classroom world: Diary studies and participant observation differences. On TESOL '84, 121-134.

Brown, D. (1989). A practical guide to language learning. New York: McGraw-Hill.

Brown, D. (1994). Teaching by principles: An interactive approach to language pedagogy. Englewood Cliffs, NJ: Prentice Hall Regents.

Brown, J., \& Rodgers, T. (2002). Doing second language research. Oxford: Oxford University Press. 
Cotterall, S. (1995). Readiness for autonomy: Investigating learner beliefs. System, $23,195-205$.

Crabbe, D. A. (1993). Fostering autonomy in the language classroom: The teacher's responsibility. System, 21, 443-452.

Bevan, T., Fellner, E., \& Kenworthy, D. (Producers), \& Curtis, R. (Director). (2003). Love Actually [Motion picture]. UK/USA: Universal Pictures.

Derrick, M. A., \& Carr, P. B. (2003). Facilitating and understanding autonomy in adult learners. New Horizons in Adult Education, 17, 4-10.

Dickinson, L. (1987). Self-instruction in language learning. Cambridge: Cambridge University Press.

Dörnyei, Z. (2001). Teaching and researching motivation. Don Mills, ON: Pearson Education Ltd.

Harklau, L. (2002). The role of writing in classroom second language acquisition. Journal of Second Language Writing, 11, 329-350.

Hayet, M. C. (1990a). At-home foreign language courses and linguistic tools (part 1). Language International, 2, 27-30.

Hayet, M. C. (1990b). At-home foreign language courses and linguistic tools (part 2). Language International, 2, 9-12.

Hudelson, S. (1993). Foreword. In J. Kreeft Peyton \& J. Staton (Eds.), Dialogic journals in the multilingual classroom: Building language fluency and writing skills through written interaction (pp. xi-xiv). Norwood: Ablex Publishing Corporation.

Jones, F. R. (1993). Beyond the fringe: A framework for assessing teach-yourself 
materials for ab initio English-speaking learners. System, 21, 453-469.

Jones, F. R. (1994). The lone language learner: A diary study. System, 22, 441-454.

Jones, F. R. (1995). Learning an alien lexicon: A single-subject case study. Second Language Research, 11, 95-111.

Jones, F. R. (1996). Going it alone: Self-instruction in adult foreign language learning. Unpublished PhD thesis, Department of Education, Newcastle University, Newcastle-Upon-Tyne, UK.

Jones, F. R. (1998). Self-instruction and success: A learner profile study. Applied Linguistics, 19, 378-406.

Kohonen, V. (1991). Review of Leslie Dickinson: Self-instruction in Language Learning. Applied Linguistics, 12, 109-112.

Kreeft Peyton, J. (1993). Introduction. In J. Kreeft Peyton \& J. Staton (Eds.), Dialogic journals in the multilingual classroom: Building language fluency and writing skills through written interaction (pp. 1-11). Norwood: Ablex Publishing Corporation.

Kroll, B., \& Vann, R. (1981). Introduction. In B. Kroll \& R. Vann (Eds.), Exploring speaking-writing relationships: Connections and contrasts (pp. vii-xi). Urbana, IL: National Council of Teachers of English.

Lam, W. (2000). L2 literacy and the design of the self: A case study of a teenager writing on the internet. TESOL Quarterly, 34, 457-482.

Matsuda, P. (2001). Reexamining audiolingualism: On the genesis of reading and 
writing in L2 studies. In D. Belcher \& A. Hirvela (Eds.), Linking literacies:

Perspectives on L2 reading-writing connections (pp. 84-105). Ann Arbor: The University of Michigan Press.

Matsuda, P. (2003). Second language writing in the twentieth century: A situated historical perspective. In B. Kroll (Ed.), Exploring the dynamics of second language writing (pp. 15-34). Cambridge: Cambridge University Press.

Naiman, N., Frölich, M., Stern, H. H., \& Todesco, A. (1978). The good language learner. Toronto: Ontario Institute for Studies in Education.

Norton, B., \& Toohey, K. (2001). Changing perspectives on good language learners. TESOL Quarterly, 35, 307-322.

O’Malley, J., \& Chamot, A. (1990). Learning Strategies in Second Language Acquisition. Cambridge, MA: Cambridge University Press.

Oxford, R. (1989). Use of language learning strategies: A synthesis of studies with implications for strategy training. System, 17, 235-247.

Rivers, W. (1964). The psychologist and the foreign language teacher. Chicago: University of Chicago Press.

Roberts, J. (1995). An anatomy of home-study foreign language courses. System, 23, 513-530.

Schmidt, R. W., \& Frota, S. (1986). Developing basic conversational ability in a second language: A case study of an adult learner of Portuguese. In R. Day (Ed.), Talking to Learn: Conversation in Second Language Acquisition (pp. 237-326). Rowley, MA: Newbury House Publishers, Inc.

Schumann, F. (1980). Diary of a language learner: A further analysis. In R. Scarcella 
\& S. Krashen (Eds.), Research in second language acquisition (pp. 51-57). Rowley, MA: Newbury House Publishers, Inc.

Schumann, F., \& Schumann, J. (1977). Diary of a second language learner: An introspective study of second language learning. On TESOL '77, 241-249.

Staton, J., Shuy, R., Kreeft Peyton, J., \& Reed, L. (Eds.). (1988). Dialogic journal communication: Classroom, linguistic, social and cognitive views. Norwood: Ablex Publishing Corporation.

Vann, R. (1981). Bridging the gap between oral and written communication in EFL. In B. Kroll \& R. Vann (Eds.), Exploring speaking-writing relationships: Connections and contrasts (pp. 154-167). Urbana, IL: National Council of Teachers of English.

Victori, M., \& Lockhart, W. (1995). Enhancing metacognition in self-directed language learning. System, 23, 223-234.

Weissberg, B. (2000). Developmental relationships in the acquisition of English syntax: Writing vs. speech. Learning and Instruction, 10, 37-53.

Wenden, A. (1998). Metacognitive knowledge and language learning. Applied Linguistics, $19,515-537$.

White, C. (1995). Autonomy and strategy use in distance foreign language learning: Research findings. System, 23, 207-221.

White, C. (1999). Expectations and emergent beliefs of self-instructed language learners. System, 27, 443-457. 